\author{
Aus der Abteilung Psychiatrie und Psychotherapie \\ (Komm. Leiter: Prof. Dr. med. Dipl.-Psych. B. Bandelow) \\ im Zentrum Psychosoziale Medizin \\ der Medizinischen Fakultät der Universität Göttingen
}

\title{
s100 $\beta$ und Homocystein im Serum von stationär behandelten alkoholabhängigen Patienten als Verlaufsvariablen des akuten Alkoholentzugssyndroms
}

\author{
INAUGURAL - DISSERTATION \\ zur Erlangung des Doktorgrades \\ der Medizinischen Fakultät der \\ Georg-August-Universität zu Göttingen \\ vorgelegt von \\ Karoline Neumann \\ aus \\ Saarbrücken
}

Göttingen 2013 
Dekan:
I. Berichterstatter:
PD Dr. med. D. Wedekind
II. Berichterstatter/in:
PD Dr. med. C. Bachmann
III. Berichterstatter/in:

Tag der mündlichen Prüfung: 21.01 .2014 


\section{INHALTSVERZEICHNIS}

\section{EINLEITUNG}

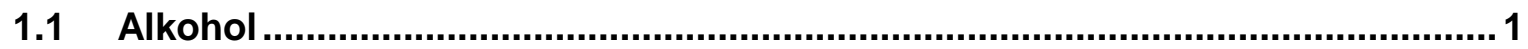

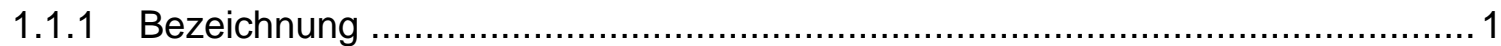

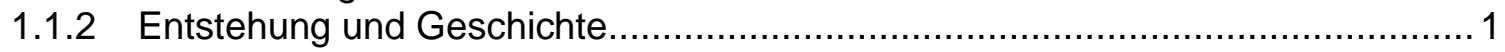

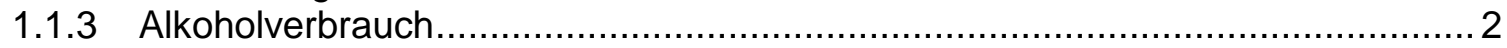

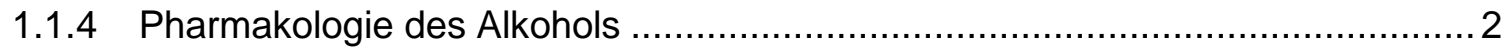

1.1.5 Blutalkoholkonzentration (BAK) …...................................................... 3

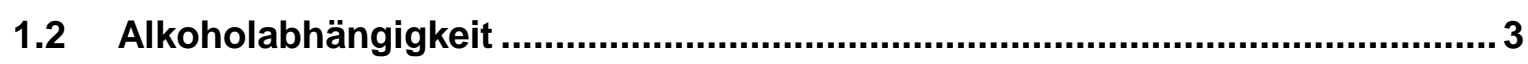

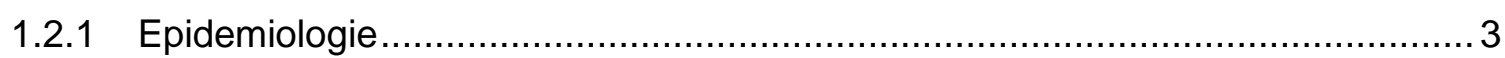

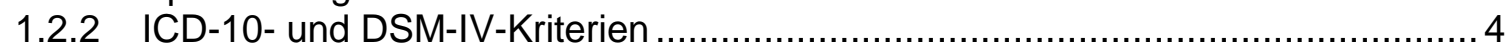

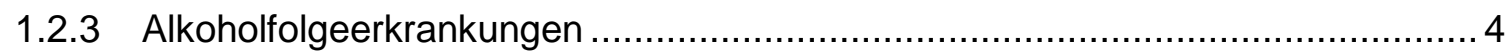

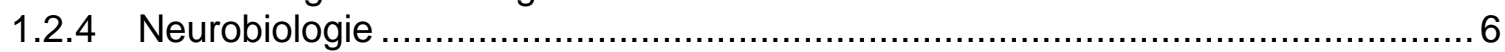

1.2.5 Alkoholgebrauch, schädlicher Gebrauch und Abhängigkeit ........................... 7

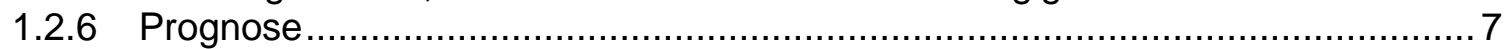

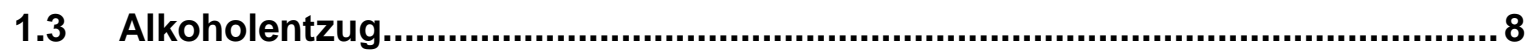

1.3.1 Diagnose, Symptome und Komplikationen ............................................... 8

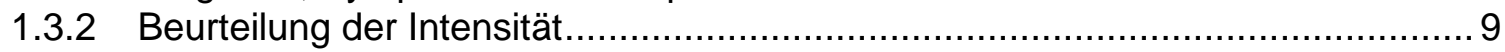

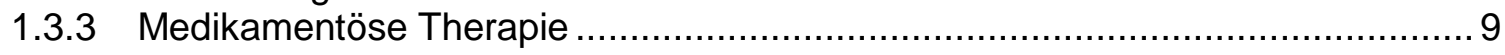

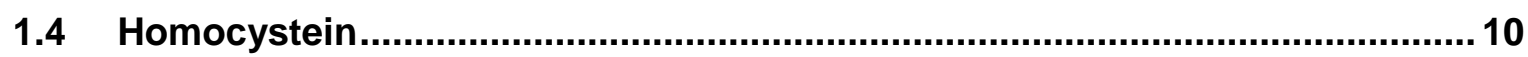

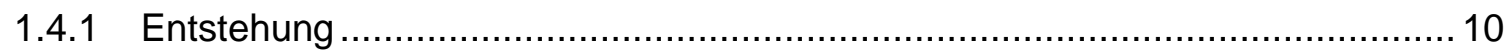

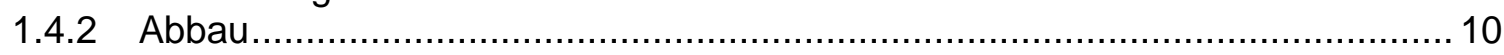

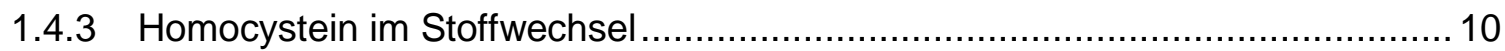

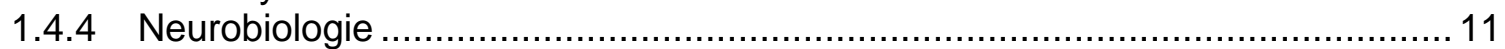

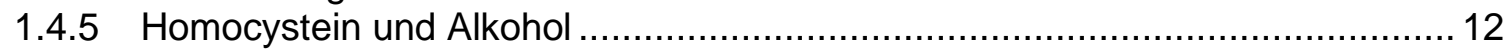

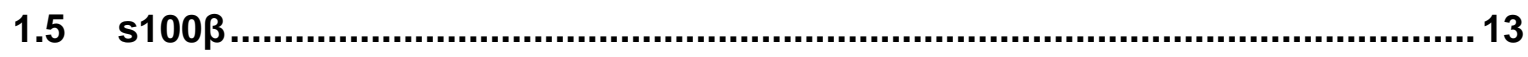

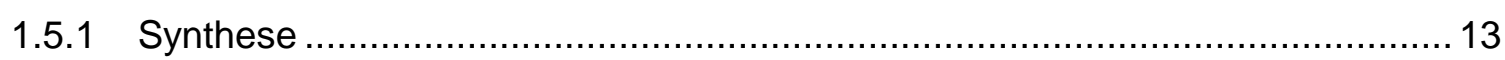

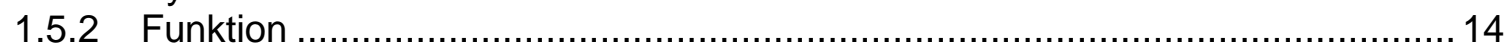

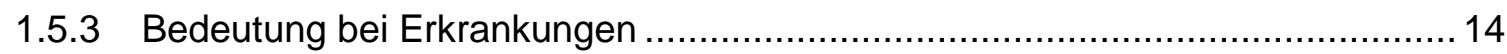

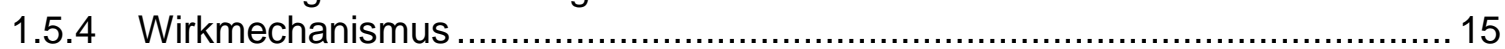

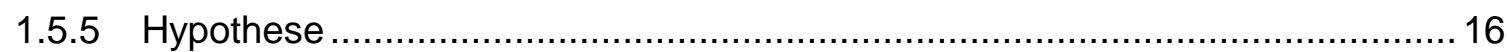

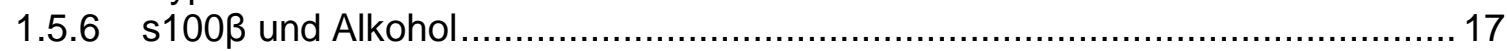

2. STUDIENZIEL ...............................................................18

3. MATERIAL UND METHODEN .........................................19

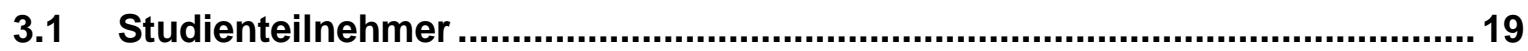

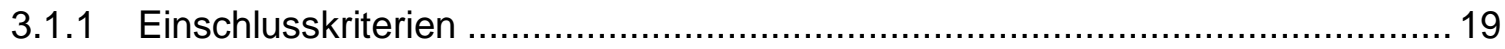

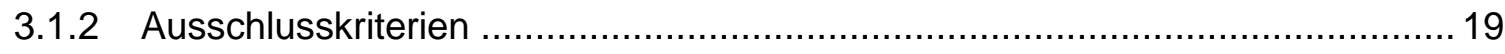

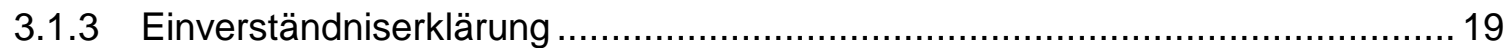

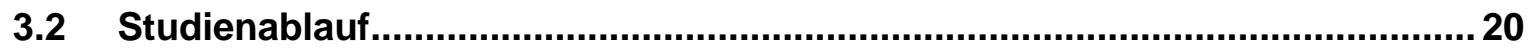

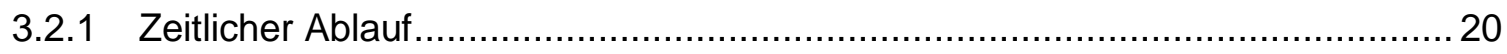




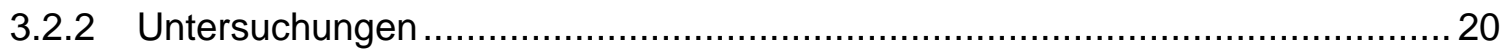

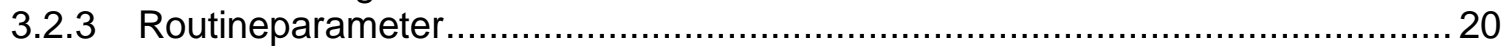

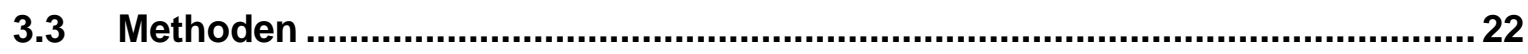

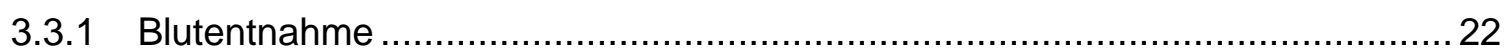

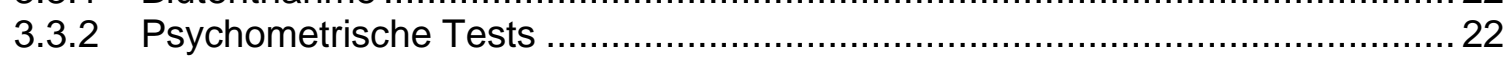

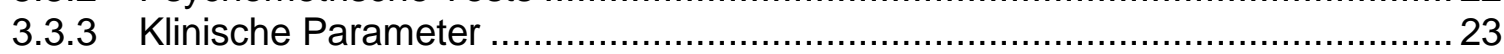

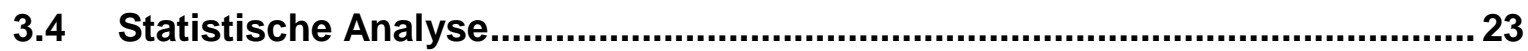

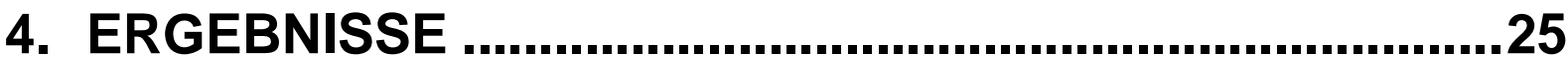

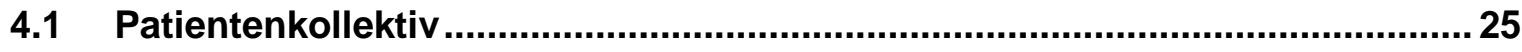

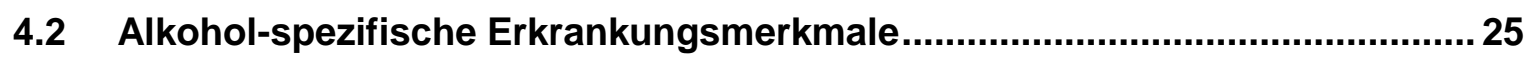

4.2.1 Dauer der Alkoholabhängigkeit........................................................... 25

4.2.2 Lebensalter zu Beginn der Alkoholabhängigkeit ........................................ 26

4.2.3 Alkoholkonsum vor Untersuchungsbeginn............................................... 26

4.2.4 Ethanolgehalt in Atem oder Blut bei Aufnahme............................................. 27

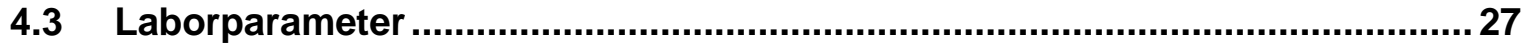

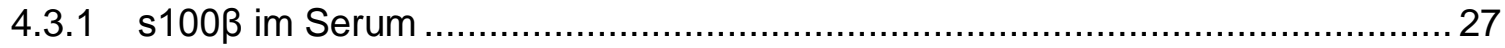

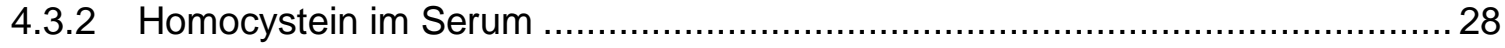

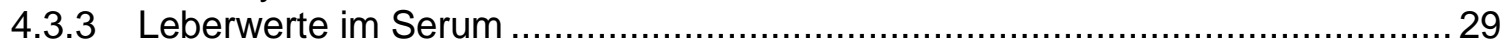

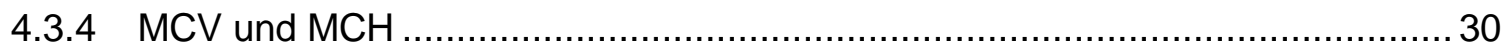

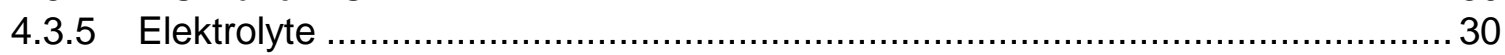

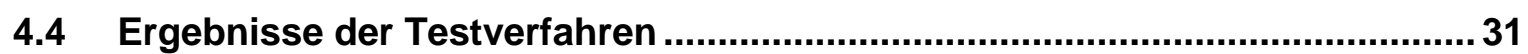

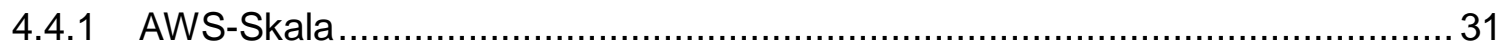

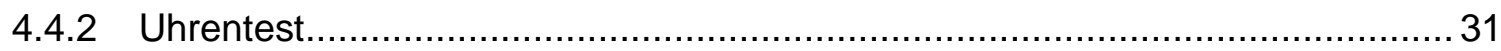

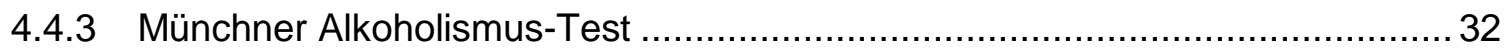

4.5 Ergebnisse der klinischen Parameter ................................................................. 32

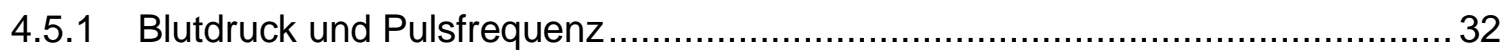

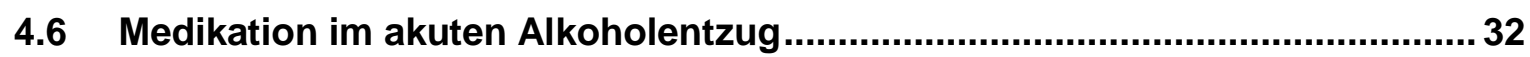

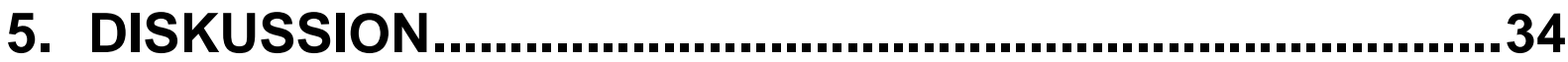

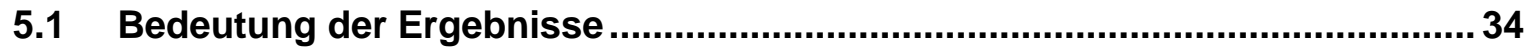

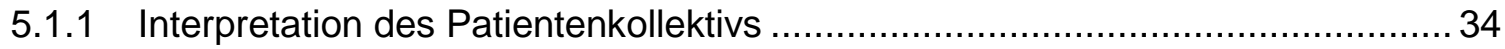

5.1.2 Interpretation der Alkohol-spezifischen Erkrankungsmerkmale........................ 35

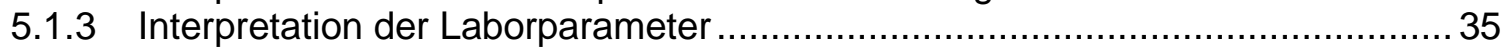

5.1 .4 Interpretation der Testverfahren ........................................................... 44

5.1 .5 Interpretation der klinischen Parameter ................................................... 45

5.1.6 Interpretation der verabreichten Medikamente.......................................... 45

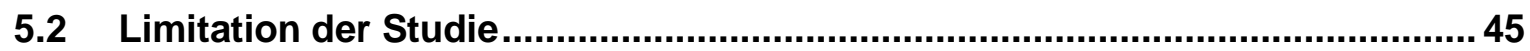

6. ZUSAMMENFASSUNG................................................47

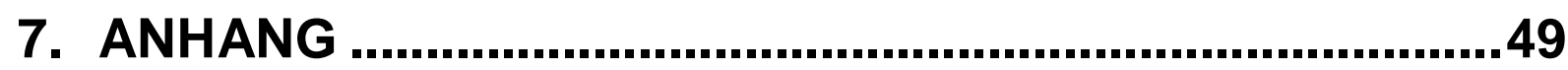

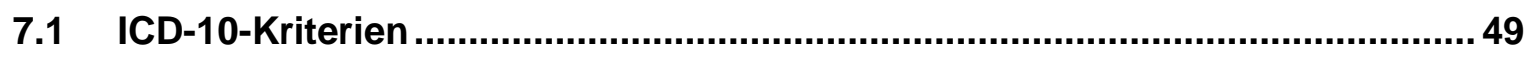

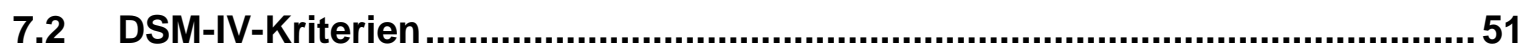

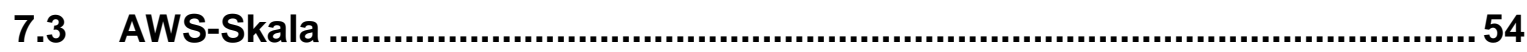




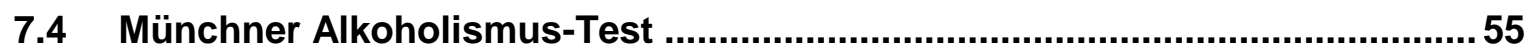

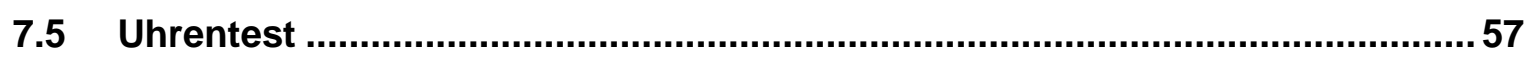

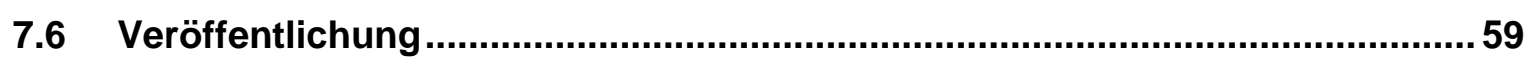

8. LITERATURVERZEICHNIS ............................................65 


\section{ABBILDUNGSVERZEICHNIS}

Abbildung 1: Altersverteilung der Studienteilnehmer................................................ 25

Abbildung 2: Dauer der Alkoholabhängigkeit der Probanden bei Studienbeginn .................. 26

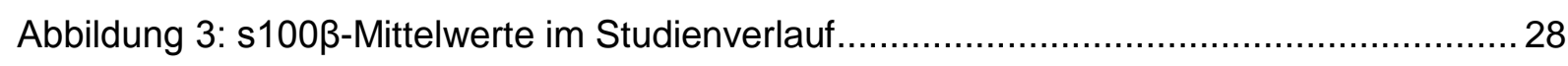

Abbildung 4: Homocystein-Mittelwerte im Studienverlauf .................................................. 29

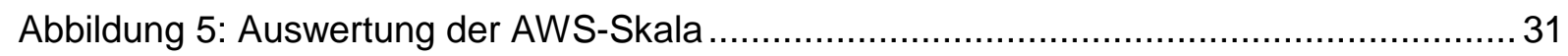

Abbildung 6: Medikation während des Untersuchungszeitraums .................................... 33 


\section{TABELLENVERZEICHNIS}

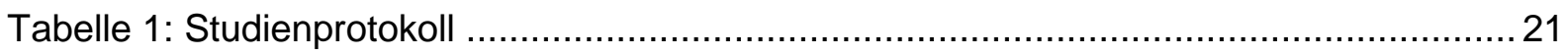

Tabelle 2: ICD-10-Kriterien - Schädlicher Gebrauch von Alkohol ........................................ 49

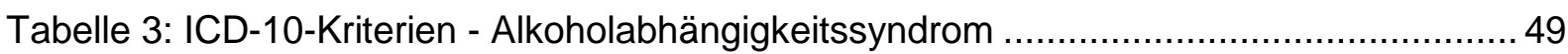

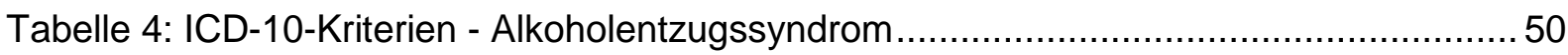

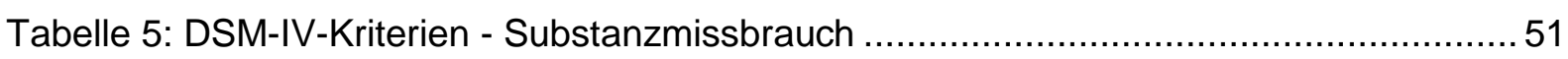

Tabelle 6: DSM-IV-Kriterien - Alkoholabhängigkeit .................................................. 51

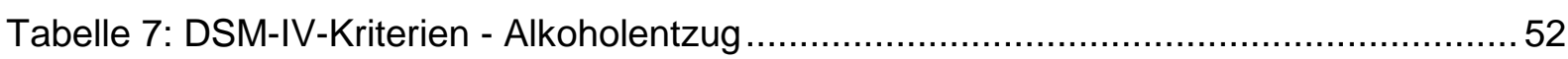




\section{ABKÜRZUNGSVERZEICHNIS}

ACTH

AES

ALT

ANOVA

APA

AST

ATP

AUDIT

AWS

BAK

CAGE

CDT

$\mathrm{CO}_{2}$

d

DSM-IV

ELISA

$\mathrm{fl}$

g

GABA

Y-GT

$\mathrm{h}$

HRP

$5 \mathrm{HT}$

ICD-10

i.v.

$\mathrm{kDa}$

$\mathrm{kg}$

KG

I

LARS

LAST

MALT

$\mathrm{MCH}$
Adrenocorticotropes Hormon

Alkohol-Entzugssyndrom-Skala

Alanin-Aminotransferase

Analysis of variance

American Psychiatric Association

Aspartat-Aminotransferase

Adenosintriphosphat

Alcohol-Use-Disorders-Identification-Test

Alcohol-Withdrawal-Syndrome

Blutalkoholkonzentration

Cut down Annoyance Guilty Eye Opener

Carbohydrate deficient transferrin

Kohlenstoffdioxid

Tag

Diagnostisches und Statistisches Manual Psychischer Störungen (Diagnostic and Statistical Manual of Mental Disorders)

Enzyme-linked immunosorbent assay

Femtoliter

Gramm

Gammaaminobuttersäure

Gammaglutamyltransferase

Stunde(n)

Horseradish peroxidase

Serotonin

Internationale Klassifikation psychischer Störungen

intravenös

Kilodalton

Kilogramm

Körpergewicht

Liter

Lübecker Alkoholentzugs-Risiko-Skala

Lübecker Alkoholismusscreeningtest

Münchner Alkoholismus-Test

Mittleres Corpuskuläres Hämoglobin 


$\begin{array}{ll}\text { MCV } & \text { Mittleres Corpuskuläres Volumen } \\ \text { MEOS } & \text { Mikrosomales Ethanol Oxidierendes System } \\ \mathrm{Mg} & \text { Magnesium } \\ \mathrm{mg} & \text { Milligramm } \\ \mu \mathrm{g} & \text { Mikrogramm } \\ \mathrm{min} & \text { Minute(n) } \\ \mu \mathrm{l} & \text { Mikroliter } \\ \mathrm{mmHg} & \text { Millimeter Quecksilbersäule } \\ \mathrm{mmol} & \text { Millimol } \\ \mu \mathrm{mol} & \text { Mikromol } \\ \mathrm{NMDA} & \text { N-Methyl-D-Aspartat } \\ \mathrm{pg} & \text { Pikogramm } \\ \mathrm{PCP} & \text { Phencyclidin } \\ \mathrm{SAH} & \text { S-Adenosylhomocystein } \\ \mathrm{SAM} & \text { S-Adenosylmethionin } \\ \mathrm{SD} & \text { Standardabweichung } \\ \text { WHO } & \text { World Health Organization } \\ \text { ZNS } & \text { Zentralnervensystem } \\ \% & \text { Promille } \\ \% & \text { Prozent }\end{array}$




\section{EINLEITUNG}

\subsection{Alkohol}

\subsubsection{Bezeichnung}

Der Begriff „Alkohol“ ist auf das spanische Wort „alcohol = feines Pulver“ zurückzuführen. Er stammt ursprünglich von dem arabischen Ausdruck „al-kuhl” ab, der das traditionelle arabische Schminkpulver „Antimon“ bezeichnet. Später wurde der Ausdruck in der Bedeutung „Essenz“ gebraucht. Im 16. Jahrhundert gab es den Begriff „alcohol vini“, der „Geist des Weines“, der zunächst von Paracelsus, später auch in der internationalen Terminologie, verwendet wurde. Seit Mitte des 19. Jahrhunderts bezeichnet das Wort „Alkohol“ auch andere berauschende Getränke (Kluge und Seebold 2011).

\subsubsection{Entstehung und Geschichte}

Als Alkohol wird im allgemeinen Sprachgebrauch das zur chemischen Stoffklasse der Alkohole, einer Gruppe organischer Verbindungen, gehörende Ethanol (Synonym: Ethylalkohol) bezeichnet. Es ist eine klare, farblose Flüssigkeit (Summenformel: $\mathrm{C}_{2} \mathrm{H}_{5} \mathrm{OH}$ ), die sowohl wasser- als auch fettlöslich ist und bei der Vergärung von zuckeroder stärkehaltigen Materialien durch Hefe oder Bakterien entsteht.

Die geschichtlichen Wurzeln des Alkohols gehen zurück bis in die prähistorische Zeit. Es gibt Aufzeichnungen, die belegen, dass bereits die Sumerer 3000 Jahre vor Christus Bier brauten. In der Antike konsumierten Römer und Griechen hauptsächlich Wein.

Allerdings war es bis zur Entwicklung der Destillation nicht möglich, einen Ethanolgehalt von über 15 Prozent (\%) herzustellen, da Hefezellen und Bakterien bei dieser Konzentration absterben. Die ersten Rezepte der Destillation von Wein erschienen in Italien um 1100 nach Christus (Deibele 1991).

Im Mittelalter und in der Neuzeit war der Genuss von Alkohol weit verbreitet. Während der Industrialisierung wurden Arbeiter zum Teil damit entlohnt. Die Entwicklung von industriellen Brennapparaten führte im 19. Jahrhundert schließlich zu einem Überangebot.

Bis ins 19. Jahrhundert wurde Alkohol als Lebenselixier und Heilmittel geachtet und war ein fester Bestandteil der Medizin. Des Weiteren wurde er wegen seines Kaloriengehalts im alltäglichen Leben als Nahrungs- und Stärkungsmittel genutzt.

Bereits in der Neuzeit gab es Bestrebungen gegen den übermäßigen Alkoholkonsum und ab Ende des 18. Jahrhunderts kämpften Ärzte gegen den exzessiven Konsum von Branntwein. Anfang des 19. Jahrhunderts tauchten die Begriffe „Trunksucht“ und 
„Chronischer Alkoholismus" erstmals in der medizinischen Literatur auf (Schott 2001). In den letzten beiden Jahrhunderten entstanden immer mehr Gesetze, um die Erzeugung und den Handel mit alkoholischen Getränken zu kontrollieren. So begann im Jahre 1920 in den USA das Zeitalter der Prohibition, das die Herstellung und den Verkauf von alkoholischen Getränken verbot. Da der Alkoholkonsum jedoch durch diese Maßnahme nicht verhindert, sondern lediglich in die Illegalität gedrängt wurde, wurde dieses Gesetz 1933 wieder aufgehoben.

Im Jahre 1968 wurde der Alkoholismus vom Bundessozialgericht als Suchtkrankheit anerkannt (Schott 2001).

\subsubsection{Alkoholverbrauch}

Die west- und osteuropäischen Länder zeigen im globalen Vergleich innerhalb der WHORegionen die höchsten Alkoholkonsumraten, wobei Deutschland zu den Hochkonsumländern gehört (Shield et al. 2011).

Der durchschnittliche Alkoholverbrauch lag 2010 in Deutschland bei 9,6 Litern (I) reinem Alkohol je Einwohner. Er ist damit im Vergleich zum Jahre 1990, wo er 12,1 I betrug, leicht abgesunken. Dabei wurde 2010 ein bundesdeutscher Pro-Kopf-Konsum alkoholischer Getränke von 137,2 I ermittelt. Dieser lag um 1,3 \% unter dem Wert des Vorjahres.

Über die Hälfte (53,6 \%) der alkoholischen Getränke wurden 2010 in Deutschland in Form von Bier konsumiert. Der restliche Anteil verteilt sich mit 23,4 \% auf Wein, 18,5\% auf Spirituosen und 4,5\% auf Schaumwein. Im Vergleich zum Vorjahr hat der Gesamtalkoholkonsum, gemessen in Reinalkohol, um ein Prozent abgenommen (Gaertner et al. 2012).

\subsubsection{Pharmakologie des Alkohols}

Alkohol wird nach oraler Aufnahme zu etwa $20 \%$ aus dem Magen resorbiert. Die restliche Resorption findet im Dünndarm statt. Nach der Resorption erfolgt die Verteilung über das Blut vor allem in die wasserhaltigen Körperbestandteile, während nur geringe Mengen im Fettgewebe aufgenommen werden.

Die Elimination des Alkohols beginnt direkt nach der Aufnahme. Ein geringer Teil wird dabei unverändert über Niere, Haut und Lunge ausgeschieden. Der überwiegende Anteil wird aber enzymatisch durch die Alkoholdehydrogenase abgebaut. Diese Metabolisierung findet hauptsächlich in der Leber, aber auch in Herz, Lunge und Niere statt. Hierbei entsteht aus Alkohol zunächst Acetaldehyd. Dieser erste Schritt kann außer 
durch die Alkoholdehydrogenase durch zwei weitere Abbausysteme erfolgen. Eines dieser Systeme stellt das Cytochrom-P450-CYP2E-System (früher „Mikrosomales Ethanol-oxidierendes System“ = MEOS) dar (Singer und Teyssen 2005). Die Aktivität dieses Enzyms ist induzierbar, das heißt es wird mit steigender Blutalkoholkonzentration (BAK) vermehrt gebildet (Feuerlein 2008) und ist durch chronischen Alkoholkonsum beeinflussbar. Ein weiterer Eliminationsweg läuft über die Katalase in den Peroxisomen der Leber, wobei diese unter physiologischen Bedingungen nur von geringer Bedeutung zu sein scheint (Singer und Teyssen 2005). Im zweiten Abbauschritt wird Acetaldehyd unter Einwirkung des Enzyms Aldehyddehydrogenase weiter zu Acetat oxidiert, welches anschließend im Zitronensäurezyklus unter Freisetzung von Adenosintriphosphat (ATP) zu Kohlenstoffdioxid $\left(\mathrm{CO}_{2}\right)$ und Wasser abgebaut wird.

Da die Aktivität der Alkoholdehydrogenase sich durch chronischen Alkoholmissbrauch nicht ändert und die Metabolisierung erst bei höherer Alkoholkonzentration über das Cytochrom-P450-CYP2E-System läuft, erfolgt der Alkoholabbau nahezu zeitlich linear. Bei Frauen wird daher von einer Abbaurate von 0,085 Gramm pro Kilogramm Körpergewicht pro Stunde und bei Männern von 0,1 Gramm pro Kilogramm Körpergewicht pro Stunde ausgegangen.

\subsubsection{Blutalkoholkonzentration (BAK)}

Die BAK ist ein Maß der Menge des Alkohols im Blut. Sie wird üblicherweise in Promille $(\%)$ oder in $\mathrm{g} / \mathrm{kg}$ angegeben. Eine Möglichkeit, die BAK zu berechnen, bietet die nachfolgende Widmark-Formel:

$$
\mathbf{C}=\mathbf{A} / \mathbf{m} \times \mathbf{r}
$$

c = Alkoholkonzentration im Blut

A = aufgenommene Masse des Alkohols in Gramm (g)

$\mathbf{m}=$ Körpergewicht in Kilogramm $(\mathrm{kg})$

$\mathbf{r}$ = Reduktionsfaktor im Körper (Synonym: Verteilungsfaktor): Anteil des Körpers, in dem sich der Alkohol verteilt.

\subsection{Alkoholabhängigkeit}

\subsubsection{Epidemiologie}

Pabst und Kraus (2008) untersuchten im Epidemiologischen Suchtsurvey 2006 anhand einer Zufallsstichprobe die Prävalenz der alkoholbezogenen Störungen in der deutschen 
Allgemeinbevölkerung. Dabei wurde, nach dem Diagnostic and Statistical Manual of Mental Disorders (DSM-IV, (APA 1994)), bei 3,8 \% der 18- bis 64-Jährigen die Diagnose eines Alkoholmissbrauchs und bei 2,4 \% die Diagnose einer Alkoholabhängigkeit gestellt. Die geschätzten direkten und indirekten Gesundheitskosten, die in Deutschland durch alkoholassoziierte Erkrankungen entstehen, werden auf jährlich etwa 20 Milliarden Euro geschätzt.

\subsubsection{ICD-10- und DSM-IV-Kriterien}

Nach der Internationalen Klassifikation psychischer Störungen (ICD-10, (Dilling et al. 2010)) wird zwischen dem schädlichen Gebrauch psychotroper Substanzen und einem Abhängigkeitssyndrom unterschieden. Dabei werden die Störungen durch Alkohol im Kapitel F10 abgebildet. Im Gegensatz dazu erfolgt nach dem DSM-IV (Saß et al. 2001) eine Differenzierung zwischen Substanzmissbrauch und Substanzabhängigkeit (zu den Diagnosekriterien siehe Anhang).

\subsubsection{Alkoholfolgeerkrankungen}

Die Toxizität des Alkohols in höherer Dosierung bedingt eine erhebliche Zahl unterschiedlicher Organerkrankungen. Vielfach führt die Manifestation einer solchen Erkrankung erst zur Diagnose der Alkoholabhängigkeit. Des Weiteren gibt es eine Reihe psychischer Erkrankungen, die mit einer Alkoholabhängigkeit im Zusammenhang stehen.

\section{Somatische Begleiterkrankungen}

Chronischer Alkoholkonsum führt besonders häufig zu einer alkoholtoxischen Schädigung der Leber, dem wichtigsten Organ des Alkoholabbaus. Es kann zum Auftreten einer Fettleber, einer alkoholischen Hepatitis und einer alkoholinduzierten Zirrhose kommen. Die Dekompensation einer Leberzirrhose kann zur hepatischen Encephalopathie führen und im Leberausfallskoma enden. Als Spätfolge des Alkoholkonsums kann ein Leberzellkarzinom auftreten.

Weitere Erkrankungen, die durch einen regelmäßigen Alkoholabusus begünstigt werden, sind die akute und die chronisch-kalzifizierende Pankreatitis mit der Komplikation einer sekundären exokrinen und/oder endokrinen Pankreasinsuffizienz.

Durch eine vermehrte Katecholaminfreisetzung kann Alkohol das Auftreten von Herzrhythmusstörungen begünstigen. Als weitere kardiale Folge des chronischen Konsums ist die alkoholische Kardiomyopathie (Mann et al. 1995) zu nennen.

Alkoholabusus kann außerdem zu einer metabolischen Azidose mit Hyperurikämie und 
den damit verbunden Komplikationen (z. B. Gichtanfällen) führen.

Bei Diabetikern kann der übermäßige Alkoholkonsum zu einer Hypoglykämie führen, welche je nach Ausmaß einen akut lebensbedrohlichen Notfall darstellen kann.

Außerdem kann chronischer Alkoholkonsum zu einer alkoholinduzierten peripheren Polyneuropathie führen. Im fortgeschrittenen Stadium der Alkoholabhängigkeit finden sich Großhirn- und vor allem Kleinhirnatrophien mit Gang- und Standataxien (Mann et al. 1995). Weitere neurologische Komplikationen sind epileptische Anfälle, die nicht selten nach Absetzen oder Reduktion des Alkoholkonsums auftreten und die Wernicke-Encephalopathie, ein amnestisches Syndrom mit Schädigung paraventrikulärer Hirnareale durch Vitamin-B1-Mangel.

Außer dem Leberzellkarzinom gibt es einige weitere tumoröse Erkrankungen, die mit dem chronischen Alkoholkonsum in Zusammenhang stehen. So begünstigt der Alkoholabusus das Auftreten von Karzinomen in der Mundhöhle, dem Hypopharynx, Pharynx, Larynx und Ösophagus, sowie im Colorektum. Der beim Abbau des Ethanols entstehende Acetaldehyd wirkt hierbei karzinogen.

Außer den hier genannten Organschädigungen sind zahlreiche weitere Folgen einer Alkoholabhängigkeit bekannt.

\section{Psychische Begleiterkrankungen}

Bis zu $37 \%$ der alkoholabhängigen Patienten entwickeln im Verlauf eine weitere psychische Erkrankung (Regier et al. 1990). Es wurde gezeigt, dass bei Patienten mit chronischem Alkoholkonsum häufig zusätzlich eine affektive Störung oder eine Angsterkrankung besteht. Dabei ist unklar, ob die Alkoholabhängigkeit auch umgekehrt als Folge einer Angststörung auftritt (Schneider et al. 2001).

In der Literatur bestehen unterschiedliche Ergebnisse im Hinblick auf den Verlauf der Alkoholkrankheit bei einer gleichzeitig bestehenden Depression. In einer Studie von Holdcraft et al. (1998) wurde eine günstigere Entwicklung der Alkoholabhängigkeit beschrieben. Im Gegensatz dazu wurde in einer anderen Arbeit gezeigt, dass eine gleichzeitig bestehende Depression die Zeitspanne bis zum erneuten Trinken verkürzt und die Rückfallhäufigkeit erhöht (Greenfield et al. 1998). Ebenso konnte demonstriert werden, dass eine parallel vorhandene Angststörung die Rückfallhäufigkeit steigert. Besteht außer einer Angststörung zusätzlich eine Depression, ist die Wahrscheinlichkeit eines Rückfalls nochmals höher (Driessen et al. 2001).

Eine Studie von Driessen et al. (1998) zeigte außerdem, dass die Häufigkeit von Suizidversuchen und durchgeführten Suiziden bei alkoholabhängigen Patienten deutlich höher ist als in der Allgemeinbevölkerung. In der Arbeit von Harris und Barraclough (1997) wurde, bei bestehender Alkoholabhängigkeit oder Alkoholmissbrauch, ein 4,5fach 
erhöhtes Risiko für vollendeten Suizid angegeben. Sind bei alkoholabhängigen Patienten zusätzliche psychiatrische Erkrankungen vorhanden, ist die Häufigkeit von Suizidversuchen nochmals höher. Dies konnte vor allem bei gleichzeitig bestehender Depression bzw. Angststörung nachgewiesen werden (Driessen et al. 1998).

\subsubsection{Neurobiologie}

Da Alkohol sowohl wasserlöslich als auch fettlöslich ist, verteilt er sich rasch in allen Geweben und Körperflüssigkeiten, einschließlich des Gehirns. Er wirkt als Agonist an den Rezeptoren des GABAergen-Systems, einem inhibitorischen NeurotransmitterSystem im ZNS. Bei chronischem Alkoholkonsum kommt es an diesen Rezeptoren zu einer Herabregulierung bestimmter Rezeptoruntereinheiten und konsekutiv zu einer veränderten Sensitivität auf GABAerge Substanzen (Mhatre et al. 1993).

Lovinger et al. (1989) demonstrierten, dass Ethanol, in klinisch relevanter Konzentration, in Neuronen des Hippokampus zu einer dosisabhängigen Hemmung von lonenströmen des NMDA-Rezeptors führt und die Übertragung am glutamatergen NMDA-Rezeptor blockiert (Tsai et al. 1995). Kompensatorisch führt chronischer Alkoholkonsum zu einer Heraufregulierung der NMDA-Rezeptoren auf transkriptionaler und post-transkriptionaler Ebene (Grant et al. 1990, Tsai und Coyle 1998).

Während des akuten Alkoholentzugssyndroms kommt es durch die verminderte agonistische GABAerge Aktivierung zu einer verstärkten Wirkung der glutamatergen Neurotransmission (Tsai et al. 1998) mit konsekutiver Hyperexzitabilität und Neurotoxizität. Dieser Mechanismus scheint, während des Alkoholentzugs, der Grund für die Entstehung von charakteristischen Symptomen zu sein. Hierzu zählen zum Beispiel Alkoholentzugsanfälle, motorische und psychische Erregtheit, Angor, sowie Prädelire, Delire und kardiovaskuläre Entgleisungen. In Bezug auf letztgenannte wurde gezeigt, dass NMDARezeptoren der kaudalen ventrolateralen Medulla oblongata und des Nucleus tractus solitarius eine bedeutende Rolle bei der kardiovaskulären Regulierung spielen (Lin et al. 2004, Wang et al. 2004). In der Studie von Li et al. (2003) konnte dargestellt werden, dass eine gesteigerte glutamaterge Aktivität mediiert via NMDA-Rezeptor-Stimulation zu einem erhöhten Sympathotonus und somit konsekutiv zu einem Anstieg des Blutdrucks und der Herzfrequenz führt. Ebenso wurde ein Zusammenhang zwischen einer verminderten GABAergen Neurotransmission im Nucleus paraventricularis des Hypothalamus und einer erhöhten sympathischen Aktivität aufgezeigt (Zhang et al. 2002).

Alkohol wirkt außerdem auf einige andere Rezeptorgruppen im ZNS. Bekannt ist, dass es die Dopaminfreisetzung im Striatum stimuliert (Boileau et al. 2003) und es während des 
Alkoholentzugs zu einem starken Abfall der Freisetzung kommt (Rossetti et al. 1992). Es wird angenommen, dass Dopamin außerdem eine entscheidende Rolle in der Entstehung des Alkoholverlangens spielt.

Des Weiteren gibt es zahlreiche Studien, die die Wirkung des Ethanols auf das serotonerge und das endogene Opioid-System untersucht haben. Die Zusammenhänge sind jedoch noch nicht abschließend geklärt.

\subsubsection{Alkoholgebrauch, schädlicher Gebrauch und Abhängigkeit}

\section{Laborparameter}

Bestimmte Veränderungen im Blut können Hinweise auf das Vorliegen eines übermäßigen Alkoholkonsums liefern. Dazu zählen charakteristischerweise erhöhte Konzentrationen der Gammaglutamyltransferase ( $\mathrm{Y}-\mathrm{GT})$ und der Transaminasen (Aspartat-Amino-transferase (AST), Alanin-Aminotransferase (ALT)), als Zeichen der Leberschädigung. Außerdem können das mittlere Erythrozyten-Zellvolumen (MCV) und der carbohydrate- deficient-transferrin-Wert (CDT) gesteigert sein.

Der CDT-Wert dient als ein Maß des Alkoholkonsums der letzten Wochen. Er ist durchschnittlich nach einer täglichen Aufnahme von mehr als $60 \mathrm{~g}$ Alkohol an mindestens 7 aufeinander Tagen erhöht (Renz-Polster et al. 2004).

Pathologisch erhöhte Laborparameter dienen oft als erste Anhaltspunkte für das Vorliegen eines Alkoholabusus. Die Diagnose einer Alkoholabhängigkeit kann jedoch letztlich nur anhand einer direkten Befragung und anhand des klinischen Zustandsbildes gestellt werden.

\section{Validierte Fragebögen}

Sie dienen vorrangig als Screening-Methode zur Verifizierung eines übermäßigen Alkoholkonsums (z. B. CAGE-Test, AUDIT, LAST).

In dieser Studie kam der Selbstbeurteilungsteil des MALT (Münchner Alkoholismus-Test) zur Anwendung (siehe Anhang).

\subsubsection{Prognose}

Die durchschnittliche Lebenserwartung von Alkoholikern ist ohne Therapie um circa 15 Jahre vermindert. Suizide zählen mit $15 \%$, neben Unfällen und Herzerkrankungen, zu den häufigsten Todesursachen chronischer Alkoholiker (Herold 2009). 


\subsection{Alkoholentzug}

\subsubsection{Diagnose, Symptome und Komplikationen}

Die Diagnose eines Alkoholentzugs(syndroms) kann anhand der ICD-10- (Dilling et al. 2010) und DSM-IV-Kriterien ( $\mathrm{SaB}$ et al. 2001) gestellt werden (siehe Anhang). Die Symptome, die es charakterisieren, sind ein typisches Kennzeichen der körperlichen Abhängigkeit und treten nach Unterbrechung der regelmäßigen Alkoholzufuhr auf. Unterschieden werden 2 Formen:

\section{Entzugssyndrom ohne Delir}

Es beginnt circa 10 Stunden nach dem Entzug von Alkohol und ist nach ein bis 2 Tagen am stärksten ausgeprägt.

Typische Symptome, die dieses Stadium kennzeichnen, sind:

- vegetative Störungen (Schwitzen, Mydriasis, Schlafstörungen, Fieber)

- neurologische Symptome (Tremor, Artikulationsstörungen)

- kardiovaskuläre Symptome (Tachykardie, Hypertonie)

- psychische Symptome (Innere Unruhe, Angst)

- gastrointestinale Beschwerden (Nausea, Diarrhoe).

\section{Entzugssyndrom mit Delir}

Es wird auch als Delirium tremens bezeichnet und beginnt charakteristischerweise am zweiten bis dritten Tag nach dem Entzug von Alkohol. Ohne Therapie wird in diesem Stadium eine Letalität von bis zu $20 \%$ beschrieben. Mit Behandlung liegt diese bei circa $2 \%$ (Herold 2009).

Zusätzlich zu den oben genannten Merkmalen können folgende Symptome auftreten:

- Bewusstseinsstörungen

- Desorientierung

- Halluzinationen

- schwere psychomotorische Unruhe

- Auffassungsstörungen.

Außer den hier genannten Krankheitsmerkmalen gibt es zahlreiche weitere Symptome, die den Entzug beeinträchtigen können. Häufige Komplikationen sind beispielsweise generalisierte tonisch-klonische Anfälle. Hier liegt die Prävalenz zwischen 20 bis $35 \%$ (Singer und Teyssen 2001). 


\subsubsection{Beurteilung der Intensität}

Neben dem klinischen Erscheinungsbild bietet eine Reihe von Tests eine Möglichkeit, die Schwere des Alkoholentzugssyndroms zu beurteilen. Hierzu zählt z. B. die, in dieser Studie angewendete, AWS-Skala (Alcohol-Withdrawal-Syndrome-Skala).

Weitere Tests, die die Erfassung der Schwere des Alkoholentzugssyndroms ermöglichen, sind beispielsweise die Lübecker Alkoholentzugs-Risiko-Skala (LARS) und die Alkohol-Entzugssyndrom-Skala (AES).

\subsubsection{Medikamentöse Therapie}

Die Medikation, die zur Milderung des Alkoholentzugssyndroms eingesetzt wird, sollte idealerweise eine Dämpfung der autonomen Überaktivität, eine Anhebung der Krampfschwelle, eine Angst- und Anspannungsreduktion, eine antipsychotische Wirkung sowie eine Sedierung mit Erhalt der Schutzreflexe bewirken.

Mittel der Wahl in der Behandlung des schweren Entzugssyndroms und des Delirs mit und ohne Entzugsanfälle ist in Deutschlands Clomethiazol, ein Hypnotikum, das sowohl antikonvulsiv als auch muskelrelaxierend wirkt. Des Weiteren können auch Benzodiazepine Entzugssymptome mildern und das Risiko von Entzugsanfällen und Delirien vermindern. Sie sind jedoch aktuell in dieser Indikation in Deutschland nicht zugelassen (Benkert und Hippius 2009). Benzodiazepine verstärken die GABAerge Wirkung und wirken anxiolytisch, antikonvulsiv, zentral muskelrelaxierend und sedierend.

Des Weiteren sind orales Clonidin und das Antikonvulsivum Carbamazepin zur Behandlung von leichten bis mittleren Entzugssymptomen geeignet. Auch ist bekannt, dass die Kombination von retardiertem Carbamazepin plus Tiaprid, ein typisches Neuroleptikum, die Entzugssymptomatik mildern kann (Franz et al. 2001).

Eine Monotherapie mit einem Antipsychotikum sollte grundsätzlich nicht eingesetzt werden.

Bei Patienten, die einen Alkoholentzugsanfall in der Vergangenheit erlebt haben, sollte die medikamentöse Therapie unabhängig vom aktuellen Schweregrad des Entzugssyndroms erfolgen.

Symptome eines Delirs können medikamentös mit Benzodiazepinen in Kombination mit Antipsychotika z. B. vom Butyrophenon-Typ (wie Haloperidol) behandelt werden. Gegebenenfalls kann eine intravenöse Verabreichung von Diazepam plus Haloperidol oder Midazolam plus Dihydrobenperidol notwendig sein. Fakultativ kann zusätzlich eine intravenöse Gabe von Clonidin, einem zentral angreifenden a2-Rezeptor-Agonist, zur Dämpfung der sympathikotonen Überaktivität erfolgen. Bei lebensbedrohlichen Delirien ist eine intensivmedizinische Überwachung erforderlich. 


\subsection{Homocystein}

\subsubsection{Entstehung}

Homocystein, chemisch als 1-Amino-3-Mercaptobuttersäure bezeichnet, ist eine schwefelhaltige Aminosäure. Es entsteht im Körper durch Demethylierung von Methionin. Der normale Nüchtern-Plasmaspiegel liegt zwischen $5 \mu \mathrm{mol} / \mathrm{l}$ und $15 \mu \mathrm{mol} / \mathrm{l}$. Es liegt im Blut in 3 Formen vor, wobei der größte Anteil proteingebunden, ein geringerer Teil als freie Form und Spuren als Disulfid vorhanden sind (Bleich et al. 2003).

Methionin ist eine essentielle proteinogene Aminosäure. Sie kann folglich vom Körper nicht gebildet werden und muss mit der Nahrung aufgenommen werden.

Die Bildung von Homocystein aus Methionin erfolgt in 2 Schritten, wobei im ersten Teil SAdenosylmethionin (SAM) entsteht. Im zweiten Schritt wird SAM zu S-Adenosylhomocystein (SAH) abgebaut, welches daraufhin zu Homocystein und Adenosin hydrolysiert wird.

\subsubsection{Abbau}

Homocystein wird etwa zu gleichen Teilen durch Remethylierung zu Methionin oder durch Transsulfurierung über Cystathionin zu Cystin verstoffwechselt.

Die Remethylierung dient der Aufrechterhaltung des intrazellulären Methioninspiegels (Ullrich und Wendel 1999). Diese Reaktion findet in Anwesenheit des Co-Faktors MethylCobalamin (Vitamin B12) statt. Dabei wird der Methylgruppendonator 5-Methyltetrahydrofolat durch die Methioninsynthase zu Tetrahydrofolat umgewandelt. Ist dieser Schritt der Remethylierung von Homocystein zu Methionin gestört, so kommt es zum Erliegen des Folsäurestoffwechsels mit konsekutiver Anhäufung von 5-Methyltetrafolat und einem Folsäuremangel, da die Folataufnahme aus dem Blut nicht gesteigert werden kann. Alternativ kann die Homocystein-Remethylierung auch in einer Vitamin-B12unabhängigen Reaktion mit Betain als Methylgruppendonator ablaufen. Während die Reaktion mit 5-Methyltetrahydrofolat in allen Geweben stattfindet, ist die Reaktion mit Betain auf die Leber begrenzt (Cravo und Camilo 2000).

Der Transsulfurierungsweg findet hauptsächlich in Leber, Pankreas, Nieren und Dünndarm statt. Hier wird Homocystein irreversibel zu Cystathionin abgebaut. Für diese Reaktion werden die Aminosäure Serin und Pyridoxin (Vitamin B6) als Co-Faktoren für das Enzym Cystathion- $\beta$-Synthase benötigt (Durand et al. 2001).

\subsubsection{Homocystein im Stoffwechsel}

Homocystein fungiert durch die oben beschriebenen Metabolisierungswege als wichtiger 
Methylgruppendonator im menschlichen Organismus. Es gewährleistet unter anderem die Synthese von Katecholaminen und Purinbasen. Eine Störung dieses MethylierungsSystems wird als Ursache vieler neurologischer Störungen, wie zum Beispiel der demyelinisierenden Polyneuropathien, angesehen (Bleich et al. 2003).

Liegt bei einem Patienten eine Homocysteinämie vor, so kann dies verschiedene Ursachen haben. Neben einem angeborenen Enzymdefekt ist der Mangel an CoEnzymen (Vitamin B6, Vitamin B12, Folsäure) ein möglicher Grund. Des Weiteren konnte eine positive Korrelation zwischen erhöhten Homocysteinwerten und männlichem Geschlecht, Alter, Anzahl von konsumierten Zigaretten, Alkohol, Koffein, Einnahme von Antihypertensiva und Kreatinin-Konzentration ermittelt werden (Jacques et al. 2001). Zusätzlich können z. B. eine Hypothyreose oder die Einnahme verschiedener Pharmaka (z. B. Phenobarbital, Methotrexat), zu einer Homocysteinämie führen (Guilliams 2004).

Bei der autosomal-rezessiv vererbten Homocystinurie kommt es durch einen Enzymdefekt zu einem erhöhten Homocysteinspiegel. Dieses Krankheitsbild führt neben psychotischen, schizophrenieähnlichen Verhaltensstörungen frühzeitig zu Arteriosklerose und Thrombembolien (Sitzmann 2007). Der Zusammenhang zwischen der Homocysteinkonzentration und dem Auftreten von Arteriosklerose ist seit Jahrzehnten bekannt. Eine Korrelation zwischen moderat erhöhten Homocysteinwerten und kardiovaskulären Ereignissen konnte unter anderem in der Studie von Guilliams (2004) aufgezeigt werden.

\subsubsection{Neurobiologie}

Homocystein wirkt im Gehirn agonistisch an der Glutamat-Bindungsstelle des N-MethylD-Aspartat (NMDA)-Rezeptors (Lipton et al. 1997). Dieser Rezeptor gehört zu den ligandengesteuerten lonenkanälen und ist ein exzitatorischer Aminosäurerezeptor, der durch Glutamat aktiviert werden.

Der NMDA-Rezeptor besitzt neben der Bindungsstelle für den Agonisten Glutamat einige weitere Bindungsstellen. So findet sich auf der extrazellulären Seite des Rezeptors eine Bindungsstelle für Glycin, ein zusätzlicher Agonist, der zur Aktivierung notwendig ist. Im Inneren des lonenkanals liegen außerdem Bindungsstellen für Magnesium ( $\mathrm{Mg})$ und Phencyclidin (PCP).

Während des Ruhemembranpotentials wird der lonenkanal durch Mg-lonen blockiert. Erst bei der Depolarisation wird dieser Block aufgehoben. Dies bedeutet, dass 2 Bedingungen erfüllt sein müssen, damit sich der Kanal für den loneneinstrom öffnet: Glutamat und Glycin müssen an den Rezeptor gebunden sein und eine Depolarisation des Neurons muss vorliegen (Bleich et al. 2003). 
Durch den agonistischen Effekt Homocysteins an der Glutamatbindungsstelle des NMDA-Rezeptors ist die Aminosäure als ein Exitotoxin zu bezeichnen. Dies bedeutet, dass es zu einer überschießenden glutamatergen Neurotransmission durch Homocystein kommen kann.

Des Weiteren wirkt die Aminosäure jedoch auch partial antagonistisch an der Glycinbindungstelle des NMDA-Rezeptors (Lipton et al. 1997). Dieser Wirkmechanismus kommt bei einem Glycinspiegel im Normbereich zum Tragen. Unter diesen Konditionen wird die NMDA-Rezeptor-Aktivität folglich gehemmt.

Es konnte demonstriert werden, dass, bei Glycinkonzentrationen innerhalb des Normbereichs, die neurotoxische Wirkung Homocysteins im Bereich von einigen Millimol (mmol) liegt, während bei einer über den Normwert erhöhten Glycinkonzentration der neurotoxische Effekt Homocysteins bereits bei einer Konzentration von 10 bis 100 Mikromol ( $\mu \mathrm{mol}$ ) beginnt. Es wird daher angenommen, dass Homocystein und Glycin um die Glycinbindungsstelle des NMDA-Rezeptors konkurrieren und dass Homocystein ab einer Glycinkonzentration von über $50 \mu \mathrm{mol} z u$ einem NMDA-Rezeptor-Agonisten mit hoher Affinität wird. Erhöhte Glycinwerte, die folglich zu einer neurotoxischen Wirkung Homocysteins als Agonist an der Glutamatbindungsstelle des NMDA-Rezeptors führen können, sind zum Beispiel im Liquor cerebrospinalis von Patienten mit Hirnverletzungen nachgewiesen worden (Palmer et al. 1994).

\subsubsection{Homocystein und Alkohol}

In einer Studie von Hultberg et al. (1993) wurde erstmals über erhöhte Homocysteinwerte im Plasma von chronischen Alkoholikern berichtet. Im Vergleich zur Kontrollgruppe zeigte sich bei alkoholabhängigen Patienten, die zur Entgiftung stationär aufgenommen wurden, eine signifikant erhöhte Plasma-Homocysteinkonzentration. Diese Werte normalisierten sich ein bis 2 Wochen nach der stationären Aufnahme. Ein vergleichbares Ergebnis zeigte die Studie von Cravo et al. (1996): hier wurden die Homocysteinwerte von 32 Alkoholikern und 31 gesunden Kontrollpersonen untersucht. Dabei war die mittlere Serum-Homocysteinkonzentration der alkoholabhängigen Patienten doppelt so hoch wie die der Kontrollgruppe.

Eine mögliche Erklärung der Homocysteinämie bei chronischen Alkoholikern liefert die Studie von Selhub et al. (1993). Hier konnte demonstriert werden, dass es eine negative Assoziation zwischen Homocystein und der Plasmakonzentration verschiedener Vitamine, wie Folat, Vitamin B12 und Pyridoxalphosphat, gibt. Somit wäre der Mangel dieser Co-Enzyme des Homocystein-Stoffwechsels bei Alkoholikern eine mögliche Ursache der erhöhten Homocysteinkonzentrationen. 
Da Folat unter den Co-Enzymen im Homocystein-Metabolismus eine bedeutende Rolle einnimmt, wurde eine Studie unternommen, um die Wichtigkeit des Folatmangels in der Entstehung der alkoholassoziierten Homocysteinämie zu identifizieren (Stickel et al. 2000). Hierfür wurde eine Gruppe von Ratten mit einer alkohol- und folsäurehaltigen Kost ernährt. Der Folsäuregehalt lag dabei über dem 20-fachen des Grundbedarfs. Nach 4 Wochen zeigten sich bei diesen Ratten keine Reduktion der Folat-, Vitamin-B12- und Pyridoxalphosphat-Konzentrationen. Gleichzeitig kam es aber zum Auftreten einer Homocysteinämie, die folglich durch die folsäurehaltige Kost nicht verhindert werden konnte. Die Diskrepanz dieser beiden Studien verdeutlicht, dass die Rolle des Vitaminmangels bei chronisch alkoholkranken Patienten als Ursache einer Homocysteinämie nicht geklärt ist.

Ein weiterer Erklärungsansatz bietet die Untersuchung von Kenyon et al. (1998). Hier konnte gezeigt werden, dass Acetaldehyd, welches im Alkoholabbau entsteht, in vitro die Methioninsynthase hemmt. Die Hemmung dieses Enzyms, das für die Remethylierung von Homocystein zu Methionin benötigt wird, führt zu einem Anhäufen von Homocystein. Gleichzeitig kommt es zu einer Erhöhung der SAH-Konzentration, als Vorläufer von Homocystein, und einer Reduktion von SAM. Das gleiche Ergebnis erbrachte auch eine Studie von Stickel et al. (2000).

Bleich et al. (2000 a) konnten in ihrer Arbeit nachweisen, dass die Plasma-Homocysteinkonzentration positiv mit der Wahrscheinlichkeit eines Grand-mal-Anfalls korreliert. Dafür wurde die Homocysteinkonzentration bei 32 chronischen Alkoholikern gemessen, die zur Alkoholentgiftung stationär aufgenommen wurden. 27 der untersuchten 32 Patienten litten an einer Homocysteinämie; von diesen entwickelten 6 Patienten Grand-malEntzugsanfälle. Pathogenetisch könnte dabei, außer der entzugsbedingten verstärkten Aktivierung der NMDA-Rezeptoren mit konsekutiver Hyperexzitabilität, die NMDAagonistische Wirkung Homocysteins bedeutsam sein.

\section{$1.5 \mathrm{~s} 100 \beta$}

\subsubsection{Synthese}

s100ß ist ein Kalzium-bindendes Zytokin. Es gehört zur Gruppe der azidischen s100Proteine und besitzt eine Größe von 10 bis 12 Kilodalton (kDa). Das Zytokin wird von Astrozyten sowie von den Follikulostellat-Zellen des Hypophysenvorderlappens sezerniert (Shirasawa und Yamanouchi 1999). Außerdem wurde in einer Studie von Steiner et al. (2007) demonstriert, dass $5100 \beta$ außer in Astrozyten und FollikulostellatZellen auch in zahlreichen weiteren Hirngeweben vorhanden ist. 
Die Abgabe von $s 100 \beta$ aus den Astrozyten wird durch Bindung von Serotonin an die 5HT1A-Rezeptoren initiiert (Whitacker-Azmitia et al. 1990).

\subsubsection{Funktion}

s100 $\beta$ wirkt als mitogener und neurotropher Faktor, der die Proliferation von Gliazellen und die Differenzierung unreifer Neurone anregt (Barger und Van Eldik 1992). Das Zytokin fördert das neuritische Wachstum verschiedener neuronaler Populationen, wie zum Beispiel serotonerger Zellen (Liu und Lauder 1992). Außerdem begünstigt s100ß das Überleben von Neuronen während der Entwicklung (Bhattacharyya et al. 1992, Reeves et al. 1994).

\subsubsection{Bedeutung bei Erkrankungen}

s100ß hat außer dem oben beschriebenen neurotrophen Effekt auch eine schädliche Wirkung auf Nervenzellen (Hu et al. 1996). So wird eine gesteigerte s100ß-Konzentration im Plasma mit Krankheiten assoziiert, denen eine strukturelle Hirnverletzung oder ein neurodegenerativer Prozess zugrunde liegt (Rothermundt et al. 2001).

Erhöhte Plasmakonzentrationen der s100-Proteine bestehen beispielsweise nach einer traumatischen Hirnverletzung (Lamers et al. 1995) oder bei Patienten mit einer Subarachnoidalblutung nach Ruptur eines Aneurysmas (Wiesmann et al. 1997).

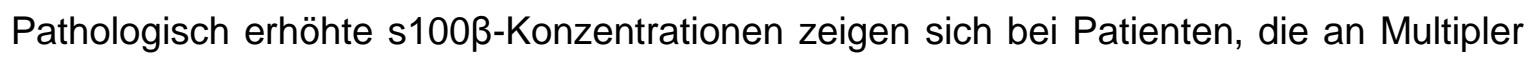
Sklerose (Massaro et al. 1985), Morbus Down oder Alzheimer-Demenz (Griffin et al. 1989) erkrankten. Bezüglich der Alzheimer-Demenz wurde nachgewiesen, dass $s 100 \beta$ selektiv in den neuropathologisch betroffenen Regionen erhöht ist (Van Eldik und Griffin 1994) und die Überexpression von $s 100 \beta$ mit der Prävalenz neuritischer Plaques korreliert (Sheng et al. 1994). Ebenso konnten erhöhte s100ß-Konzentrationen im Liquor cerebrospinalis bei psychiatrischen Erkrankungen, wie der Schizophrenie (Schroeter et al. 2009, Wiesmann et al. 1999) nachgewiesen werden. Die Studie von Schroeter et al. (2009) demonstrierte eine Assoziation zwischen erhöhten s100ß-Werten und einer Gedächtnis-Verschlechterung bei chronisch schizophrenen Patienten.

Außerdem zeigte sich eine signifikante Zunahme der s100ß-Serumkonzentrationen bei bipolar erkrankten Patienten, die aktuell an einer manischen oder depressiven Episode litten im Gegensatz zu euthymen Patienten mit einer bipolaren affektiven Störung (Andreazza et al. 2007). Arolt et al. (2003) stellten signifikant erhöhte s100ß-Werte im Plasma bei Patienten mit einer Major Depression im Vergleich zur gesunden Kontrollgruppe fest. 
Ferner ist bekannt, dass Melanomzellen $s 100 \beta$ exprimieren. Dabei korreliert die Höhe im Blut positiv mit der Metastasenzahl und Aggressivität des Tumors (Mohammed et al. 2001) und negativ mit der Prognose (Hauschild et al. 1999). $S 100 \beta$ dient daher als Tumormarker für das maligne Melanom. Vom Zentrallabor des Universitätsklinikums Göttingen wird hierfür ein Referenzwert von $\leq 0,12 \mu \mathrm{g} / \mathrm{l}$ angegeben.

\subsubsection{Wirkmechanismus}

s100ß kann mutmaßlich als ein sensitiver, nicht-spezifischer Marker struktureller Hirnverletzungen und neurodegenerativer Prozesse betrachtet werden. Pathogenetisch scheint bei diesen Erkrankungen eine Schädigung von Astrozyten im Vordergrund zu stehen, die dazu führt, dass $s 100 \beta$ über den Extrazellulärraum und den Liquor cerebrospinalis in das Blut übertritt.

Rothermundt et al. (2001) verglichen in ihrer Arbeit die s100ß-Werte im Plasma von Patienten mit melancholischer und nicht-melancholischer Major Depression. Hier zeigten sich signifikant erhöhte Werte bei Patienten mit melancholischer Depression im Vergleich zur Kontrollgruppe, während Patienten mit nicht-melancholischer Depression Werte im Normbereich aufwiesen. Es wurde daher hypothetisiert, dass ein struktureller Hirnschaden an der Pathogenese der melancholischen Depression oder aber ein axonaler Umbauprozess beteiligt sein könnte. Auch die Studie von Wiesmann et al. (1999), in der gezeigt wurde, dass Patienten, die an Schizophrenie leiden, erhöhte s100ß-Werte im Plasma aufweisen, lässt vermuten, dass pathogenetisch ein struktureller Zelldefekt im ZNS zugrunde liegt.

In einer weiteren Untersuchung konnte demonstriert werden, dass $s 100 \beta$ zu einem Anstieg der freien intrazellulären Kalzium-Konzentration in Neuronen und Gliazellen des ZNS führt (Barger und Van Eldik 1992). Zu diesem Kalziumanstieg in Neuronen des Hippokampus bewirkte $s 100 \beta$ jedoch parallel einen Schutz vor Zelltod und mitochondrialer Dysfunktion in Zellen, die einem Glukose-Entzug ausgesetzt wurden (Barger et al. 1995). Im Gegensatz dazu berichteten Fanò et al. (1993) über einen toxischen Effekt der s100-Proteine auf PC12-Zellen, der mit einem Anstieg der intrazellulären Kalzium-Konzentra-tion assoziiert ist. Somit wäre eine Beteiligung von s100 $\beta$ in der Pathogenese verschiedener neurologischer und psychiatrischer Erkrankungen, möglicherweise in Zusammenhang mit einem Kalzium-Anstieg, denkbar. Um die Möglichkeit der Induktion eines toxischen Signalwegs durch s100ß zu erforschen, untersuchten $\mathrm{Hu}$ et al. (1996) die Wirkung des Proteins auf die Nitritoxid-Synthase in kortikalen Astrozyten von Ratten. Hier zeigte sich, dass die Behandlung dieser Zellen mit $s 100 \beta$, in mikromolarer Konzentration, zu einer Stimulation der Nitritoxid-Synthase- 
Aktivität führt. Konsekutiv kam es zur Produktion von Stickstoff-Monoxid, das außer seiner Funktion als Signalstoff auch mit einer schädlichen Wirkung im ZNS in Verbindung gebracht wird (Chao et al. 1992).

Eine Studie von Suzuki et al. (1987) ergab, dass die Freisetzung des s100-Proteins aus Glioblasten von Ratten durch die Zugabe von Adrenocorticotropem Hormon (ACTH) gefördert wird. Somit wäre eine stressinduzierte Aktivierung der Hypothalamus-Hypophysen-Nebennierenrinde-Achse und konsekutive Ausschüttung von s100ß zu diskutieren. Der Zusammenhang zwischen Stress und der Serumkonzentration von $s 100 \beta$ wurde in einer Arbeit von Scaccianoce et al. (2004) untersucht. Sie ergab einen stressinduzierten Anstieg der s100ß-Serumkonzentration. Die Ergebnisse dieser Studie lassen jedoch auf einen Glukokortikoid-unabhängigen Mechanismus schließen.

Eine Untersuchung von Janković et al. (1991) ergab eine Korrelation zwischen anti-s100Antikörpern und dem Auftreten von Alzheimer- und seniler Demenz.

Diese Studien bieten eine Reihe von Erklärungsmöglichkeiten, die eine Beteiligung von $s 100 \beta$ in der Pathogenese verschiedener Erkrankungen vermuten lassen. Die Rolle sowie der genaue Mechanismus, die $s 100 \beta$ spielt, sind aber weiterhin nicht vollständig geklärt.

Eine weitere Hypothese, die eine erhöhte s100ß-Konzentration im Plasma begründen würde, wäre der kompensatorische Anstieg von s100ß bei diesen Erkrankungen. Passend hierzu wäre der oben genannte neuroprotektive Effekt, den s100 $\beta$ auf Neurone des ZNS ausübt (Barger und Van Eldik 1992).

\subsubsection{Hypothese}

Der neuronalen Wirkung von $s 100 \beta$ scheint ein dosisabhängiger Mechanismus zugrunde zu liegen. In physiologischen Konzentrationen, das heißt im nanomolaren Bereich, wirkt es neurotroph (Huttunen et al. 2000) und mitogen (Hu et al. 1996). Es fördert beispielsweise das neuritische Wachstum (Liu und Lauder 1992) und das Überleben von Neuronen während der Entwicklung (Bhattarcharyya et al. 1992). Außerdem übt es eine anti-apoptotische Wirkung auf Neurone aus (Druse et al. 2007). Aufgrund dieser Funktionen wurde das Zytokin auch als Wachstumsfaktor des Gehirns beschrieben (Reeves et al. 1994).

In höheren Konzentrationen, das heißt im mikromolaren Bereich, wirkt s100 $\beta$ hingegen neurotoxisch. Erhöhte s100ß-Konzentrationen wurden bei verschiedenen neurodegenerativen Erkrankungen, wie beispielsweise der Alzheimer-Demenz oder dem Morbus Down, nachgewiesen (Griffin et al. 1989).

Der Mechanismus, der dieser dosisabhängigen Wirkung von s100ß zugrunde liegt, wurde 
mehrfach untersucht. Eine Assoziation mit dem Kalzium-Haushalt, wie in der Studie von Fanò et al. (1993) beschrieben, scheint hierbei eine Rolle zu spielen. Der Anstieg der intrazellulären Kalziumkonzentration führt mutmaßlich zur Hochregulierung der Expression von Fos (Fulle et al. 2000), dem Proteinprodukt des c-fos-Gens, das zu den immediately early genes gehört. Hierüber scheint die neurotoxische Wirkung von $s 100 \beta$ vermittelt zu werden.

Shirasawa und Yamanouchi (1999) demonstrierten außerdem, dass s100ß zeitgleich mit der Glutamin-Synthetase sezerniert wird. Diese Assoziation mit dem Glutamat-Stoffwechsel im ZNS sowie die exzitatorische Wirkung Glutamats bieten eine weitere Erklärungsmöglichkeit für die durch $s 100 \beta$ mediierte Neurotoxizität.

Der Zusammenhang zwischen der Freisetzung von s100ß und ACTH lässt auf eine stressinduzierte Ausschüttung des Zytokins schließen (Suzuki et al. 1987), was auch die Studie von Scaccianoce et al. (2004) zeigte.

\subsection{6 s100 $\beta$ und Alkohol}

Insgesamt gibt es wenige Daten zu s100ß in Verbindung mit Alkoholkonsum bzw. Alkoholabhängigkeit. Im Tierversuch zeigten sich erhöhte Werte des s100-Proteins im Gehirn von Wüstenrennmäusen nach einer chronischen Alkoholzufuhr über einen Zeitraum von 3 Monaten (Rosengren et al. 1985).

Des Weiteren wurde demonstriert, dass das Zytokin die höchste Dichte von intrazellulären Bindungsstellen in Neuronen auf Gliazellen des Hippokampus aufweist, der bei chronisch Alkoholkranken oft volumengemindert ist (Agartz et al. 1999).

Im Tierversuch wurde außerdem demonstriert, dass $s 100 \beta$ eine Ethanol-induzierte Apoptose von Neuronen verhindern kann (Druse et al. 2007).

Liappas et al. (2006) untersuchten, ähnlich wie in dieser Arbeit, die s100ß-Konzentration im Serum von alkoholabhängigen Patienten während des stationären Alkoholentzugs. Dabei verglichen sie die Werte bei Aufnahme und Entlassung, nach circa 4 bis 5 Wochen. Hier wurde ein signifikanter Unterschied der s100ß-Werte zum Zeitpunkt der stationären Aufnahme bei Patienten mit starker Abhängigkeit und früherem hohem durchschnittlichem Alkoholkonsum im Vergleich zu Werten bei Entlassung detektiert. Die Methode dieser Studie scheint aber wenig reliabel. 


\section{STUDIENZIEL}

Das Ziel dieser Studie war es, zu untersuchen, ob die Serumspiegel von Homocystein und $s 100 \beta$ mit dem Schweregrad des akuten Alkoholentzugssyndroms bei Alkoholabhängigen im Zusammenhang stehen. Vorherige Studien haben erhöhte Homocysteinwerte im Plasma von chronischen Alkoholikern nachgewiesen (Cravo et al. 1996, Hultberg et al. 1993). Zu s100ß in Verbindung mit Alkohol gibt es insgesamt wenige Daten. Ein Zusammenhang zwischen Homocystein und $\mathrm{s} 100 \beta$ wurde bisher nicht aufgezeigt.

Diese Studie sollte außerdem untersuchen, ob die Serumspiegel von Homocystein und s100ß während der akuten Alkoholentzugsbehandlung mit den Konsummustern der Probanden (Dauer der Alkoholabhängigkeit, Menge der konsumierten Alkoholika vor der stationären Aufnahme) zusammenhängen. Des Weiteren sollte in dieser Arbeit überprüft werden, ob die Serumspiegel von Homocystein und s100ß miteinander korrelieren und ob diese durch pharmakologische Maßnahmen während der Entzugsbehandlung beeinflusst werden. Ferner sollte diese Studie klären, ob die Konzentration beider Variablen im Serum mit kognitiven Defiziten oder nachweisbaren hirnatrophischen Prozessen in Zusammenhang steht. Möglicherweise stellen Patienten mit Veränderungen der Homocystein- und s100ß-Werte während des akuten Alkoholentzugssyndroms eine Risikogruppe für charakteristische Spätfolgen der chronischen Alkoholabhängigkeit dar.

Da eine Veränderung der Spiegel von Homocystein und $5100 \beta$ im Serum vermutlich den Entzugssymptomen vorausgehen würde, könnten diese Werte möglicherweise eine prädiktive Bedeutung für die frühzeitige Beurteilung des Schweregrads eines gegebenenfalls folgenden Entzugssyndroms bekommen.

Die Studie ist eine offene, prospektive Studie ohne direkten Nutzen für die untersuchten Probanden. Bei Verifizierung der wissenschaftlichen Hypothesen könnte sie aber in Zukunft prognostischen und prophylaktischen Wert für Patienten während einer Alkoholentzugsbehandlung und bei der chronischen Alkoholabhängigkeit bekommen. 


\section{MATERIAL UND METHODEN}

\subsection{Studienteilnehmer}

Im Rahmen der vorliegenden Studie wurde ein Kollektiv von 31 Patienten untersucht, die in dem Zeitraum von Oktober 2006 bis August 2007 zur akuten Alkoholentgiftung in den stationären Bereich der Klinik für Psychiatrie und Psychotherapie des Universitätsklinikums Göttingen aufgenommen wurden.

\subsubsection{Einschlusskriterien}

In die Studie wurden ausschließlich Patienten mit der Diagnose einer Alkoholabhängigkeit nach ICD-10-Kriterien (Dilling et al. 2010) sowie einem stationären Alkoholentgiftungswunsch aufgenommen. Das Alter der Patienten, die an der Studie teilnahmen, sollte zwischen 18 und 65 Jahren liegen.

\subsubsection{Ausschlusskriterien}

Alkoholabhängige Patienten, bei denen es Hinweise oder den Verdacht auf das Vorliegen einer psychotischen Störung, einer hirnorganischen Störung oder eines klinisch relevanten depressiven Syndroms gab, wurden von der Studienteilnahme ausgeschlossen.

Des Weiteren wurde die regelmäßige Einnahme von Antidepressiva im Zeitraum von 4 Wochen vor der stationären Aufnahme als Ausschlusskriterium festgelegt.

Nicht zugelassen waren zudem Patienten, bei denen ein polyvalenter Substanzgebrauch (ausgenommen Nikotin) vorlag.

\subsubsection{Einverständniserklärung}

Zu Beginn der Untersuchung wurden alle Probanden mündlich und schriftlich über Dauer, Durchführung und Zielsetzung der Studie informiert. Alle Teilnehmer gaben ihr mündliches und schriftliches Einverständnis.

Die Ethikkommission der Medizinischen Fakultät der Universität Göttingen erhob zu dieser Studie keine Bedenken. 


\subsection{Studienablauf}

\subsubsection{Zeitlicher Ablauf}

Alle Studienteilnehmer wurden jeweils zu 4 aufeinander folgenden Zeitpunkten untersucht. Die erste Untersuchung erfolgte dabei möglichst zeitnah zur stationären Aufnahme, maximal jedoch $48 \mathrm{~h}$ danach. Die zweite Untersuchung erfolgte $24 \mathrm{~h}$ nach der Ersten, die Dritte im Abstand von $48 \mathrm{~h}$ zum ersten Termin. Der vierte Untersuchungszeitpunkt lag $120 \mathrm{~h}$ nach dem Ersten.

Die Untersuchungs- bzw. Studiendauer eines Patienten betrug somit insgesamt 5 Tage.

\subsubsection{Untersuchungen}

Bei den Studienteilnehmern erfolgte zu den 4 Untersuchungszeitpunkten jeweils eine Blutentnahme, um die s100ß- und Homocysteinwerte im Serum zu bestimmen.

Des Weiteren wurde zu allen 4 Zeitpunkten der Blutdruck der Studienteilnehmer gemessen und die Pulsfrequenz ausgezählt.

Die erste Untersuchung der Studienteilnehmer umfasste zudem die Protokollierung der aktuellen Medikation. An den folgenden 3 Terminen wurde die Medikation der letzten 24 $\mathrm{h}$ erhoben, dabei vor allem die Pharmaka, die zur Milderung eines akuten Alkoholentzugssyndroms verabreicht wurden.

Während der zweiten, dritten und vierten Untersuchung erfolgte eine klinische Abschätzung des Alkoholentzugssyndroms mittels der AWS-Skala. Auch wurde zu diesen 3 Terminen stets der Uhrentest (s.u.) durchgeführt.

Zum vierten Untersuchungszeitpunkt füllten die Studienteilnehmer zusätzlich den Selbstbeurteilungsteil des Münchner Alkoholismus-Tests (MALT-S) aus.

\subsubsection{Routineparameter}

Im Rahmen der stationären Diagnostik wurden bei den Studienteilnehmern am Aufnahmetag verschiedene Laborwerte bestimmt, von denen einige Routineparameter (Mittleres Corpuskuläres Volumen (MCV), Mittleres Corpuskuläres Hämoglobin ( $M C H)$, Elektrolyte, Leberwerte) in dieser Studie übernommen wurden. Die gleichen Parameter wurden bei 16 der 31 Patienten nochmals 120 bis maximal $192 \mathrm{~h}$ nach der ersten Untersuchung bestimmt und konnten dann für die vorliegende Studie verwendet werden. Auch die Ermittlung des Ethanolspiegels (im Serum oder Atem) zum ersten und zweiten Untersuchungszeitpunkt erfolgte im Rahmen der stationären Routinediagnostik. 
Tabelle 1: Studienprotokoll

\begin{tabular}{|c|c|}
\hline Parameter & Zeitpunkt \\
\hline $\begin{array}{l}\text { Ethanol im Serum oder Atem, } \\
\text { s100ß im Serum, } \\
\text { Homocystein im Serum, } \\
\text { Blutdruck und Herzfrequenz, } \\
\text { aktuelles Medikationsprotokoll, } \\
\text { ggf. MCV, MCH, Elektrolyte und Leberwerte } \\
\text { im Plasma }\end{array}$ & $\begin{array}{l}0 \text { bis } 48 \mathrm{~h} \text { nach der } \\
\text { stationären Aufnahme }\end{array}$ \\
\hline $\begin{array}{l}\text { Ethanol im Serum oder Atem, } \\
\text { s100ß im Serum, } \\
\text { Homocystein im Serum, } \\
\text { Blutdruck und Herzfrequenz, } \\
\text { Medikationsprotokoll der letzten } 24 \mathrm{~h}, \\
\text { AWS-Skala, } \\
\text { Uhrentest }\end{array}$ & $\begin{array}{l}24 \mathrm{~h} \text { nach der ersten } \\
\text { Blutentnahme }\end{array}$ \\
\hline $\begin{array}{l}\text { s100ß im Serum, } \\
\text { Homocystein im Serum, } \\
\text { Blutdruck und Herzfrequenz, } \\
\text { Medikationsprotokoll der letzten } 24 \text { h, } \\
\text { AWS-Skala, } \\
\text { Uhrentest }\end{array}$ & $\begin{array}{l}48 \mathrm{~h} \text { nach der ersten } \\
\text { Blutentnahme }\end{array}$ \\
\hline $\begin{array}{l}\text { s100ß im Serum, } \\
\text { Homocystein im Serum, } \\
\text { Blutdruck und Herzfrequenz, } \\
\text { Medikationsprotokoll der letzten } 24 \mathrm{~h}, \\
\text { AWS-Skala, } \\
\text { Uhrentest, } \\
\text { MALT-S, } \\
\text { ggf. MCV, MCH, Elektrolyte und Leberwerte } \\
\text { im Plasma }\end{array}$ & $\begin{array}{l}120 \text { bis } 192 \mathrm{~h} \text { nach der } \\
\text { ersten Blutentnahme }\end{array}$ \\
\hline
\end{tabular}




\subsection{Methoden}

\subsubsection{Blutentnahme}

Die für die Bestimmung der Homocystein- und s100ß-Serumspiegel notwendigen Blutproben wurden durch die Punktion einer Kubitalvene mittels Einwegkanülen gewonnen.

Die Messung der s100ß- und Homocysteinwerte erfolgte im Zentrallabor des Universitätsklinikums Göttingen.

S100 $\beta$ wurde entsprechend Leite et al. (2008) anhand eines enzyme-linked immunosorbent assay (ELISA) ermittelt. Die 50-Mikroliter ( $\mu$ l)-Serumproben wurden unter Anwendung monoklonaler Antikörper (Klon SH-B1, Sigma Chemical Co.) als CaptureAntikörper und unter der Verwendung polyklonaler Antikörper (DAKO) analysiert.

Die Homocystein-Bestimmung erfolgte durch ELISA anhand der von Frantzen et al. (1998) beschriebenen Methode. Dafür wurden 25- $\mu$ l-Serumproben unter Verwendung von anti-SAH-Antikörpern (Abbott Labs.) und HRP-konjugierten Antikörpern (DAKO) untersucht.

\subsubsection{Psychometrische Tests}

In der vorliegenden Studie wurden die AWS-Skala, der Uhrentest sowie der Selbstbeurteilungsteil des Münchner Alkoholismus-Test verwendet.

\section{AWS-Skala}

Diese wurde genutzt, um den Schweregrad der Entzugssymptomatik jedes Patienten einheitlich beurteilen zu können. Sie setzt sich aus Subskala S (vegetative Symptomatik) und Subskala M (psychomotorische Symptomatik) zusammen. Subskala $S$ erfasst Pulsfrequenz, Blutdruck, Körpertemperatur, Atemfrequenz, Schwitzen und Tremor. Subskala $M$ erfasst Agitiertheit, Kontaktfähigkeit, Orientierung, Halluzinationen und Angst. Insgesamt kann eine Punktzahl von 0 bis 33 erreicht werden.

\section{Uhrentest}

Der Uhrentest ermöglicht die Überprüfung der räumlichen Orientierung und untersucht die visokonstruktiven Fähigkeiten.

Bei diesem Test (Shulman 2000) bekommt der Patient ein Blatt Papier mit einem aufgedruckten Kreis. Er wird aufgefordert, in den Kreis die Ziffern einer Uhr und eine vorgegebene Uhrzeit (z. B. zehn nach elf) einzuzeichnen. Die Leistungseinschätzung erfolgt nach vorgegebenen Kriterien (Vollständigkeit und Platzierung der Ziffern, 
korrektes Einzeichnen der Uhrzeit) anhand von 6 Kategorien. Dabei bedeutet ein Wert von 1 eine fehlerlose Zeichnung und ein Wert von 6 keinerlei Darstellung einer Uhr. Kategorien 1 bis 2 werden als normales, 3 bis 6 als pathologisches Ergebnis im Sinne eines kognitiven Defizits (Uhrentest und Bewertungskriterien s. Anhang) gewertet.

\section{Münchner Alkoholismus-Test (MALT)}

Dieser Test dient der Diagnosestellung einer Alkoholabhängigkeit. Der in der vorliegenden Studie verwendete Selbstbeurteilungsteil (MALT-S) besteht aus 24 Aussagen, die als zutreffend oder unzutreffend bewertet werden können. Die Fragen beziehen sich auf die Phasen des Alkoholkonsums, die Einstellung zu Alkohol, die psychischen und sozialen Beeinträchtigungen durch den Konsum sowie die somatischen Symptome. Pro zutreffende Aussage wird ein Punkt vergeben, so dass eine maximale Punktzahl von 24 erreicht werden kann.

Der zweite Abschnitt dieses Tests ist der Fremdbeurteilungsteil (MALT-F) bestehend aus 7 Items. Dieser kam in der vorliegenden Studie nicht zur Anwendung.

Bei einer Punktzahl zwischen 6 und 10 besteht der Verdacht auf eine Alkoholabhängigkeit, ab 11 Punkten wird von einer Alkoholabhängigkeit ausgegangen.

\subsubsection{Klinische Parameter}

Die Erhebung der klinischen Parameter erfolgte im Rahmen der Komplettierung der AWS-Skala. Der arterielle Blutdruck wurde auskultatorisch nach Riva-Rocci und die Pulsfrequenz manuell bestimmt. Die Ermittlung der Atemfrequenz erfolgte durch Auszählen. Zur Messung der Körpertemperatur wurde ein Infrarot-Ohr-Thermometer verwendet.

Zudem wurden alle Studienteilnehmer auf Tremor und vermehrtes Schwitzen untersucht.

\subsection{Statistische Analyse}

Es handelt sich um eine prospektive, nicht kontrollierte Studie. Die Mediane, der Mittelwert, die Standardabweichung, als Maß für die Streuung der Werte um den Mittelwert, sowie die maximalen und minimalen Werte wurden in Tabellen dargestellt. Die statistische Auswertung erfolgte anhand des Computerprogramms SPSS Version 17.0 für Windows.

Zur Quantifizierung eines Zusammenhangs zwischen den Merkmalen „Alter/Geschlecht“ und "Homocystein-/s100ß-Spiegel“ zu den verschiedenen Untersuchungszeitpunkten wurde der Korrelationskoeffizient nach Pearson berechnet. 
Dieser wurde außerdem zur Ermittlung einer Korrelation zwischen Homocystein-/s100ßWerten im Serum und Dauer sowie Alter zu Beginn der Alkoholabhängigkeit eingesetzt. Des Weiteren wurde der Pearson'sche Korrelationskoeffizient berechnet, um einen Zusammenhang zwischen Homocystein-/s100ß-Spiegel im Serum und Anzahl der eingenommenen Clomethiazol-Kapseln sowie Stärke des Alkoholentzugssyndroms, ermittelt durch die AWS-Skala, zu verifizieren.

Es wurde eine multivariate Messwiederholungsvarianzanalyse (MANOVA) für die Maße s100ß und Homocystein am Untersuchungstag 1, 2, 3 und 4 durchgeführt. Anschließend wurden paarweise Vergleiche mit Bonferroni-Korrektur über die Mittelwertsunterschiede von s $100 \beta$ und Homocystein an den einzelnen Tagen berechnet. p-Werte kleiner als 0,05 wurden als signifikant erachtet. 


\section{ERGEBNISSE}

\subsection{Patientenkollektiv}

30 von 31 Patienten absolvierten die Untersuchung gemäß dem Studienprotokoll über 4 Untersuchungszeitpunkte innerhalb von 120 bis maximal $192 \mathrm{~h}$. Die unterschiedliche Studiendauer ergibt sich aus der Erhebung der Routineparameter (MCV, $\mathrm{MCH}$, Elektrolyte, Leberwerte), die im Rahmen der stationären Diagnostik bestimmt und in dieser Studie übernommen wurden. Eine Patientin brach die Studie auf eigenen Wunsch vorzeitig ab, so dass in diesem Fall lediglich die Befunde zum ersten und zweiten Untersuchungstermin erhoben werden konnten.

Insgesamt bestand die Untersuchungsgruppe aus 9 Frauen und 22 Männern. Der jüngste Patient war 28 alt. Ein Patient lag mit 68 Jahren über dem vorher veranschlagten maximalen Alter von 65 Jahren, wurde aber dennoch in die Studie aufgenommen.

Das Durchschnittsalter der Frauen lag bei 49,44 Jahren (SD 11,33) und das der Männer bei 45,82 Jahren (SD 7,15). Das Gesamtdurchschnittsalter betrug 46,87 Jahre (SD 8,73), wobei 13 der 31 Patienten (41,93\%) zwischen 40 und 49 Jahre alt waren. Diese Gruppe bestand ausschließlich aus männlichen Probanden.

\section{Abbildung 1: Altersverteilung der Studienteilnehmer}

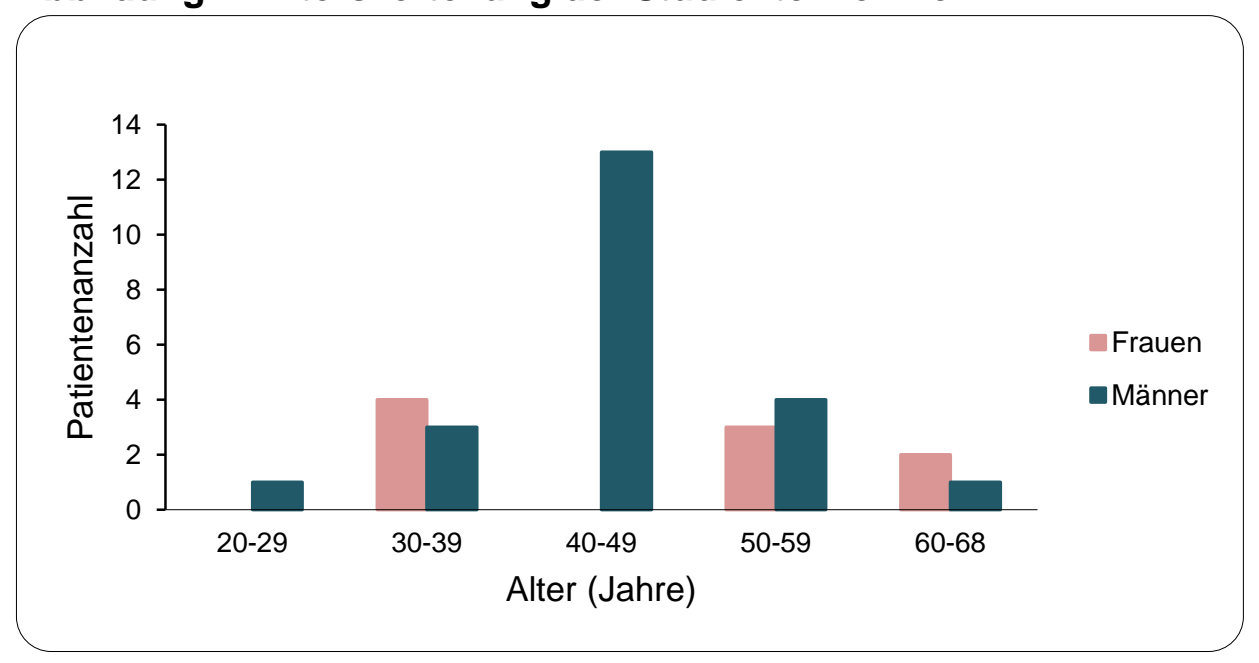

\subsection{Alkohol-spezifische Erkrankungsmerkmale}

\subsubsection{Dauer der Alkoholabhängigkeit}

14 von 30 Patienten gaben in der Untersuchung an, seit einem Zeitraum von bis zu 9 Jahren alkoholabhängig zu sein. 7 Patienten nannten eine Dauer von 10 bis 19 Jahren und 8 Patienten einen Zeitraum von 20 bis 29 Jahren. Lediglich ein Patient bestimmte die 
Dauer seiner Alkoholabhängigkeit zwischen 30 und 39 Jahren.

Bei den Frauen lag der ermittelte Durchschnittswert der Abhängigkeitsdauer bei 9,06 Jahren (SD 7,35) und bei den Männern bei 15,3 Jahren (SD 8,35). Im Gesamtdurchschnitt betrug die Dauer der Abhängigkeit 13,65 Jahre (SD 8,56).

Ein Zusammenhang zwischen der Dauer der Alkoholabhängigkeit und den untersuchten Parametern, speziell der $\mathbf{s} 100 \beta$ - und Homocysteinkonzentrationen, stelle sich nicht dar.

\section{Abbildung 2: Dauer der Alkoholabhängigkeit der Probanden bei Studienbeginn}

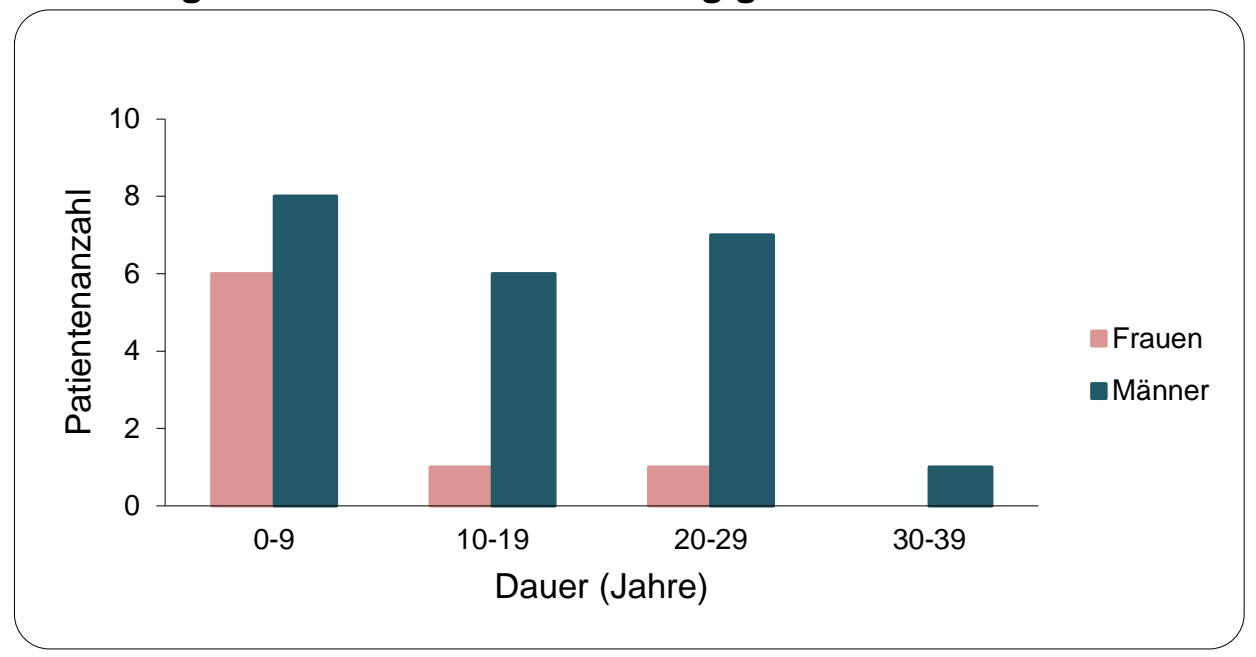

\subsubsection{Lebensalter zu Beginn der Alkoholabhängigkeit}

13 von 30 Patienten gaben an, seit dem 35. bis 44. Lebensjahr alkoholabhängig zu sein. 9 Patienten legten den Zeitraum zwischen ihrem 18. und 24. Lebensjahr fest. 6 Probanden der Studie gaben an, in der Dauer zwischen ihrem 25. und ihrem 34. Lebensjahr alkoholabhängig geworden zu sein. Jeweils ein Patient benannte den Zeitraum zwischen dem 45. und 54. bzw. zwischen dem 55. und 64. Lebensjahr.

Das durchschnittliche Lebensalter zu Beginn der Alkoholabhängigkeit lag bei den weiblichen Studienteilnehmern bei 39,69 Jahren (SD 11,83) und bei den männlichen Teilnehmern bei 30,5 Jahren (SD 8,81). Im Gesamtdurchschnitt aller Studienteilnehmer ergab sich ein Wert von 32,95 Jahren (SD 10,52).

\subsubsection{Alkoholkonsum vor Untersuchungsbeginn}

29 Patienten, die in dieser Studie untersucht wurden, machten Angaben zu ihrem durchschnittlichen täglichen Alkoholkonsum. 10 Patienten gaben einen täglichen Konsum von über $300 \mathrm{~g}$ reinem Alkohol an. 17 Patienten lagen in dem Bereich zwischen 100 bis $300 \mathrm{~g}$ pro Tag, während 2 Patienten in dem Bereich unter $100 \mathrm{~g}$ reinem Alkohol pro Tag lagen. Insgesamt ergab sich für alle Probanden ein Mittelwert von 268,08 g (SD 123,88), 
wobei der durchschnittliche Alkoholkonsum der Frauen bei 192,25 g (SD 82,12) lag. Für die Männer ergab sich ein Wert von 296,97 g (SD 124,90).

Eine Korrelation zwischen der Menge des Alkoholkonsums und den weiteren Parametern, die in dieser Studie erhoben wurden, zeigte sich nicht.

\subsubsection{Ethanolgehalt in Atem oder Blut bei Aufnahme}

Am Tag der stationären Aufnahme wurde bei 11 der teilnehmenden Patienten der Ethanolgehalt im Blut und bei 17 Patienten der Ethanolgehalt im Atem gemessen. Diese Messungen ergaben bei 5 Patienten einen Gehalt von 0 Promille. Bei 7 Patienten wurde ein Ethanolgehalt zwischen 0,1 und 0,99 \%o nachgewiesen. 6 Patienten lagen zwischen 1 und 1,99 \%o, während bei 7 ein Ethanolgehalt zwischen 2 und 2,99 \%o bestimmt wurde. Bei 3 Patienten lag ein Ethanolgehalt von über 3 \% vor. Der Gesamtdurchschnittswert betrug dabei $1,40 \%$ (SD 1,05), wobei der Durchschnittswert der weiblichen Probanden bei $1,53 \%$ (SD 1,23) lag. Bei den männlichen Studienteilnehmern errechnete sich ein durchschnittlicher Promillegehalt von 1,34 \%o (SD 0,97).

Bezüglich der untersuchten Parameter dieser Studie und des Promillegehalts zum Zeitpunkt der stationären Aufnahme ergab sich keine Korrelation.

\subsection{Laborparameter}

\subsection{1 s100ß im Serum}

Die Ermittlung der $\mathrm{s} 100 \beta-W e r t e$ im Serum ergab zum ersten Untersuchungszeitpunkt bei 6 der 31 Patienten eine Erhöhung über den Normwert $(\leq 0,12 \mu \mathrm{g} / \mathrm{l})$. Die Werte lagen dabei gering erhöht zwischen $0,13 \mu \mathrm{g} / \mathrm{l}$ und $0,16 \mu \mathrm{g} / \mathrm{l}$.

Zum zweiten Zeitpunkt zeigte sich bei 3 Patienten eine Erhöhung der s100ß-Serumwerte über $0,12 \mu \mathrm{g} / \mathrm{l}$. 2 dieser 3 Patienten gehörten dabei zu denen, die bereits in der ersten Untersuchung pathologisch erhöhte Werte hatten. Die Messung von s100 $\beta$ im Serum ergab bei diesen Patienten Werte von $0,17 \mu \mathrm{g} / \mathrm{l}$ und $0,18 \mu \mathrm{g} / \mathrm{l}$. Bei einem Patienten wurde zum zweiten Untersuchungszeitpunkt ein s100ß-Wert von 0,78 $\mu \mathrm{g} / \mathrm{l}$ ermittelt. Dieser Wert wurde als Ausreißer gewertet und nicht in die Mittelwertberechnung einbezogen. Bei diesem Patienten lagen die $s 100 \beta-W e r t e$ des ersten, dritten und vierten Untersuchungszeitpunktes innerhalb des Normbereichs.

Zum dritten Untersuchungszeitpunkt ergab sich lediglich bei einem Patienten ein über dem Normwert liegendes Messergebnis für $\mathrm{s} 100 \beta$ von $0,17 \mu \mathrm{g} / \mathrm{l}$. Hierbei handelte es sich um einen Patienten, der bereits zum ersten und zweiten Untersuchungszeitpunkt erhöhte 
s100ß-Werte aufwies.

Zum vierten Untersuchungszeitpunkt wurden bei 2 Patienten $s 100 \beta$-Werte ermittelt, die den Normwert überschritten. Sie lagen geringgradig erhöht bei $0,13 \mu \mathrm{g} / \mathrm{l}$ und $0,14 \mu \mathrm{g} / \mathrm{l}$. Bei einem dieser Patienten hatten bereits die 3 vorangehenden Untersuchungen erhöhte s100ß-Werte ergeben, während die Erhöhung des s100ß-Werts bei dem anderen Patienten einmalig auftrat.

Die Mittelwerte der s100ß-Konzentrationen für die gesamte Gruppe im Serum lagen zu allen 4 Untersuchungszeitpunkten innerhalb des vom Zentrallabor des Universitätsklinikums Göttingen angegebenen Normbereichs. Dieser lag zum ersten Untersuchungszeitpunkt bei 0,071 $\mu \mathrm{g} / \mathrm{l}$ (SD 0,041), zum zweiten bei 0,060 $\mu \mathrm{g} / \mathrm{l}$ (SD 0,047) (ohne Ausreißer) und beim dritten bei $0,054 \mu \mathrm{g} / \mathrm{l}$ (SD 0,033). Der Gruppenmittelwert zum vierten Untersuchungszeitpunkt betrug 0,050 $\mu \mathrm{g} / \mathrm{l}(\mathrm{SD} 0,031)$.

Die statistische Auswertung ergab zum ersten Untersuchungszeitpunkt höhere s100ßWerte (95\%iges Konfidenzintervall) als zum letzten Untersuchungszeitpunkt mit einem signifikanten Abfall der s100ß-Konzentration im Studienverlauf $(p<0,05)$. Des Weiteren ergab die Analyse einen Trend zu einer geringeren $s 100 \beta$-Serum-konzentration $(p=$ $0,064, r=0,35)$ zum letzten Untersuchungszeitpunkt bei den weiblichen Probanden.

\section{Abbildung 3: s100ß-Mittelwerte im Studienverlauf}

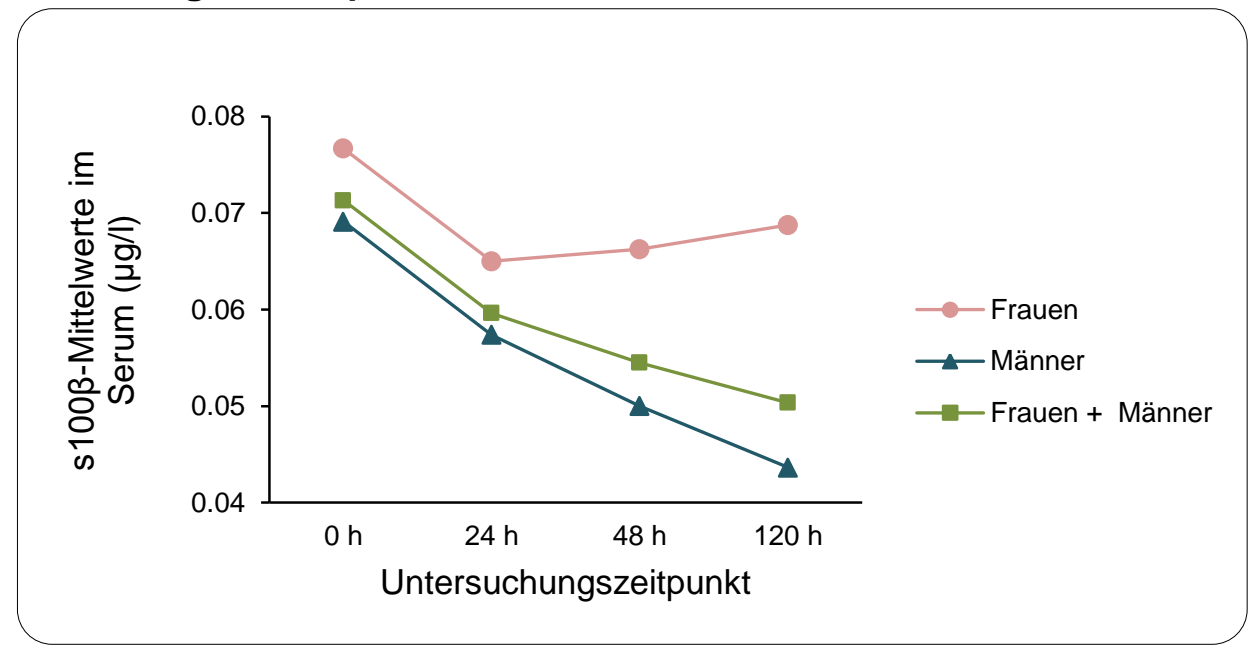

\subsubsection{Homocystein im Serum}

Die Blutanalyse zum ersten Untersuchungszeitpunkt ergab bei 16 der 31 Probanden dieser Studie über der Norm (5 bis $15 \mu \mathrm{mol} / \mathrm{l}$ ) liegende Homocysteinwerte. Bei der zweiten Untersuchung lag die Anzahl der Patienten, die pathologisch erhöhte Werte aufwiesen, bei 15, zum dritten Untersuchungszeitpunkt lag diese bei 11. Zum letzten Untersuchungszeittermin wurden bei 6 Patienten Homocysteinwerte ermittelt, die den vom Zentrallabor des Universitätsklinikums Göttingen angegebenen Normwert 
überschritten.

Die Homocystein-Mittelwerte der Gesamtgruppe lagen zum ersten Untersuchungszeitpunkt mit 18,95 $\mu \mathrm{mol} / \mathrm{l}$ (SD 11,18) und zum zweiten Untersuchungszeitpunkt mit 16,79 $\mu \mathrm{mol} / \mathrm{l}$ (SD 6,98) über dem Normbereich. Die Blutentnahme zum dritten Untersuchungszeitpunkt ergab einen Homocystein-Mittelwert von 14,77 $\mu \mathrm{mol} / \mathrm{I}$ (SD 5,74), während die Blutanalyse des vierten Zeitpunkts einen Wert von $13,53 \mu \mathrm{mol} / / \mathrm{I}$ (SD 5,18) ermittelte. Die beiden Werte lagen damit innerhalb des Referenzbereichs.

In der statistischen Analyse zeigte sich über den Untersuchungszeitraum von $120 \mathrm{~h}$ ein signifikanter Abfall der Homocystein-Serumwerte $(p<0,05)$.

Ein weiteres Ergebnis dieser Studie ist die positive Korrelation zwischen dem Alter bei Beginn der Alkoholabhängigkeit und den Homocysteinwerten nach 48 Stunden. Der ermittelte $p$-Wert lag zum dritten Untersuchungszeitpunkt bei $0,023(r=0,43)$ und zum vierten Untersuchungszeitpunkt bei $0,052(r=0,37)$. Für den zweiten Untersuchungstag wurde ein $p$-Wert von 0,076 ermittelt. Außerdem ergab die statistische Auswertung eine signifikante negative Korrelation zwischen dem Homocystein-Serumwert am dritten Untersuchungstag und der Anzahl der eingenommenen Clomethiazol-Kapseln zu diesem Zeitpunkt ( $p=0,045, r=0,64)$, während für die übrigen Untersuchungstage diesbezüglich keine signifikanten Zusammenhänge ermittelt werden konnten.

\section{Abbildung 4: Homocystein-Mittelwerte im Studienverlauf}

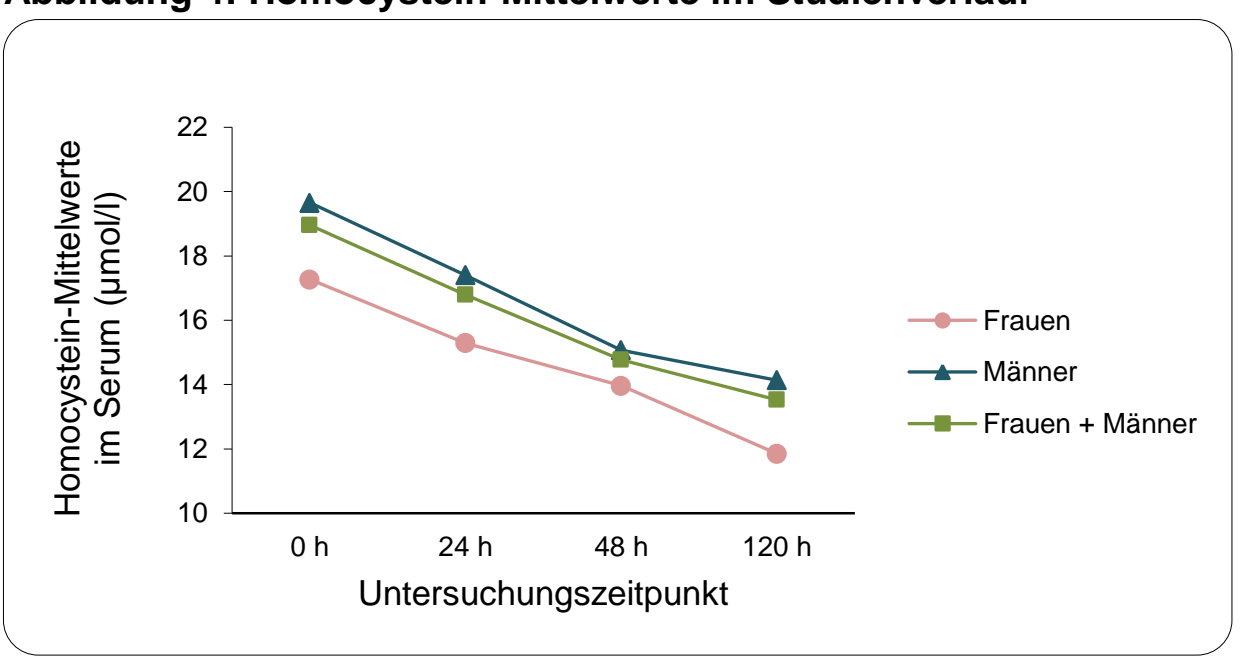

\subsubsection{Leberwerte im Serum}

Zum Zeitpunkt der stationären Aufnahme bzw. zum Untersuchungsbeginn wurden bei 27 der 31 Patienten AST, ALT und Y-GT im Blut bestimmt. Bei 2 Patienten wurden nur AST und ALT untersucht, während bei 2 weiteren Patienten keine verwertbaren Leberwerte vorlagen. 
120 bis $192 \mathrm{~h}$ nach dem ersten Untersuchungszeitpunkt wurden bei 14 Patienten wiederum AST, ALT und Y-GT bestimmt. Bei den übrigen Patienten fand zu diesem Zeitpunkt keine erneute Untersuchung der Leberwerte statt.

Insgesamt waren es 13 Patienten, bei denen die AST- und ALT-Werte zu Untersuchungszeitpunkt 1 und 4 ermittelt wurden. Hier zeigte sich bei Patienten mit einer klinisch relevanten Erhöhung der AST (über dem dreifachen der Norm), eine Reduktion von 7 zu Zeitpunkt 1 auf 0 zu Zeitpunkt 4. Währenddessen lag die Anzahl der Patienten mit einer stark erhöhten ALT (über dem dreifachen der Norm) zum ersten und zum letzten Untersuchungszeitpunkt konstant bei 1.

Bei insgesamt 12 Patienten konnten $y$-GT-Werte zu Zeitpunkt 1 und 4 ermittelt werden. Während des Verlaufs sank die Anzahl der Patienten mit erhöhten klinisch relevanten Werten von 10 auf 9, während die Anzahl der Patienten mit Werten im Normbereich von 2 auf 3 anstieg.

\subsubsection{MCV und $\mathrm{MCH}$}

Bei 29 der 31 Patienten, die an dieser Studie teilnahmen, konnten zum Zeitpunkt der Aufnahme die MCV- und MCH-Werte ermittelt werden. Nach 120 bis maximal $192 \mathrm{~h}$ wurden diese Werte bei 14 Probanden nachuntersucht. Hier zeigte sich, dass bei der Mehrheit der Probanden, das heißt zum ersten Untersuchungszeitpunkt bei 20 von 27 und zum vierten Untersuchungszeitpunkt bei 11 von 14, beide Werte über dem Normbereich lagen.

Der MCV-Mittelwert lag zum ersten Untersuchungszeitpunkt bei 97,90 fl (SD 8,00) und zum vierten Termin bei 101,43 fl (SD 8,99). Dabei wurde der Referenzbereich des Zentrallabors des Universitätsklinikums Göttingen zwischen 81 und $95 \mathrm{fl}$ definiert. Der MCH-Mittelwert blieb mit 33,23 pg (SD 2,39) während der ersten Untersuchung und 33,73 pg (SD 2,99) nach maximal $192 \mathrm{~h}$ nahezu konstant (Referenzbereich: 26 bis 32 $\mathrm{pg})$.

\subsubsection{Elektrolyte}

Im Rahmen der stationären Routinediagnostik wurden bei 29 der teilnehmenden Patienten zum Zeitpunkt der Aufnahme die Natrium- und Kaliumkonzentrationen im Blut und bei 27 zusätzlich die Kalziumkonzentration im Blut bestimmt. Es zeigten sich hier bei 7 Patienten abnorme Natrium- und bei 4 Patienten abnorme Kaliumwerte. Diese waren jeweils minimal erniedrigt oder erhöht. Die Kalziumwerte der Patienten lagen zu diesem Zeitpunkt im Normbereich. Bei 14 Patienten erfolgte nach maximal $192 \mathrm{~h}$ eine Kontrolle 
der Natrium- und Kaliumwerte, während bei 11 Patienten nochmals die Kalziumkonzentration bestimmt wurde. Dabei lag der Natriumwert bei einem Patienten leicht unter der Norm. Die Kaliumkonzentrationen waren bei allen Patienten normwertig, während die Kalziumwerte bei einem Patienten leicht erhöht und bei einem leicht erniedrigt waren.

\subsection{Ergebnisse der Testverfahren}

\subsubsection{AWS-Skala}

Die Auswertung der AWS-Skala zeigte eine erwartete Reduktion der Mittelwerte im Untersuchungsverlauf und weist somit auf eine rückläufige Entzugssymptomatik hin. Zum zweiten Untersuchungszeitpunkt lag ein Mittelwert von 5,97 Punkten (SD 2,97) vor. Zum dritten Messzeitpunkt ergab sich einen Mittelwert von 4,63 (SD 1,62) und zum vierten ein Mittelwert von 3,43 Punkten (SD 0,96). Insgesamt lag die Anzahl der erreichten Punktzahl der Subskala $S$ (vegetative Symptomatik) deutlich über der der Subskala M (psychomotorische Symptomatik). Eine direkte Korrelation zwischen der Punktzahl in der AWS-Skala und den Parametern, die in dieser Studie untersucht wurden, insbesondere der s100ß- und Homocysteinwerte, zeigte sich nicht.

Abbildung 5: Auswertung der AWS-Skala

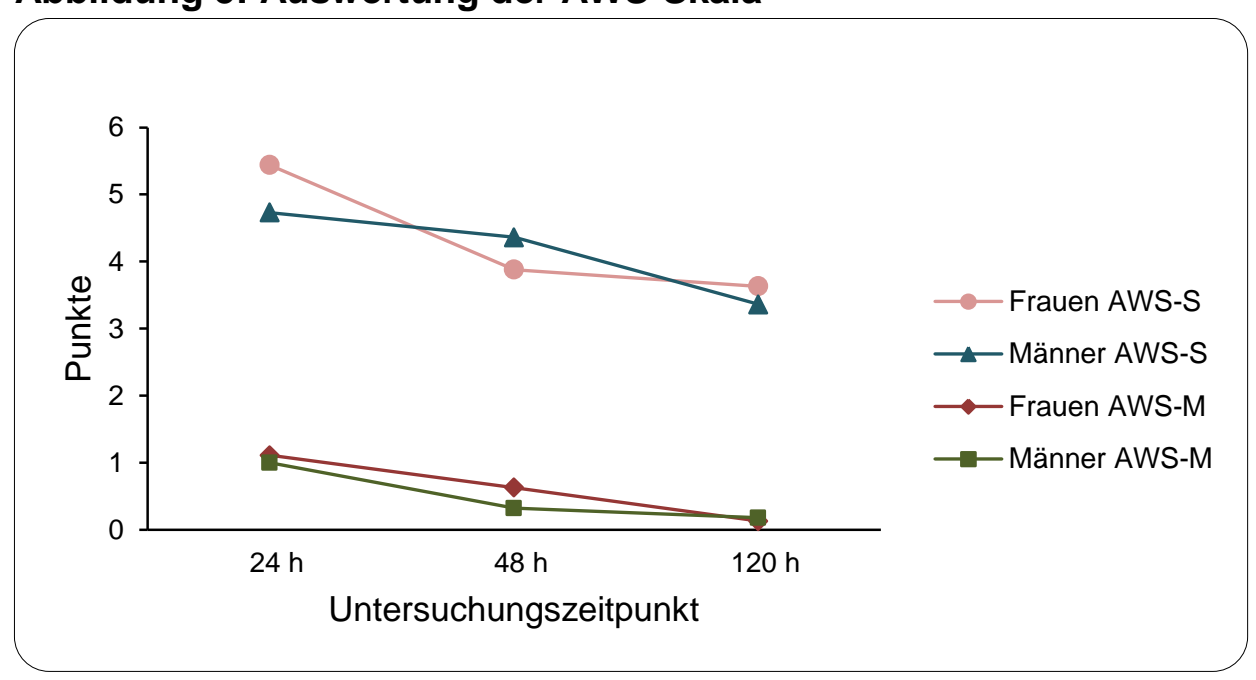

\subsubsection{Uhrentest}

Im Uhrentest zum zweiten Untersuchungszeitpunkt erhielten 15 Patienten einen Punkt und 3 Patienten 2 Punkte. Somit lagen insgesamt 18 Patienten im Normbereich und 13 Patienten im pathologischen Bereich (Punktzahl 3 bis 6). Die Anzahl der Patienten mit 
einem pathologischen Wert sank bis zum letzten Untersuchungstermin von 13 auf 7 , während die Anzahl der Patienten mit einer Punktzahl im Normbereich auf 23 anstieg. Während des gesamten Untersuchungsverlaufs erhielt kein Patient mehr als 4 Punkte. Der Mittelwert zum zweiten Untersuchungszeitpunkt lag bei 2,13 Punkten (SD 1,21), zum dritten bei 1,90 Punkten (SD 1,11) und zum vierten Zeitpunkt bei 1,73 Punkte (SD 0,96).

\subsubsection{Münchner Alkoholismus-Test}

Die Auswertung des Selbstbeurteilungsteils des MALT ergab für die Untersuchungsgruppe einen Mittelwert von 15,47 Punkten (SD 4,67). Lediglich 3 Patienten lagen in dem Bereich von weniger als 11 Punkten, ab dem von einer Alkoholabhängigkeit ausgegangen wird. Davon erreichte ein Proband 9 und ein weiterer 10 Punkte, wobei zwischen 6 und 10 Punkten der Verdacht auf eine Abhängigkeit besteht. Ein Patient erhielt nur 2 Punkte.

\subsection{Ergebnisse der klinischen Parameter}

\subsubsection{Blutdruck und Pulsfrequenz}

Der Mittelwert des systolischen Blutdrucks lag bei der ersten Untersuchung bei 145,48 $\mathrm{mmHg}(\mathrm{SD} 5,21)$ und sank bis zur letzten Untersuchung auf einen Wert von $132 \mathrm{mmHg}$ (SD 16,21). Der diastolische Blutdruck sank von $88,39 \mathrm{mmHg}$ (SD 8,46) zum ersten Untersuchungstermin auf $84,33 \mathrm{mmHg}$ (SD 9,37) zum letzten Zeitpunkt.

Der Mittelwert der Pulsfrequenz lag bei der ersten Untersuchung bei 94/min (SD 12,78) und fiel auf einen Wert von 84,97/min (SD 12,96) in der letzten Untersuchung ab.

\subsection{Medikation im akuten Alkoholentzug}

Einige Patienten in dieser Studie wurden während der akuten Alkoholentgiftung mit mehreren Medikamenten behandelt, die eine Minderung des Alkoholentzugssyndroms bewirken sollen. Daher wurde hier eine Einteilung in 3 Kategorien vorgenommen: Patienten, die keine Entzugsmedikamente erhielten, solche die ein Medikament erhielten und solche, die mit mehr als einem Medikament behandelt wurden. Hier zeigte sich vom ersten zum letzten Untersuchungstermin ein Anstieg derjenigen Patienten, die keine Medikamente benötigten von 3 auf 11, während die Anzahl der Patienten, die mehr als ein Medikament bekamen von 9 auf 4 abfiel. Die Anzahl der Patienten, die mit einem Entzugsmedikament behandelt wurden, sank von ersten zum letzten Untersuchungstag 
von 19 auf 15. Die 4 Medikamente, die überwiegend zur Behandlung des Alkoholentzugssyndroms verabreicht wurden, waren Clomethiazol, Diazepam, Carbamazepin und Phenobarbital. Bei der Einteilung der Patienten in diese 4 Gruppen zeigte sich im Untersuchungsverlauf eine Reduktion der Patienten, die Clomethiazol erhielten, von 13 am ersten auf 2 am letzten Untersuchungstag. Zeitgleich stellte sich eine Reduktion der Anzahl der verabreichten Clomethiazol-Kapseln (à $192 \mathrm{mg}$ ) dar. Der Mittelwert lag zum ersten Zeitpunkt bei 7,38 Kapseln (SD 4,16) und am letzten bei 1,5 Kapseln (SD 0,5). Die Anzahl der Patienten, die Diazepam erhielten sank während des 5Tage-Untersuchungszeitraums von 12 auf 10 ab. 9 Patienten wurden bei Untersuchungsbeginn mit Carbamazepin behandelt. Diese Anzahl stieg bis zum letzten Untersuchungstag auf 11 an. Die Summe der Patienten, die Phenobarbital einnahmen, sank zeitgleich von 3 auf 0 .

3 Patienten wurden zum ersten Untersuchungszeitpunkt mit weiteren Psychopharmaka behandelt. Die Summe dieser Patienten erhöhte sich bis zum vierten Untersuchungstag auf 6. Davon erhielt ein Patient vom ersten bis zum letzten Untersuchungstermin 3 Mal täglich zwei Tabletten (à $333 \mathrm{mg}$ ) des Alkoholentwöhnungsmittels Acamprosat. Ferner wurde ein Patient während des gesamten Untersuchungszeitraums mit dem Antidepressivum Doxepin 25 mg zur Nacht behandelt, während ein weiterer Patient zum dritten und vierten Untersuchungstermin jeweils 7,5 mg Mirtazapin zur Nacht erhielt. Am letzten Untersuchungstag wurde 2 Patienten Doxepin $25 \mathrm{mg}$ zur Nacht verabreicht. Davon erhielt einer zusätzlich Melperon $25 \mathrm{mg}$. Ein weiterer Patient wurde am ersten Untersuchungstag einmalig mit Haloperidol $5 \mathrm{mg}$ behandelt.

\section{Abbildung 6: Medikation während des Untersuchungszeitraums}

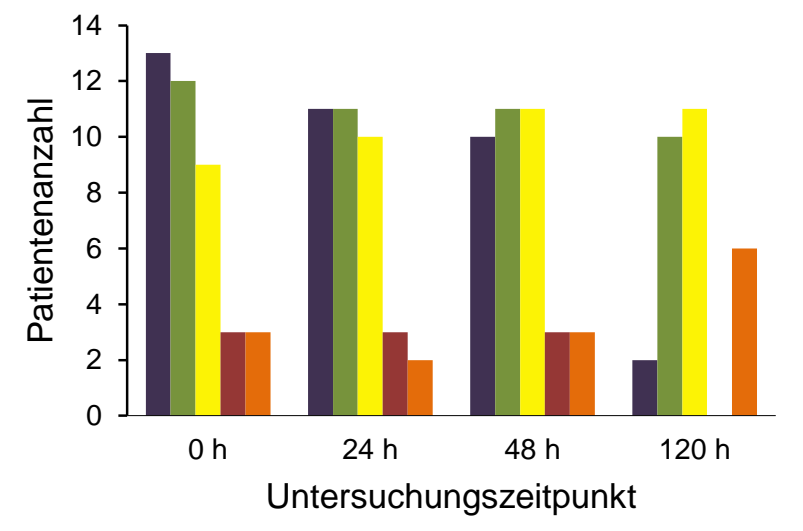

- Clomethiazol

- Diazepam

Carbamazepin

- Phenobarbital

- Andere Psychopharmaka

Untersuchungszeitpunkt 


\section{DISKUSSION}

In der vorliegenden Studie wurden Serumwerte von $s 100 \beta$ und Homocystein bei Patienten mit einer Alkoholabhängigkeit während der initialen Phase der stationären qualifizierten Entgiftung untersucht. Zusammenhänge mit der Entzugssyndromschwere, der Menge angewandter Entzugsmedikationen, dem Geschlecht und anderen Abhängigkeitsvariablen wurden erfasst.

Das Ergebnis dieser Studie zeigt einen signifikanten Abfall der Homocystein- und s100ßSerumkonzentrationen bei alkoholabhängigen Patienten über $120 \mathrm{~h}$ in der Initialphase des akuten stationären Alkoholentzugs. Im gleichen Zeitraum stellte sich ein signifikanter Rückgang der Entzugssymptomatik, gemessen an der etablierten AWS-Skala, dar. Eine direkte Korrelation zwischen der AWS-Skala und den s100ß- und Homocysteinwerten konnte jedoch nicht nachgewiesen werden.

\subsection{Bedeutung der Ergebnisse}

\subsubsection{Interpretation des Patientenkollektivs}

Von den 31 Patienten, die an dieser Studie teilgenommen haben, waren 9 Probanden weiblich. Der jüngste Studienteilnehmer hatte ein Alter von 28 Jahren und der älteste war 68 Jahre alt. Das ermittelte Durchschnittsalter des Gesamtkollektivs lag bei 46,87 Jahren (SD 8,73), wobei das Durchschnittsalter der Frauen bei 49,44 Jahren (SD 11,33) und das der Männer bei 45,82 Jahren (SD 7,15) lagen. Es zeigte sich in der Auswertung, dass keine Probandin zwischen 40 und 49 Jahren alt war. Hingegen waren 13 Männer in dieser Altersklasse. Zusammenfassend bestand in dieser Studie ein heterogenes Patientenkollektiv.

In der Studie von Liappas et al. (2006), die die s100ß-Serumkonzentration bei 20 alkoholabhängigen Patienten untersuchte, bestand das Kollektiv aus 20 Patienten, davon 16 männliche und 4 weibliche. Das Durchschnittsalter lag dabei vergleichbar wie in der vorliegenden Studie bei 48,94 Jahren (SD 9,27).

Auch in der Untersuchung von Rothermundt et al. (2001), in der erhöhte s100ßSerumkonzentrationen bei Patienten mit einer melancholischen Depression gezeigt wurden, lag das Durchschnittsalter der Probanden gleichrangig bei 47,21 Jahren (SD 9,72). Hier wurde $s 100 \beta$ im Serum bei 28 erkrankten Patienten, davon 10 männliche und 18 weibliche, zwischen 29 und 62 Jahren, bestimmt und mit der Serumkonzentration gesunder Probanden verglichen.

Die Studie von Yang et al. (2008) hingegen, in der die Rolle von s100ß bei Patienten mit 
einer Major Depression, untersucht wurde, bestand aus einem deutlich jüngeren Kollektiv. Hier lag das Durchschnittsalter der 54 Probanden (19 Männer und 35 Frauen) bei 33,98 Jahren (SD 12,54).

Auch in der Studie von Wiesmann et al. (1999), die s100ß im Serum von Schizophrenieerkrankten Patienten untersuchten, war das Durchschnittsalter niedriger als in der vorliegenden Studie. Es wurden 20 Patienten im Alter zwischen 19 und 58 Jahren untersucht. Das Durchschnittsalter der 8 männlichen und 12 weiblichen Probanden lag dabei bei 35,7 Jahren (SD 10,7).

\subsubsection{Interpretation der Alkohol-spezifischen Erkrankungsmerkmale}

Zum Aufnahmezeitpunkt lag die durchschnittliche Abhängigkeitsdauer der weiblichen Probanden mit 9,06 Jahren (SD 7,35) deutlich unter der der Männer (15,3 Jahre, SD 8,35). Die statistische Auswertung ergab keinerlei Zusammenhänge zwischen der Dauer der Alkoholabhängigkeit und den in dieser Studie untersuchten Parametern, insbesondere der $100 \beta$ - oder Homocysteinkonzentrationen.

Des Weiteren ergaben sich keine Korrelationen in Bezug auf die Höhe des täglichen Alkoholkonsums in Gramm vor Untersuchungsbeginn.

Bei 28 der teilnehmenden Probanden wurde der Alkoholgehalt zum Zeitpunkt der Aufnahme entweder in Blut oder Atem gemessen. Dabei lag der durchschnittliche Promillegehalt aller Probanden bei 1,40 \%o (SD 1,05), wobei bei 5 Patienten ein Gehalt von 0 Promille und bei 3 Patienten ein Gehalt von über $3 \%$ gemessen wurde. Ein direkter Zusammenhang zwischen den untersuchten primären Parametern dieser Arbeit und dem Promillegehalt zeigte sich nicht. Jedoch ist die Differenz der ermittelten Promillewerte zwischen den Teilnehmern der Studie sehr groß, sodass die Voraussetzungen der Probanden sehr unterschiedlich waren und ein denkbarer Zusammenhang zwischen dem Promillegehalt und den s100ß- und Homocysteinwerten möglicherweise aus diesem Grund nicht aufgezeigt werden konnte.

\subsubsection{Interpretation der Laborparameter}

$\underline{s 100 \beta}$

Die s100ß-Serumwerte der Probanden waren zum ersten Untersuchungszeitpunkt, im Vergleich zu den Werten am letzten Untersuchungstag, signifikant höher (95\%iges Konfidenzintervall). Während des Studienverlaufs konnte ein signifikanter Abfall der s100ß-Konzentration beobachtet werden $(p<0,05)$ : die Mittelwerte nahmen von 0,071 $\mu \mathrm{g} / \mathrm{l}(\mathrm{SD} 0,041)$ am ersten Untersuchungstag auf $0,050 \mu \mathrm{g} / \mathrm{l}(\mathrm{SD} 0,031)$ am vierten 
Untersuchungstag (120 h nach dem ersten) ab. Dabei lagen sie jedoch im Vergleich zu Werten aus der Literatur stets im Normbereich. Auch nach dem Grenzwert $(\leq 0,12 \mu \mathrm{g} /)$ des Zentrallabors des Universitätsklinikums Göttingen, in dem die Blutwerte analysiert wurden, waren die Mittelwerte stets normwertig. Der hier angegebene Wert wurde jedoch für das maligne Melanom festgelegt.

Es wurde bereits mehrfach aufgezeigt, dass s100ß-Konzentrationen im nanomolaren Bereich mit stimulierenden Effekten auf das Neuronenwachstum assoziiert sind (Barger et al. 1995), während höhere Werte, d.h. im mikromolaren Bereich, eine zytotoxische Wirkung ausüben (Hu et al. 1996). Daher ist es denkbar, dass die in dieser Studie ermittelten leicht höheren Werte, die sich im Vergleich vom Anfangs- bis zum Endzeitpunkt darstellten, einen neuroprotektiven, trophischen Effekt des Zytokins als gegenregulatorische Wirkung zum neurotoxischen Alkohol widerspiegeln.

Liappas et al. (2006) untersuchten in einer Studie, ähnlich wie in der vorliegenden Arbeit, die s100ß-Serumkonzentration bei 20 alkoholabhängigen Patienten im Alter zwischen 25 und 65 Jahren, die zur Alkoholentgiftung stationär aufgenommen wurden. Dabei wurde der s100ß-Serumwert am Tag der Aufnahme und nochmals bei Entlassung, nach circa 4 bis 5 Wochen, bestimmt. Alle Patienten erfüllten die DSM-IV-Kriterien des Alkoholmissbrauchs und der Alkoholabhängigkeit. Daneben galt das Vorliegen einer weiteren psychiatrischen Erkrankung als Ausschlusskriterium. Im Vergleich zu der vorliegenden Studie waren die teilnehmenden Patienten zu Beginn der Untersuchung seit durchschnittlich 28 Tagen (SD 15,2) abstinent. Das Ergebnis dieser Untersuchung war eine Assoziation zwischen der Höhe des Alkoholkonsums bis zu einem Jahr vor Studienbeginn und dem Verlauf der $s 100 \beta$-Konzentration während der stationären Entgiftung. So stellte sich bei 10 Patienten mit einem mäßigen Alkoholkonsum ein Abfall der s100ß-Serumwerte während des stationären Aufenthalts dar. Hingegen kam es bei den Probanden mit einem hohen Alkoholkonsum zu einem Anstieg von s100 $\beta$ im Serum. In der vorliegenden Studie konnte allerdings keine Korrelation bezüglich des vorangehenden Alkoholkonsums ermittelt werden. Es bleibt jedoch zu berücksichtigen, dass der Untersuchungszeitraum dieser Studie mit 5 Tagen wesentlich kürzer war, als in der Studie von Liappas et al. (2006), in der die s100ß-Konzentration lediglich zum Zeitpunkt der stationären Aufnahme und nochmals circa 4 bis 5 Wochen später gemessen wurde. Des Weiteren wurde zum Zeitpunkt der stationären Aufnahme in dieser Studie bei 23 Probanden eine positive Blutalkoholkonzentration oder ein positiver Atemalkoholgehalt gemessen, während die Patienten der Studie von Liappas et al. (2006) im Durchschnitt seit 28 Tagen abstinent waren.

Ein weiteres Ergebnis der vorliegenden Arbeit war der Trend zu einer geringeren s100ßSerumkonzentration ( $p=0,064)$ zum letzten Untersuchungszeitpunkt bei Frauen. 
Allerdings ist zu beachten, dass die Anzahl der weiblichen Probanden dieser Arbeit lediglich bei 9 lag, von denen 8 die Untersuchung gemäß dem Studienprotokoll über 5 Tage absolvierten. Trotz der niedrigen Anzahl an Probandinnen könnte dieses Ergebnis einen geschlechtsspezifischen Effekt widerspiegeln. Man könnte somit annehmen, dass die neuroprotektive Wirkung von $s 100 \beta$ bei alkoholabhängigen Frauen geringer ist. Dieses Ergebnis widerspricht einer Studie von Yang et al. (2008), die die s100ßSerumkonzentrationen von 54 depressiven Männern und Frauen untersuchten. Hier stellte sich eine höhere $s 100 \beta$-Serumkonzentration bei depressiven Frauen im Vergleich zu Männern dar.

Wiesmann et al. (1998) untersuchten in ihrer Studie hingegen die s100ß-Serumwerte von 200 gesunden Erwachsenen zwischen 18 und 65 Jahren. Hier ergab sich kein Unterschied zwischen den Werten von Männern und Frauen. Um geschlechtsspezifische Unterschiede zu erforschen, untersuchten Nogueira et al. (2009) die s100ß-Expression im Tiermodell. Dieses ergab eine rhythmische Expression mit entgegengesetzten Tageszyklen von weiblichen und männlichen Ratten. In Bezug auf das Ergebnis sind weitere Studien erforderlich, um Unterschiede zwischen Männern und Frauen zu verifizieren. Eine zirkadiane Rhythmizität wurde in dieser Studie nicht berücksichtigt.

Eine weitere Erklärungsmöglichkeit der niedrigeren s100ß-Serumwerte der weiblichen Probanden wäre ein geringerer Alkoholkonsum vor Entzugsbeginn. In der vorliegenden Studie zeigte sich diesbezüglich keine signifikante Korrelation. Diese kann allerdings, aufgrund der niedrigen Anzahl der weiblichen Studienteilnehmer, nicht ausgeschlossen werden.

Obwohl die s100ß-Bestimmung im Serum eine stichhaltige Messgröße ist, kann eine Veränderung der Blut-Hirn-Schranken-Funktion als Grund für die leicht erhöhten s100ßWerte bei Entzugsanfang, nicht ausgeschlossen werden. In der Literatur ist umstritten, ob erhöhte $\mathbf{s} 100 \beta$-Serumwerte auf einen neuronalen/parenchymatösen Schaden im ZNS hinweisen oder ob sie eine Störung der Blut-Hirn-Schranke darstellen (Kanner et al. 2003).

Es gibt mehrere Studien, die belegen, dass peripher bestimmte s100ß-Werte eine Dysfunktion der Blut-Hirn-Schranke widerspiegeln (Kanner et al. 2003, Kapural et al. 2002, Marchi et al. 2003). Kanner et al. (2003) verglichen hierfür die s100ß-Serumwerte von 6 Patienten, die an einem ZNS-Lymphom erkrankt waren, bei denen zu therapeutischen Zwecken mehrmals eine osmotische Öffnung der Blut-Hirn-Schranke vollzogen wurde, mit den Werten von 51 Patienten, die entweder an einem primären ZNS-Tumor oder an einem metastatischen Hirnschaden erkrankt waren. Die Blutentnahme der ersten Gruppe erfolgte vor, während und nach Öffnung der Blut-HirnSchranke. Das Ergebnis war eine Korrelation zwischen s100ß und dem Ausmaß der Blut- 
Hirn-Schranken-Störung.

Passend hierzu untersuchte die Gruppe von Kornhuber et al. (1987) den Einfluss des akuten Alkoholkonsums auf die Blut-Hirn-Schranke. Im Ergebnis zeigte sich, dass Alkohol die Durchlässigkeit der Blut-Hirn-Schranke dosisabhängig steigert. Dieses Ergebnis könnte demnach die Hypothese von $s 100 \beta$ als Marker für eine Störung der BlutHirn-Schranke bestätigen.

Auf der anderen Seite wurde aber auch mehrfach die Funktion von s100ß als Marker für einen zerebralen Parenchymschaden postuliert. Demnach gelangt $s 100 \beta$ durch Schädigung von Astrozyten in den Liquor cerebrospinalis und tritt folgend über die BlutHirn-Schranke ins Blut über. Erhöhte s100ß-Plasmakonzentrationen wurden so beispielsweise nach traumatischen Hirnverletzungen (Lamers et al. 1995, Sedaghat et al. 2008) und nach der Ruptur eines intrazerebralen Aneurysmas (Wiesmann et al. 1997) beobachtet.

Die Ergebnisse der vorliegenden Studie zeigen eine lineare Reduktion der s100ßSerumkonzentration im Verlauf des akuten Alkoholentzugs, zeitgleich zu dem Absinken der Homocystein-Serumkonzentration. Obwohl keine direkte Korrelation in Bezug auf den Schweregrad des Entzugssyndroms, gemessen mit der AWS-Skala, ermittelt werden konnte, bestand parallel zu der Reduktion dieser Serumwerte, ein linearer Abfall der in der AWS-Skala erreichten Punktzahl. Somit könnte s100ß eine relevante Funktion in der Neurobiologie des Alkoholentzugs haben.

Dass der s100ß-Serummittelwert zum ersten Untersuchungszeitpunkt signifikant höher lag als zum letzten Untersuchungszeitpunkt, könnte die Hypothese stützen, dass diese Serumwerte indirekt das Stress-Niveau oder die glutamaterge Aktivität während des Alkoholentzugs widerspiegeln.

Eine stressassoziierte Ausschüttung von s100 wurde bereits von Suzuki et al. (1987) postuliert. In dieser Studie wurde eine vermehrte Freisetzung von s100 aus Glioblasten von Ratten nach Zugabe von ACTH beobachtet. Die Studie von Scaccianoce et al. (2004) ergab ebenso erhöhte $s 100 \beta$-Serumwerte bei Ratten nach einem RestraintStress. Allerdings konnte dieser Effekt nicht bei Ratten aufgezeigt werden, die eine Corticosteron-Injektion erhielten. Dieses Ergebnis deutet auf einen Glukokortikoidunabhän-gigen Mechanismus hin.

Des Weiteren wurde demonstriert, dass s100 in den Follikulären Sternzellen von Ratten zeitgleich mit Glutamin-Synthetase sezerniert wird (Shirasawa und Yamanouchi 1999), einem Enzym, das eine entscheidende Rolle in der Glutamat-Synthese spielt. Dieses Ergebnis stellt eine mögliche Assoziation zwischen $s 100 \beta$ und dem GlutamatStoffwechsel im ZNS dar.

Da chronischer Alkoholkonsum zu einer Heraufregulierung der NMDA-Rezeptoren führt 
(Tsai und Coyle 1998, Grant et al. 1990), kommt es während des Alkoholentzugs zu einer verstärkten Wirkung der glutamatergen Neurotransmission (Tsai et al. 1998). Aufgrund der Homocysteinämie, die während des Alkoholentzugs besteht (Bleich et al. 2000 b) und der agonistischen Wirkung Homocysteins am NMDA-Rezeptor wird diese nochmals verstärkt. Daher wäre $\mathrm{s} 100 \beta$ als Marker für die glutamaterge Aktivität oder das Stress-Niveau durchaus denkbar. Allerdings kann in der vorliegenden Studie, bezüglich der stressassoziierten Ausschüttung von s100ß, keine Aussage über die HypothalamusHypophysen-Nebennieren-Funktion gemacht werden. In dieser Frage wäre eine weitere Untersuchung interessant.

Aufgrund der dosisabhängigen Wirkung von $s 100 \beta$, ist nach den Ergebnissen dieser Studie denkbar, dass das Zytokin während des akuten Alkoholentzugs möglicherweise eine neurotrophe oder neuroprotektive Wirkung ausübt. Da in diesem Zeitraum ebenso erhöhte Homocysteinwerte gemessen wurden, könnte der s100ß-Anstieg möglicherweise eine Gegenregulation zu den schädlichen Effekten der Homocysteinämie repräsentieren, die bei den Probanden dieser Studie gegeben war.

Ein Zusammenhang zwischen der $\mathbf{1 0 0 \beta}$-Serumkonzentration und anderen psychiatrischen Erkrankungen, wie z. B. der Schizophrenie (Schroeter et al. 2009, Wiesmann et al. 1999), wurde bereits in mehreren Studien demonstriert. Ebenfalls konnte eine Assoziation zwischen der s100ß-Serumkonzentration und der Major Depression (Rothermundt et al. 2001) aufgezeigt werden. Alle diese Krankheitsbilder gehen mit einer kognitiven und emotionalen Beeinträchtigung einher. Man könnte daher annehmen, dass die ermittelte erhöhte $s 100 \beta$-Serumkonzentration nicht spezifisch ist für das Alkoholentzugssyndrom, sondern dass $s 100 \beta$ beispielsweise mit neurotrophen aber auch neurotoxischen Effekten in der Hippokampus-Region in Zusammenhang steht, die diese unspezifischen Symptome wie z. B. kognitive Defizite verschiedener psychiatrischer Erkrankungen bedingen könnten. Agartz et al. (1999) demonstrierten, dass s100ßBindungsstellen die höchste Dichte auf Neuronen im Hippokampus aufweisen.

Da die Wirkung von $s 100 \beta$ sich konzentrationsabhängig verändert, weisen die hier dargestellten Ergebnisse auf eine adaptive, dem Stress gegenregulatorische Funktion des Zytokins hin, die möglicherweise dem Schutz sensitiver neuronaler Strukturen des ZNS vor den schädlichen Effekten durch Homocystein oder Glutamat dient. S100ß kann daher möglicherweise als ein indirekter Marker für Stress während des Alkoholentzugs verwendet werden.

\section{Homocystein}

Die Homocystein-Serumwerte der Probanden waren zum ersten Untersuchungszeitpunkt mäßiggradig erhöht, der Mittelwert lag bei 18,95 $\mu \mathrm{mol} / \mathrm{I}$ (SD 11,18), während der 
Normwert des Zentrallabors des Universitätsklinikums Göttingen mit 5-15 $\mu \mathrm{mol} / /$ angegeben wurde. Wie nach Voruntersuchungen erwartet kam es über den Untersuchungszeitraum von $120 \mathrm{~h}$ zu einem signifikanten Abfall der Serumwerte, so dass die Homocystein-Serumkonzentration zum dritten Untersuchungszeitpunkt, das heißt 48 bis maximal $72 \mathrm{~h}$ nach der stationären Aufnahme, wieder im Normbereich lag (Mittelwert $14,77 \mu \mathrm{mol} / /$, SD 5,74). Bis zum vierten Untersuchungstag sank der Mittelwert weiter auf durchschnittlich 13,53 $\mu \mathrm{mol} / /$ (SD 5,18).

Dieses Ergebnis entspricht unter anderem dem von Bleich et al. (2000 b) in ihrer Studie mit 29 alkoholabhängigen Patienten, die zur Alkoholentgiftung stationär aufgenommen wurden. Hier stellte sich eine erhöhte Serum-Homocysteinkonzentration zum Zeitpunkt der Aufnahme mit einem stetigen Abfall innerhalb der untersuchten 3 Folgetage dar. Diese Reversibilität wurde ebenso in der vorliegenden Studie dargestellt. Auch in der Arbeit von Hultberg et al. (1993) mit 42 alkoholabhängigen nicht-abstinenten Patienten zeigten sich signifikant erhöhte Homocysteinwerte im Vergleich zur Kontrollgruppe, die sich nach ein bis 2 Wochen Abstinenz normalisierten. In der Studie von Cravo et al. (1996) stellte sich ebenso eine Homocysteinämie bei chronisch alkoholabhängigen Patienten dar. Hierfür wurden 32 alkoholabhängige Patienten untersucht, die seit weniger als 2 Wochen abstinent waren. Dabei lagen die errechneten Werte der Alkoholiker doppelt so hoch wie die der gesunden Kontrollgruppe.

Allerdings zeigte sich im Vergleich zu anderen Studien, dass die in der vorliegenden Arbeit bestimmten Homocystein-Mittelwerte niedriger waren. In der Arbeit von Bleich et al. (2000 b) mit 29 alkoholabhängigen Patienten lag der Homocystein-Mittelwert zum Zeitpunkt der stationären Aufnahme zur Alkoholdetoxikation bei 33,6 $\mu \mathrm{mol} / \mathrm{l}$ (SD 25,2), an

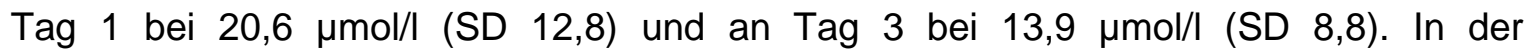
vorliegenden Studie hingegen wurde zum ersten Untersuchungszeitpunkt ein Mittelwert von 18,95 $\mu \mathrm{mol} / \mathrm{I}$ (SD 11,18), zum zweiten Untersuchungstag ein Wert von 16,79 $\mu \mathrm{mol} / \mathrm{l}$ (SD 6,98) und am dritten Untersuchungstag ein Wert von 14,77 $\mu \mathrm{mol} / / \mathrm{l}$ (SD 5,74) ermittelt. Zum letzten Untersuchungszeitpunkt betrug der Homocystein-Mittelwert 13,53 $\mu \mathrm{mol} / \mathrm{I}(\mathrm{SD} 5,18)$ und war somit vergleichbar mit dem Wert von Tag 3 in der Studie von Bleich et al. (2000 b). Auch in einer weiteren Studie (Bleich et al. 2000 a) mit 32 alkoholabhängigen Patienten, die zur Entgiftung stationär aufgenommen wurden, stellte sich zum Zeitpunkt der Aufnahme ein höherer Mittelwert $(40,45 \mu \mathrm{mol} / \mathrm{l}$, SD 32,32) als in der vorliegenden Arbeit dar. Dieser sank bis zu Tag 3 auf 15,8 $\mu \mathrm{mol} / \mathrm{l}$ (SD 10,7). Allerdings lagen die Blutalkoholkonzentrationen, die in den beiden Studien (Bleich et al. 2000 a, Bleich et al. 2000 b) ermittelt wurden, höher als in der hier vorgestellten. Des Weiteren stellte sich in den Arbeiten eine positive Korrelation zwischen den Homocysteinwerten und der BAK dar. In der Untersuchung von Bleich et al. (2000 b) 
ergab sich eine BAK von 177 mg/dl (SD 68), was circa einer Promillezahl von 1,68 entspricht, während in der zweiten Studie (Bleich et al. 2000 a) eine BAK von 184,10 mg/dl (SD 69,31), entsprechend 1,75\%, ermittelt wurde. Vergleichend hierzu lag der Mittelwert der Probanden der vorliegenden Studie bei 1,40 \%o (SD 1,05). Gegebenenfalls ergaben sich daher niedrigere Homocysteinwerte in dieser Studie.

Vergleicht man die Mittelwerte weiterer Krankheitsmerkmale, beispielsweise die konsumierte Alkoholmenge vor der stationären Aufnahme und die Dauer der Alkoholabhängigkeit, ergeben sich ähnliche Werte zwischen der vorliegenden Studie (Alkoholkonsum 268,08 g/d (SD 123,88), Dauer der Abhängigkeit 13,65 Jahre (SD 8,56)) und der Studie von Bleich et al. (2000 b) (Alkoholkonsum $230 \mathrm{~g} / \mathrm{d}$, Dauer der Abhängigkeit 14,8 Jahre).

Zwar wurde bereits in mehreren Studien ein Zusammenhang zwischen dem chronischen Alkoholkonsum und einer Homocysteinämie aufgezeigt, dennoch ist der zugrunde liegende Mechanismus bislang nicht vollständig geklärt. Dabei wurden ein Mangel der Co-Enzyme des Homocystein-Metabolismus (Folat, Vitamin B12, Pyridoxalphosphat) (Selhub et al. 1993) und die Hemmung der Methioninsynthase (Kenyon et al. 1998) als Gründe für die Homocysteinämie bei Alkoholikern postuliert.

Da chronischer Alkoholkonsum zu einer Heraufregulierung der NMDA-Rezeptoren führt (Grant et al. 1990, Tsai und Coyle 1998) kommt es während des Alkoholentzugs zu einer verstärkten glutamatergen Aktivität. Diese wird durch die agonistische Wirkung Homocysteins an den zerebralen NMDA-Rezeptoren nochmals gesteigert. Durch den Wegfall der GABAergen agonistischen Effekte des Ethanols führen diese Mechanismen zu einer Hyperexzitabilität. Ebenso wurden neurotoxische Effekte durch die Wirkung Homocysteins am NMDA-Rezeptor beschrieben (Lipton et al. 1997).

Es wurde zwar mehrfach aufgezeigt, dass die Aufnahme von Ethanol positiv mit den Plasma-Homocysteinwerten korreliert, jedoch sind die Studien nicht eindeutig was nichtalkoholabhängige Probanden betrifft.

So wurde von Bleich et al. (2001) eine Korrelation zwischen mäßigem Alkoholkonsum und der Plasma-Homocysteinkonzentration bei gesunden männlichen Probanden aufgezeigt. In der Studie wurden 60 nicht-alkoholabhängige Männer im Alter von 28 bis 44 Jahren untersucht, von denen 45 während 6 Wochen täglich $30 \mathrm{~g}$ Alkohol zu sich nahmen. Die restlichen 15 Probanden tranken in diesem Zeitraum lediglich Wasser. Es stellte sich bei denjenigen Probanden, die täglich Alkohol konsumierten ein signifikanter Anstieg der Serum-Homocysteinwerte dar. Auch die Framingham-Herz-Studie mit insgesamt 5209 Probanden ergab eine positive Assoziation zwischen der Alkoholaufnahme und der Höhe der Homocysteinwerte bei Männern und Frauen (Jacques et al. 2001). 
Auf der anderen Seite erbrachte eine weitere große Arbeit (Burger et al. 2004) mit 7124 stichprobenartig aus der Bevölkerung gewählten Probanden ein abweichendes Ergebnis. In dieser Studie zeigte sich für die weiblichen Probanden eine U-förmige Korrelation zwischen dem Alkoholkonsum und der Plasma-Homocysteinkonzentration und für die männlichen Probanden eine negative Korrelation. Auch die Untersuchung von Ubbink et al. (1998) mit 2398 männlichen Probanden erbrachte eine negative Korrelation. Hingegen stellte sich in einer weiteren Studie ein U-förmiger Verlauf für Männer und Frauen dar (Dixon et al. 2002).

Im Gegensatz zu diesen Ergebnissen konnte bei Ayaori et al. (2000) keine Korrelation zwischen der Alkoholaufnahme und den Homocysteinwerten bei gesunden männlichen Probanden ermittelt werden. Die Attica-Studie (Pitsavos et al. 2004) ergab bei Männern und Frauen indessen einen J-förmigen Kurvenverlauf zwischen der Alkoholaufnahme und der Homocysteinkonzentration.

Insgesamt bestehen divergierende Ergebnisse bezüglich des Einflusses eines mäßigen Alkoholkonsums auf die Serum-Homocysteinkonzentration bei nicht-alkoholabhängigen Patienten. Außerdem ist die Bedeutung des Geschlechts in diesen Studien nicht eindeutig.

Hingegen wurden bereits in mehreren Studien signifikant höhere Homocysteinwerte bei Männern im Vergleich zu Frauen demonstriert (Mayer et al. 1999, Powers et al. 2002). Die vorliegende Studie ergab diesbezüglich keine signifikanten Unterschiede. Allerdings ist zu beachten, dass in dieser Arbeit die Anzahl der Probandinnen, die die Untersuchung über die 4 Zeiträume absolvierten, lediglich bei 8 lag und damit die Aussagekraft niedrig ist.

Welchen Einfluss die Art des alkoholischen Getränks auf die Homocysteinwerte im Serum ausübt, wurde in zahlreichen Studien untersucht.

Das Ergebnis der Arbeit von van der Gaag et al. (2000) war ein Anstieg der Homocysteinwerte nach dem regelmäßigen Konsum von Rotwein und Spirituosen, während die Aufnahme von Bier keinen Effekt auf die Homocysteinkonzentration ergab. Die Autoren dieser Studie brachten das Ergebnis mit dem Vitamin-B6-Gehalt von Bier in Verbindung. Diese Erklärung würde die Hypothese eines Mangels an Co-Enzymen im Homocystein-Metabolismus als Ursache für die Homocysteinämie bei chronisch alkoholabhängigen Patienten bestätigen.

Auch die Arbeit von Beulens et al. (2005) ergab unveränderte Homocysteinkonzentrationen nach dem regelmäßigen Konsum von Bier. Des Weiteren zeigten sich ein Anstieg der Vitamin-B6- und ein Abfall der Vitamin-B12-Konzentrationen. Die Studie von Bleich et al. (2001) stellte hingegen einen Anstieg der SerumHomocysteinwerte, unabhängig von der Art des konsumierten alkoholischen Getränks, 
nach dem täglichen Konsum von $30 \mathrm{~g}$ Alkohol über 6 Wochen dar. Dieser Anstieg war in der Gruppe der Rotwein- oder Spirituosen-Konsumenten mit einem Abfall des PlasmaFolats verbunden, während der Folat-Wert bei den Bier-Konsumenten unverändert blieb. Insgesamt sind die Ergebnisse bezüglich des Einflusses der Art des konsumierten alkoholischen Getränks auf die Homocysteinkonzentration sehr heterogen.

Ein weiteres Ergebnis dieser Studie war eine positive Korrelation zwischen den SerumHomocysteinwerten und dem Alter bei Beginn der Alkoholabhängigkeit. Diese Assoziation stellt sich nicht direkt bei Aufnahme, sondern erst zum zweiten Untersuchungstag dar. Die Korrelation ist nach $48 \mathrm{~h}(\mathrm{p}=0,023)$ am stärksten und nach $24 \mathrm{~h}(\mathrm{p}=0,076)$ und $120 \mathrm{~h}(\mathrm{p}=0,052)$ niedriger ausgeprägt. Aufgrund dieses Ergebnisses wäre ein Zusammenhang zwischen erhöhten Homocysteinwerten und einer kürzeren Erkrankungsdauer denkbar. Dies wurde in der Literatur bisher nicht beschrieben. Es zeigte sich auch in dieser Studie keine direkte Korrelation zwischen der Dauer der Alkoholabhängigkeit und den Homocysteinkonzentrationen. Daher könnte es sich diesbezüglich auch um ein zufälliges Ergebnis handeln. Jedoch könnte der erste Homocysteinwert noch mehr von der akuten BAK abhängig sein, obwohl sich auch hier keine direkte Korrelation fand.

Des Weiteren könnte dieses Ergebnis eine Korrelation zwischen erhöhten Homocysteinwerten und dem Alter implizieren. Auch wenn diese Studie diesbezüglich keine direkte Korrelation nachweisen konnte, wurde dies bereits in mehreren Studien postuliert. In der Arbeit von Selhub et al. (1993) mit 1160 Probanden im Alter von über 67 Jahren, wurden bei 29,3 \% erhöhte Homocysteinwerte ermittelt. Es wurde außerdem eine Erhöhung der Werte mit zunehmendem Alter aufgezeigt. Auch in der Studie von Ganji et al. (2003) mit 6545 Probanden zeigten sich bei den über 70-Jährigen signifikant höhere Homocysteinwerte als bei den unter 30-Jährigen. Ebenso demonstrierten Strassburg et al. (2004) eine Zunahme der Plasma-Homocysteinkonzentration mit dem Alter. Eine Korrelation zwischen Homocystein und dem Alter wurde demnach mehrmals aufgezeigt und kann auch als Trend aus dieser Studie entnommen werden.

Ein weiteres interessantes Ergebnis dieser Studie ist die negative Korrelation zwischen dem Serum-Homocysteinwert und der Anzahl der eingenommenen ClomethiazolKapseln, was bedeutet, dass diejenigen Patienten mit höheren Homocysteinwerten weniger Clomethiazol-Kapseln benötigten. Dieser Effekt stellte sich nicht sofort, sondern erst 2 Tage nach der stationären Aufnahme dar. Da Clomethiazol GABA $A_{A}-$ Rezeptoren aktiviert und somit GABA-agonistisch wirkt (Nelson et al. 2002), könnte diese negative Korrelation auf einen adaptiven GABA-vermittelten Effekt bzw. auf einen Homocysteinsenkenden Effekt des Medikaments hinweisen.

Bleich et al. (2000 a, 2000 b) demonstrierten außerdem eine positive Korrelation 
zwischen dem Serum-Homocysteinwert bei Aufnahme und der BAK. Diese Korrelation konnte in mehreren Studien dieser Gruppe aufgezeigt werden, in der vorliegenden Arbeit jedoch nicht. Allerdings wurde auch bei 3 Patienten, die an der vorliegenden Studie teilnahmen, kein Alkoholspiegel bestimmt. Bei 5 von den restlichen 28 Patienten lag der Alkoholpegel bei $0 \%$. Von den übrigen Probanden wurde lediglich bei 8 die BAK bestimmt und bei den restlichen der Atemalkoholgehalt gemessen. Die Patienten mit negativem Blutalkoholspiegel wurden, im Gegensatz zu zahlreichen vorangehenden Studien (z. B. Bleich et al. 2000 b) trotzdem in diese Studie eingeschlossen, was ein Grund sein könnte, warum diese Arbeit keine Korrelation zwischen dem SerumHomocysteinwert und der BAK ergab.

\section{Transaminasen}

Bei insgesamt 13 Patienten wurden die Transaminasen sowohl bei der stationären Aufnahme als auch zum Zeitpunkt 4 bestimmt. Während die Anzahl der Patienten mit einer stark erhöhten AST in diesem Zeitraum von 7 auf 0 absank, blieb die Anzahl der Patienten mit einem ALT-Wert über dem dreifachen der Norm konstant. Es konnte keine Korrelation der Transaminasen mit den Homocystein- und s100ß-Werten im Serum ermittelt werden.

Im Gegensatz dazu ergab die Studie von Liappas et al. (2006) eine positive Korrelation zwischen den AST-Konzentrationen und den s100ß-Werten im Serum bei Aufnahme. Wiederum ist zu beachten, dass zumindest 23 Patienten der vorliegenden Studie zum Zeitpunkt der stationären Aufnahme alkoholisiert waren, während die Patienten der Arbeit von Liappas et al. (2006) zum Zeitpunkt der Aufnahme im Durchschnitt seit 28 Tagen abstinent waren.

\section{Übrige Laborparameter}

Im Hinblick auf die Höhe der zusätzlich bestimmten Laborparameter ( $\mathrm{Y}-\mathrm{GT}, \mathrm{MCV}, \mathrm{MCH}$, Elektrolyte) ergab die Auswertung, insbesondere in Bezug auf $s 100 \beta$ und Homocystein, keine signifikanten Korrelationen.

\subsubsection{Interpretation der Testverfahren}

Bei der Auswertung der AWS-Skala zeigte sich wie erwartet eine Reduktion der hierdurch abgebildeten Entzugssymptomatik über den Untersuchungszeitraum. So sank der Mittelwert von 5,97 Punkten (SD 2,97) am zweiten Untersuchungstag auf 3,43 Punkte (SD 0,96) zum Zeitpunkt der letzten Untersuchung. Eine statistisch signifikante Korrelation zwischen dem Schweregrad des Entzugssyndroms und den Serumwerten 
von $5100 \beta$ und Homocystein, wie in dieser Studie untersucht werden sollte, stellte sich nicht dar. Trotzdem nahmen diese 3 untersuchten Variablen während des Untersuchungszeitraums über $120 \mathrm{~h}$ linear und signifikant ab. Dies wäre bei der geringen Probandenzahl auch nicht zwingend zu erwarten gewesen.

Des Weiteren konnte in dieser Studie kein signifikanter Unterschied zwischen den Geschlechtern in der Stärke des Entzugssyndroms, gemessen mit der AWS-Skala, gefunden werden.

Die Auswertung des Uhrentests ergab eine nicht-signifikante Abnahme der Punktzahl über den Untersuchungszeitraum und somit eine verbesserte Zeichnung der Uhr mit abnehmender Entzugssymptomatik im Sinne verbesserter kognitiver bzw. visokonstruktiver Fähigkeiten.

\subsubsection{Interpretation der klinischen Parameter}

Bezüglich der Blutdruckwerte und der ermittelten Herzfrequenz der Patienten zeigte sich eine nicht-signifikante Reduktion über den Studienverlauf.

\subsubsection{Interpretation der verabreichten Medikamente}

Die Anzahl der Patienten, die mit Clomethiazol behandelt wurden, nahm von Zeitpunkt 0 zu Zeitpunkt 4 von 13 auf 2 ab. Gleichzeitig zeigte sich eine Reduktion des Mittelwerts der verabreichten Clomethiazol-Kapseln von 7,38 (SD 4,1) auf 1,5 (SD 0,5). Es wurde kein Unterschied zwischen den Geschlechtern im Hinblick auf die Anzahl der eingenommenen Kapseln ermittelt. Insgesamt gab es 3 Patienten, die keine Medikamente zur Milderung des Entzugssymptoms erhielten.

Während der Studie wurden keine zerebralen Entzugsanfälle beobachtet.

\subsection{Limitation der Studie}

Die hier dargestellten Ergebnisse sind aufgrund verschiedener Einschränkungen kritisch zu begutachten.

Zwar zeigte sich eine signifikante Erhöhung der s100ß-Konzentration im Blut von alkoholabhängigen Patienten während der stationären Entgiftung, allerdings war diese Erhöhung lediglich gering. Der errechnete Gruppen-Mittelwert lag während des ersten und während der folgenden Untersuchungszeiträume stets im Normbereich. Dennoch kam es im Verlauf der Entgiftung zu einem signifikanten Absinken der s100ß- und auch erwartungsgemäß der Homocysteinwerte. 
Zum Zweiten war die Anzahl der Probanden, die an dieser Studie teilgenommen haben, gering. Insgesamt absolvierten 30 der 31 Patienten die Untersuchung über die 4 Untersuchungszeitpunkte des Studienprotokolls. Weniger als ein Drittel $(n=9)$ der Probanden waren weiblich. Der jüngste teilnehmende Patient war 28 und der älteste 68 Jahre alt. Somit bestand insgesamt ein heterogenes Patientenkollektiv.

Des Weiteren konnte nicht bei allen 31 Studienteilnehmern, sondern lediglich bei 28, die Alkoholkonzentration zum Zeitpunkt der stationären Aufnahme bestimmt werden. Bei 11 Probanden wurde dabei die Blut- und bei 17 die Atemalkoholkonzentration ermittelt. Es gab somit 3 Patienten, bei denen keine Bestimmung des Alkoholgehaltes erfolgte.

Eine weitere Einschränkung ergibt sich daraus, dass diese Studie ohne eine Kontrollgruppe durchgeführt wurde. Es wäre wünschenswert, die ermittelten Ergebnisse mit einer Gruppe gesunder Probanden zu vergleichen. Ebenso könnten die s100ß-Werte und ihre Beziehung zu Homocystein in nicht-abstinenten Alkoholikern aufgrund des oft postulierten NMDA-Gleichgewichts zwischen exzitatorischem Homocystein und der inhibitorischen GABAergen Ethanol-Wirkung, interessant sein.

Die Bestimmung der s100ß-Konzentration erfolgte in dieser Studie durch eine serologische Untersuchung der durch die periphere venöse Blutentnahme gewonnenen Proben. Um zu verifizieren, ob die Werte im Serum denjenigen im Liquor entsprechen bzw. die erhöhten Werte auf eine Veränderung der Blut-Hirn-Schranken-Funktion hinweisen, wäre eine direkte Bestimmung aus dem Liquor von wissenschaftlichem Interesse. Jedoch ist die Risiko-Nutzen-Abwägung diesbezüglich ethisch zweifelhaft. Hinsichtlich der Hypothese, dass die ermittelte $s 100 \beta$-Serumkonzentration indirekt das Stress-Niveau widerspiegelt, wären weitere Untersuchungen interessant, die die Aktivität der Hypothalamus-Hypophysen-Nebennierenachse (z. B. durch Cortisol- oder ACTHMessungen) mitbeurteilen.

Insgesamt scheinen weitere Untersuchungen mit einer größeren Probandenzahl und einer Kontrollgruppe sinnvoll. Hierbei sollte eine positive Blutalkoholkonzentration als Einschlusskriterium definiert werden. 


\section{ZUSAMMENFASSUNG}

In mehreren Studien wurde bereits ein Zusammenhang zwischen erhöhten Homocysteinwerten und Alkoholabhängigkeit aufgezeigt. Untersuchungen zu s100 $\beta$ ergaben erhöhte Werte bei verschiedenen psychiatrischen und neurologischen Erkrankungen. Aufgrund der Assoziation von s100ß mit Glutamat und ACTH, die bei neurodegenerativen Prozessen und Alkoholabhängigkeit eine Rolle spielen, wurde in dieser Arbeit der Zusammenhang zwischen $\mathrm{s} 100 \beta$ und Homocystein während des akuten Alkoholentzugs untersucht.

Dafür wurde ein Kollektiv von 31 Patienten, 9 Frauen und 22 Männer, mit der Diagnose einer Alkoholabhängigkeit (nach ICD-10-Kriterien (Dilling et al. 2010)) in die Studie eingeschlossen. Die Probanden wurden freiwillig und mit stationärem Entgiftungswunsch in die Klinik für Psychiatrie und Psychotherapie des Universitätsklinikums Göttingen aufgenommen. Die Teilnahme an der Untersuchung erfolgte mit mündlichem und schriftlichem Einverständnis der Probanden. Das Gesamtdurchschnittsalter lag bei 46,87 Jahren (SD 8,73), die Dauer der Alkoholabhängigkeit bei 13,65 Jahren (SD 8,56). Die Alkoholkonzentration bei Aufnahme betrug im Gesamtdurchschnitt 1,34 \%o (SD 0,97). Die Studie wurde im Zeitraum von Oktober 2006 bis August 2007 durchgeführt. Die Untersuchungsdauer betrug pro Patient 120 h mit 4 Untersuchungszeitpunkten. Die erste Untersuchung erfolgte maximal $48 \mathrm{~h}$ nach der stationären Aufnahme. Die zweite Untersuchung fand $24 \mathrm{~h}$ nach der Ersten, die Dritte $48 \mathrm{~h}$ nach der Ersten und die Vierte im Abstand von $120 \mathrm{~h}$ statt. Zu diesen 4 Terminen wurde bei den Studienteilnehmern Blut entnommen, um die s100ß- und Homocysteinwerte im Serum zu bestimmen. Außerdem wurde der Blutdruck gemessen und die Pulsfrequenz bestimmt. Des Weiteren wurde jeweils die aktuelle Medikation protokolliert. Zum zweiten, dritten und vierten Termin erfolgten bei den Studienteilnehmern eine klinische Abschätzung des Alkoholentzugssyndroms mittels der AWS-Skala, sowie die Durchführung des Uhrentests.

Das wesentliche Ergebnis dieser Studie ist ein signifikanter Abfall der s100ß-Spiegel im Serum bei alkoholabhängigen Patienten während der akuten stationären Alkoholentzugsbehandlung zeitgleich zu einem signifikanten Abfall der HomocysteinSerumwerte im Untersuchungszeitraum über $120 \mathrm{~h}$. Parallel konnte in diesem Zeitabschnitt eine signifikante Abnahme der Entzugssymptomatik, gemessen an der AWS-Skala, nachgewiesen werden. Eine direkte Korrelation zwischen den Serumwerten von Homocystein/s100ß und der Punktzahl in der AWS-Skala wurde jedoch nicht belegt. Des Weiteren zeigte sich kein direkter Zusammenhang zwischen den Serumspiegeln von Homocystein und $s 100 \beta$ zu den verschiedenen Untersuchungszeitpunkten. 
Das Konsummuster der Probanden betreffend ergab diese Arbeit eine positive Korrelation zwischen dem Alter bei Abhängigkeitsbeginn und den Homocysteinwerten am dritten Untersuchungstag ( $p=0,023$ ). Ein direkter Zusammenhang zwischen dem Alter und Homocystein, wie in anderen Studien (Granji et al. 2003, Selhub et al. 1993) berichtet, kann dieser Arbeit lediglich als Trend entnommen werden.

Ein weiteres Ergebnis der vorliegenden Arbeit ist die negative Korrelation des Homocystein-Serumwerts zum dritten Untersuchungszeitpunkt und der Anzahl der eingenommenen Clomethiazol-Kapseln $(p=0,045)$. Dies könnte möglicherweise auf eine adaptive GABA-vermittelte Wirkung zurückzuführen sein.

Außerdem ergab die Auswertung dieser Studie einen Trend zu einer geringeren s100ßKonzentration im Serum von Frauen zum letzten Untersuchungszeitpunkt ( $p=0,064)$. Eine verminderte neuroprotektive Wirkung durch $s 100 \beta$ bei alkoholabhängigen Frauen wäre daher zumindest denkbar.

Während erhöhte Homocysteinwerte im Serum bei chronisch alkoholabhängigen Patienten und eine Reduktion dieser Werte während der Entzugsbehandlung bereits in mehreren Studien (z. B. Bleich et al. 2000 b) vorbeschrieben wurden, sind die Daten von $s 100 \beta$ in Verbindung mit Alkohol rar. Die Arbeit von Liappas et al. (2006) mit 20 alkoholabhängigen Patienten, die zur stationären Entzugsbehandlung über 4 bis 5 Wochen stationär behandelt wurden, demonstrierte einen Zusammenhang zwischen der s100ß-Serum-konzentration und der Höhe des Alkoholkonsums vor Beginn der Studie.

Von $s 100 \beta$ ist bekannt, dass die Wirkung sich dosisabhängig verändert, wobei eine trophische Wirkung mit geringeren Konzentrationen (im nanomolaren Bereich) und eine neurotoxische Wirkung mit höheren Konzentrationen (im mikromolaren Bereich) assoziiert ist. Die hier dargestellten Ergebnisse könnten auf eine adaptive, gegenregulatorische Funktion von $s 100 \beta$ hinweisen, die dem Schutz sensitiver neuronaler Strukturen des ZNS vor den schädlichen Effekten durch Homocystein oder Glutamat dient (Wedekind et al. 2011).

Weitere Studien mit größeren Studienpopulationen sowie einer Kontrollgruppe, die in diesem Zusammenhang die Hypothalamus-Hypophysen-Nebennierenachsen-Funktion mituntersuchen, könnten aufschlussreich sein. Des Weiteren wären, aufgrund des bekannten NMDA-Gleichgewichts aus exzitatorisch-wirkendem Homocystein und inhibitorisch-, GABAerg-wirkendem Ethanol, die Untersuchung der s100ß-Serumwerte und ihr Zusammenhang zu Homocystein bei nicht-abstinenten alkoholabhängigen Patienten interessant. 


\section{ANHANG}

\subsection{ICD-10-Kriterien}

Tabelle 2: ICD-10-Kriterien - Schädlicher Gebrauch von Alkohol

F10.1 - Schädlicher Gebrauch von Alkohol

„Ein Konsummuster (...), das zu einer Gesundheitsschädigung führt. Diese kann eine körperliche Störung (...) sein oder eine psychische Störung, z. B. eine depressive Episode nach massiven Alkoholkonsum.

Die Diagnose erfordert eine tatsächliche Schädigung der psychischen oder physischen Gesundheit des Konsumenten“. (Dilling et al. 2010, S.98)

Tabelle 3: ICD-10-Kriterien - Alkoholabhängigkeitssyndrom

F10.2 - Abhängigkeitssyndrom

„Es handelt sich um eine Gruppe körperlicher, Verhaltens- und kognitiver Phänomene, bei denen der Konsum einer Substanz oder einer Substanzklasse für die betroffene Person Vorrang hat gegenüber anderen Verhaltensweisen, die von ihr früher höher bewertet wurden. Ein entscheidendes Charakteristikum der Abhängigkeit ist der oft starke, gelegentlich übermächtige Wunsch (...) Alkohol (...) zu konsumieren“. (Dilling et al. 2010, S. 99)

Drei oder mehr der folgenden Kriterien sollten in den letzten 12 Monaten gleichzeitig vorhanden gewesen sein:

1. „Ein starker Wunsch oder eine Art Zwang, psychotrope Substanzen zu konsumieren.

2. Verminderte Kontrollfähigkeit bezüglich des Beginns, der Beendigung und der Menge des Konsums.

3. Ein körperliches Entzugssyndrom (...) bei Beendigung oder Reduktion des Konsums, nachgewiesen durch die substanzspezifischen Entzugssymptome oder durch die Aufnahme der gleichen oder einer nahe verwandten Substanz, um Entzugssymptome zu mildern oder zu vermeiden.

4. Nachweis einer Toleranz. Um die ursprünglich durch niedrigere Dosen erreichten Wirkungen der psychotropen Substanz hervorzurufen, sind 
zunehmend höhere Dosen erforderlich (...).

5. Fortschreitende Vernachlässigung anderer Vergnügungen oder Interessen zugunsten des Substanzkonsums, erhöhter Zeitaufwand, um die Substanz zu beschaffen, zu konsumieren oder sich von den Folgen zu erholen.

6. Substanzkonsum trotz Nachweis eindeutiger schädlicher Folgen, wie z. B. Leberschädigung durch exzessives Trinken, depressive Verstimmungen infolge starken Substanzkonsums (...). Es sollte dabei festgestellt werden, dass der Konsument sich tatsächlich über Art und Ausmaß der schädlichen Folgen im Klaren war oder dass zumindest davon auszugehen ist“. (Dilling et al. 2010 S.99)

Tabelle 4: ICD-10-Kriterien - Alkoholentzugssyndrom

F10.3 - Entzugssyndrom

„Es handelt es sich um einen Symptomkomplex von unterschiedlicher Zusammensetzung und wechselndem Schweregrad, bei absolutem oder relativem Entzug einer Substanz, die wiederholt und zumeist über einen längeren Zeitraum oder in hoher Dosierung konsumiert worden ist. Beginn und Verlauf des Entzugssyndroms sind zeitlich begrenzt und abhängig von der Substanzart und der Dosis, die unmittelbar vor dem Absetzen verwendet worden ist. Das Entzugssyndrom kann durch Krampfanfälle kompliziert werden“. (Dilling et al. 2010, S. 101) 


\subsection{DSM-IV-Kriterien}

\section{Tabelle 5: DSM-IV-Kriterien - Substanzmissbrauch}

Substanzmissbrauch (305.00 - Alkoholmissbrauch)

„Ein unangepasstes Muster von Substanzgebrauch führt in klinisch bedeutsamer Weise zu Beeinträchtigungen oder Leiden, wobei sich mindestens eines der folgenden Kriterien innerhalb desselben 12-Monate-Zeitraumes manifestiert:

1. Wiederholter Substanzgebrauch, der zu einem Versagen bei der Erfüllung wichtiger Verpflichtungen bei der Arbeit, in der Schule oder zu Hause führt (...).

2. Wiederholter Substanzgebrauch in Situationen, in denen es aufgrund des Konsums zu einer körperlichen Gefährdung kommen kann (...).

3. Wiederkehrende Probleme mit dem Gesetz in Zusammenhang mit dem Substanzgebrauch (...).

4. Fortgesetzter Substanzgebrauch trotz ständiger oder wiederholter sozialer oder zwischenmenschlicher Probleme, die durch die Auswirkungen der psychotropen Substanz verursacht oder verstärkt werden (...).

Die Symptome haben niemals die Kriterien für Substanzabhängigkeit der jeweiligen Substanzklasse erfüllt“. (Saß et al. 2001, S. 229)

\section{Tabelle 6: DSM-IV-Kriterien - Alkoholabhängigkeit}

\subsection{0 - Alkoholabhängigkeit}

„Ein unangepasstes Muster von Substanzgebrauch führt in klinisch bedeutsamer Weise zu Beeinträchtigungen oder Leiden, wobei sich mindestens drei der folgenden Kriterien manifestieren, die zu irgendeiner Zeit in demselben 12Monate-Zeitraum auftreten: 
1. Toleranzentwicklung, definiert durch eines der folgenden Kriterien:
a. Verlangen nach ausgeprägter Dosissteigerung, um einen Intoxikationszustand oder erwünschten Effekt herbeizuführen,
b. deutlich verminderte Wirkung bei fortgesetzter Einnahme derselben Dosis.

2. Entzugssymptome, die sich durch eines der folgenden Kriterien äußern:
a. charakteristisches Alkoholentzugssyndrom der jeweiligen Substanz,
b. dieselbe (oder eine sehr ähnliche) Substanz wird eingenommen, um Entzugssymptome zu lindern oder zu vermeiden.

3. Die Substanz wird häufig in größeren Mengen oder länger als beabsichtigt eingenommen.

4. Anhaltender Wunsch oder erfolglose Versuche, den Substanzgebrauch zu verringern oder zu kontrollieren.

5. Viel Zeit für Aktivitäten, um die Substanz zu beschaffen (...), sie zu sich zu nehmen (...) oder sich von ihren Wirkungen zu erholen.

6. Wichtige soziale, berufliche oder Freizeitaktivitäten werden aufgrund des Substanzgebrauchs aufgegeben oder eingeschränkt.

7. Fortgesetzter Substanzgebrauch trotz Kenntnis eines anhaltenden oder wiederkehrenden körperlichen oder psychischen Problems, das wahrscheinlich durch den Alkoholmissbrauch verursacht oder verstärkt wurde (...). (Saß et al. 2001, S. 227)

\section{Tabelle 7: DSM-IV-Kriterien - Alkoholentzug}

\section{8 - Alkoholentzug}

A. „Beendigung (oder Reduktion) von übermäßigem und langandauerndem Alkoholkonsum.

B. Mindestens 2 der folgenden Symptome, die sich innerhalb einiger Stunden oder weniger Tage gemäß Kriterium A entwickeln:

1. vegetative Hyperaktivität (z. B. Schwitzen oder Puls über 100),

2. erhöhter Handtremor,

3. Schlaflosigkeit,

4. Übelkeit oder Erbrechen,

5. vorübergehende visuelle, taktile oder akustische Halluzinationen oder Illusionen, 
6. psychomotorische Agitiertheit,

7. Angst,

8. Grand-mal-Anfälle.

C. Die Symptome von Kriterium B verursachen in klinisch bedeutsamer Weise Leiden oder Beeinträchtigungen in sozialen, beruflichen oder anderen wichtigen Funktionsbereichen.

D. Die Symptome gehen nicht auf einen medizinischen Krankheitsfaktor zurück und können nicht durch eine andere psychische Störung besser erklärt werden“. (Saß et al. 2001, S. 246) 


\subsection{AWS-Skala}

Subskala S (vegetative Symptomatik)

\begin{tabular}{|l|l|l|l|l|}
\hline & $\mathbf{0}$ & $\mathbf{1}$ & $\mathbf{2}$ & $\mathbf{3}$ \\
\hline Puls (/min) & $<100$ & $101-110$ & $111-120$ & $>120$ \\
\hline $\begin{array}{l}\text { Blutdruck } \\
\text { systolisch } \\
(\mathbf{m m H g})\end{array}$ & $<95$ & $96-100$ & $101-105$ & $>105$ \\
\hline $\begin{array}{l}\text { Temperatur } \\
\left({ }^{\circ} \mathbf{C}\right)\end{array}$ & $<37.0$ & $37.0-37.5$ & $37.6-38.0$ & $>38.0$ \\
\hline Atemfrequenz & $<20$ & $20-24$ & $>24$ & $\begin{array}{l}\text { stark (diffuses } \\
\text { Schwitzen) }\end{array}$ \\
\hline Schwitzen & $\begin{array}{l}\text { nicht } \\
\text { vermehrt }\end{array}$ & $\begin{array}{l}\text { leicht (feuchte } \\
\text { Hände) }\end{array}$ & $\begin{array}{l}\text { mittel (feuchte } \\
\text { Stirn) }\end{array}$ & $\begin{array}{l}\text { stark } \\
\text { (spontan) }\end{array}$ \\
\hline Tremor & keiner & $\begin{array}{l}\text { leicht (bei } \\
\text { erhobenen } \\
\text { Armen und } \\
\text { gespreizten } \\
\text { Fingern) }\end{array}$ & $\begin{array}{l}\text { mittel (bei } \\
\text { Fingern) }\end{array}$ & Fizten \\
\hline
\end{tabular}

Subskala M (psychomotorische Symptomatik)

\begin{tabular}{|c|c|c|c|c|c|}
\hline & 0 & 1 & 2 & 3 & 4 \\
\hline Agitiertheit & keine & unruhig & $\begin{array}{l}\text { wälzt sich im } \\
\text { Bett }\end{array}$ & bettflüchtig & $\begin{array}{l}\text { Erregungszustan } \\
\text { d }\end{array}$ \\
\hline Kontakt & $\begin{array}{l}\text { Gespräc } \\
\text { h } \\
\text { möglich }\end{array}$ & $\begin{array}{l}\text { leicht } \\
\text { ablenkbar }\end{array}$ & $\begin{array}{l}\text { wechselnder } \\
\text { Kontakt }\end{array}$ & $\begin{array}{l}\text { Gespräch } \\
\text { unmöglich }\end{array}$ & \\
\hline $\begin{array}{l}\text { Orientierung } \\
\text { (Zeit, Ort, } \\
\text { Person, } \\
\text { Situation) }\end{array}$ & voll & $\begin{array}{l}\text { eine Qualität } \\
\text { eingeschränk } \\
\text { t }\end{array}$ & $\begin{array}{l}2 \text { Qualitäten } \\
\text { eingeschränk } \\
\text { t }\end{array}$ & $\begin{array}{l}\text { völlig } \\
\text { desorientier } \\
\text { t }\end{array}$ & \\
\hline $\begin{array}{l}\text { Halluzinatione } \\
\text { n (optisch, } \\
\text { akustisch, } \\
\text { taktil) }\end{array}$ & keine & suggestibel & eine Qualität & $\begin{array}{l}2 \\
\text { Qualitäten }\end{array}$ & $\begin{array}{l}\text { alle Qualitäten, } \\
\text { szenisches } \\
\text { Erleben }\end{array}$ \\
\hline Angst & keine & $\begin{array}{l}\text { leicht (nur } \\
\text { auf } \\
\text { Befragen) }\end{array}$ & $\begin{array}{l}\text { schwer } \\
\text { (spontan } \\
\text { geäußert) }\end{array}$ & & \\
\hline
\end{tabular}




\subsection{Münchner Alkoholismus-Test}

Selbstbeurteilungsbogen (MALT-S)

\begin{tabular}{|c|c|c|}
\hline & $\begin{array}{l}\text { trifft } \\
\mathrm{zu}\end{array}$ & $\begin{array}{l}\text { trifft } \\
\text { nicht zu }\end{array}$ \\
\hline $\begin{array}{l}\text { 1. In der letzten Zeit leide ich häufiger an einem Zittern der } \\
\text { Hände. }\end{array}$ & & \\
\hline $\begin{array}{l}\text { 2. Ich hatte zeitweilig, besonders morgens, ein Würgegefühl oder } \\
\text { einen Brechreiz. }\end{array}$ & & \\
\hline $\begin{array}{l}\text { 3. Ich habe schon einmal versucht, Zittern oder morgendlichen } \\
\text { Brechreiz mit Alkohol zu kurieren. }\end{array}$ & & \\
\hline $\begin{array}{l}\text { 4. Zurzeit fühle ich mich verbittert wegen meiner Probleme und } \\
\text { Schwierigkeiten. }\end{array}$ & & \\
\hline $\begin{array}{l}\text { 5. Es kommt nicht selten vor, dass ich vor dem Mittagessen bzw. } \\
\text { zweiten Frühstück Alkohol trinke. }\end{array}$ & & \\
\hline $\begin{array}{l}\text { 6. Nach den ersten Gläsern Alkohol habe ich ein } \\
\text { unwiderstehliches Verlangen weiterzutrinken. }\end{array}$ & & \\
\hline 7. Ich denke häufig an Alkohol. & & \\
\hline $\begin{array}{l}\text { 8. Ich habe manchmal auch dann Alkohol getrunken, wenn es } \\
\text { mir vom Arzt verboten wurde. }\end{array}$ & & \\
\hline $\begin{array}{l}\text { 9. In Zeiten erhöhten Alkoholkonsums habe ich weniger } \\
\text { gegessen. }\end{array}$ & & \\
\hline $\begin{array}{l}\text { 10. An der Arbeitsstelle hat man mir schon einmal Vorhaltungen } \\
\text { wegen meines Alkoholtrinkens gemacht. }\end{array}$ & & \\
\hline 11. Ich trinke Alkohol lieber, wenn ich allein bin. & & \\
\hline 12. Seitdem ich mehr Alkohol trinke, bin ich weniger tüchtig. & & \\
\hline $\begin{array}{l}\text { 13. Ich habe nach dem Trinken von Alkohol schon öfters } \\
\text { Gewissensbisse (Schuldgefühle) gehabt. }\end{array}$ & & \\
\hline $\begin{array}{l}\text { 14. Ich habe ein Trinksystem versucht (z. B. nicht vor bestimmten } \\
\text { Zeiten zu trinken). }\end{array}$ & & \\
\hline 15. Ich glaube, ich sollte mein Trinken einschränken. & & \\
\hline
\end{tabular}


16. Ohne Alkohol hätte ich nicht so viele Probleme.

17. Wenn ich aufgeregt bin, trinke ich Alkohol, um mich zu beruhigen.

18. Ich glaube, der Alkohol zerstört mein Leben.

19. Einmal möchte ich aufhören mit dem Trinken, dann wieder nicht.

20. Andere Leute können nicht verstehen, warum ich trinke.

21. Wenn ich nicht trinken würde, käme ich mit meinem Partner besser zurecht.

22. Ich habe schon versucht, zeitweilig ohne Alkohol zu leben.

23. Wenn ich nicht trinken würde, wäre ich mit mir zufrieden.

24. Man hat mich schon wiederholt auf meine 'Alkoholfahne' angesprochen. 


\subsection{Uhrentest}

Patientenbogen

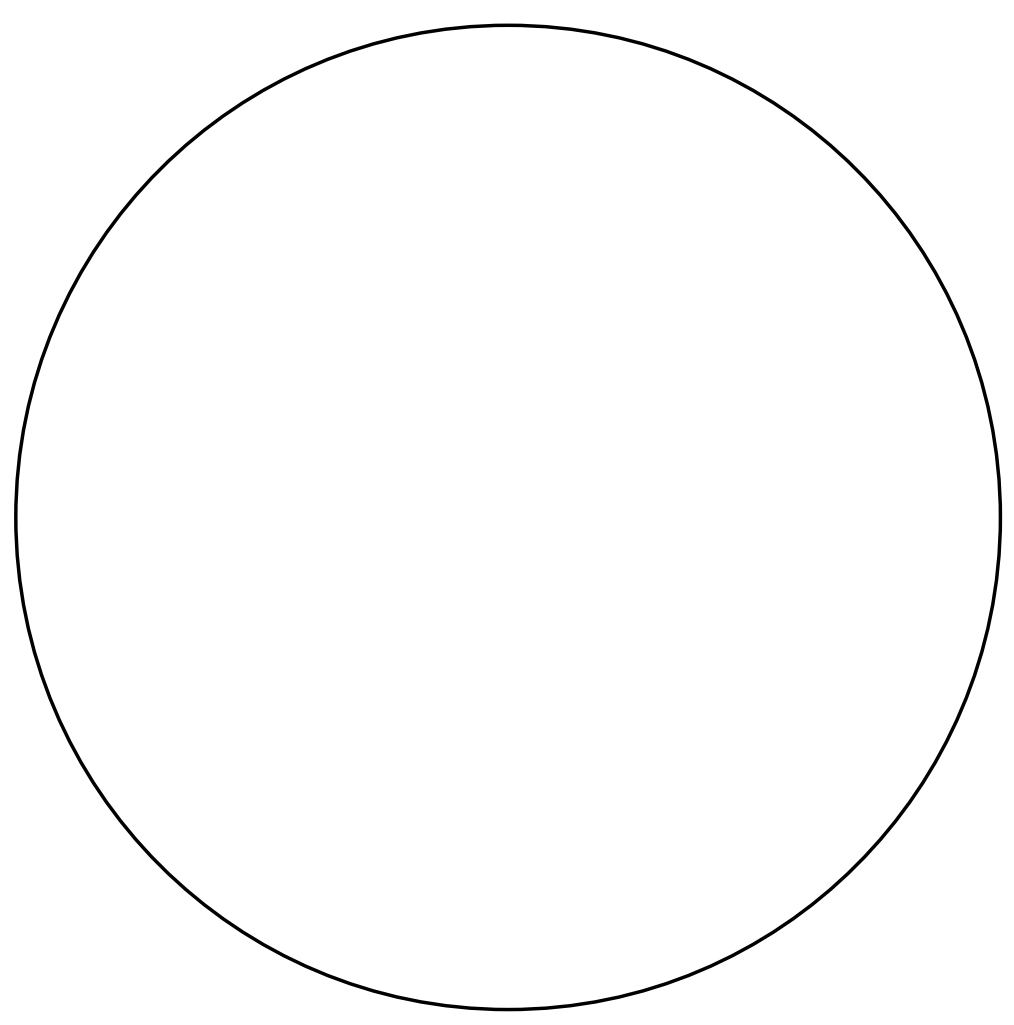




\section{Auswertung}

\begin{tabular}{|c|c|}
\hline Score & Beschreibung \\
\hline 1 & $\begin{array}{l}\text { Perfekt } \\
\text { - } \quad \text { Ziffern 1-12 richtig eingezeichnet } \\
\text { - } \quad \text { zwei Zeiger mit der richtigen Uhrzeit }\end{array}$ \\
\hline 2 & $\begin{array}{l}\text { Leichte visuell-räumliche Fehler } \\
\text { - } \quad \text { Abstände zwischen Ziffern ungleichmäßig } \\
\text { - } \quad \text { Ziffern außerhalb des Kreises } \\
\text { - } \quad \text { Blatt wird gedreht, so dass die Ziffern auf dem Kopf stehen } \\
\text { - } \quad \text { Patient verwendet Linien zur Orientierung }\end{array}$ \\
\hline 3 & $\begin{array}{l}\text { Fehlerhafte Uhrzeit bei erhaltener visuell-räumlicher Darstellung der Uhr } \\
\text { - } \quad \text { nur ein Zeiger } \\
\text { - } \quad \text { "10 nach } 11^{\prime \prime} \text { oder ähnliches als Text hingeschrieben } \\
\text { - } \quad \text { keine Uhrzeit eingezeichnet }\end{array}$ \\
\hline 4 & $\begin{array}{l}\text { Mittelgradige visuell-räumliche Desorganisation, sodass ein richtiges } \\
\text { Einzeichnen der Uhrzeit nicht möglich ist } \\
\text { - } \quad \text { unregelmäßige Zwischenräume } \\
\text { - } \quad \text { Ziffern vergessen } \\
\text { - } \quad \text { Perseveration; wiederholt den Kreis } \\
\text { - } \quad \text { Ziffern jenseits der } 12 \\
\text { - } \quad \text { Rechts-Links-Umkehr (Ziffern gegen den Uhrzeigersinn) } \\
\text { - } \quad \text { Dysgraphie - keine lesbare Darstellung der Zahlen }\end{array}$ \\
\hline 5 & $\begin{array}{l}\text { Schwergradige visuell-räumliche Desorganisation } \\
\text { - } \quad \text { wie unter } 4 \text { beschrieben, aber stärker ausgeprägt }\end{array}$ \\
\hline 6 & $\begin{array}{l}\text { Keinerlei Darstellung einer Uhr mehr } \\
\text { - } \quad \text { kein wie auch immer gearteter Versuch, eine Uhr zu zeichnen } \\
-\quad \text { keine entfernte Ähnlichkeit mit einer Uhr } \\
\text { - } \quad \text { Patient schreibt Wort oder Namen }\end{array}$ \\
\hline
\end{tabular}




\subsection{Veröffentlichung}

Eur Arch Pydintry Clin Neuraxi (2011) 261:133-138

DOI 10.1007k00406-010-01 21-2

ORIGINAL PAPER

\section{S100B and homocysteine in the acute alcohol withdrawal syndrome}

Dirk Wedekind · Karolin Neumann *

Peter Falkai - Berend Malchow - Kirsten Rita Engel ·

Katja Jamrozinskd - Ursula Havemann-Reinecke

Received: 20 April 2010/Accepted. 18 Jume 2010/Published online: 1 July 2010

D The Author(s) 2010. This aticle is published with open access at Springelinkcom

Abstract Elevations of serum homocysteine levek are a consistent finding in alcohol addiction. Serum S100B levels are altered in different neuropsychiatric disorders but not well investigated in alcohol withdrawal syndromes. Because of the close connection of S100B to ACTH and glutamate secretion that both are involved in neurodegeneration and symptoms of alcoholism the relationship of S100B and homocysteine to acute withdrawal variables has been examined. A total of 22 male and 9 fernale inpatients (mean age $46.9 \pm 9.7$ years) with an ICD-10 diagnosis of alcohol addiction without relevant affective comorbidity were examined on admission and after 24,48 , and $120 \mathrm{~h}$ during withdrawal. S100B and homocysteine levels in serum were collected, and severity of withdrawal symptoms (AWS-scale), applied withdrawal medication, initial serum ethanol levek and duration of addiction were recorded. Serum S100B and homocysteine levels declined significantly $(P<.05)$ over time. Both levels declined with withdrawal syndrome severity. Females showed a trend to a more intense

D. Wedekind (四) - K. Neumann - P. Fallai - B. Malchow K. R. Engel - U. Havemmn-Reinerke

Depastment of Paychiatry and Paychotherapy,

University of Goettingen, von-Siebold-Strasse 5 ,

37075 Goetingen, Germmy

omail dwedebil og widg de

K. Jarrocinaki

Department of Paychoscmatic Medicine and Prychotherapy,

University of Goettingen, von-Siebold-Strasse 5 ,

37075 Goetingen, Germmy

P. Falkai - U. Havernamn-Reinecke

CMPB (Center for Molecular Fhysiology of the Prain)

Goetringen, Germmy decline in serum S100B levels compered to males at day $5(P=.06)$. Homocysteine levels displayed a negative relationship to applied amount of clomethiszole $(P<.05)$ and correlated with age of onset of addiction. No withdrawal seizures were recorded during the trial. As it is known for homocysteine, $\mathrm{S100B}$ revealed to decline rapidly over withdrawal treatment in alcoholism. This effect is more pronounced in female petients. S100B could be of relevance in the neurobiology of alcohol withdrawal syndromes. It may be indirectly related to the level of stress level or glutamatergic activity during alcohol withdrawal.

Keywords Alcohol addiction - Homocysteine S100B - Withdrawal

Abbreviations

ACTH Adrenocorticotropin

AWS-scale Acute withdrawal-scale

ELISA Enzyme-linked-immuno-sorbent-assay

GABA Gamma-amino-butyric acid

HPA Hypothalamo-pituitary-adrenomedullary (axis)

HRP Horseradish-peroxydase

ICD-10 International classification of diseases, 10th revision

kDA kilo-Dalton

MALT Munich alcoholism tes

MRI Magnetic resonance imaging

NMDA $\quad N$-methyl-D-aspartate

RAGE Receptor for advanced glycation end products

SAH S-adenosyl-L-homocysteine

WHO World Health Organization 


\section{Introduction}

Alcohol addiction and aloohol withdrawal syndromes have been related to numerous biologic markers indicating syndrome severity or detrimental effects. The GABAergic system undergoes distinct adaptive processes over alcohol addiction going in line with receptor down-regulation and altered sensitivity [1]. During withdrawal, reduced GABA agonistic effects coincide with an increase in glutamatergic neurotransmission [2]. A compensatory up-regulation of glutamatergic NMDA receptors over chronic alcohol intake has been described [3].

Elevations of homocysteine and its main metabolite homocysteic acid in serum are a consistent finding in aloohol addiction [4-6] and withdrawal [7-9]. Due to excitatory NMDA and glutamatergic effects and reduction of inhibitory GABAergic drive by lack of ethanol, homocysteine has been related to excitatory somatic and psychic withdrawal symptoms, risk of withdrawal-related seizures, and excitotoxic neurodegenerative phenomena [10-12].

$S 100$ proteins are small, acidic proteins of $10-12 \mathrm{kDa}$ $\mathrm{S} 100 \mathrm{~B}$ is a calcium-binding astroglial peptide which has trophic or deleterious effects on neural cells in a dosedependent manner [13]. Mild S100B levels have been associated with stimulatory effects on neuronal growth, sprouting, and plasticity (e.g. concerning the central nervous serotonergic system and a diminution of glutamatedriven cytotoxicity) $[14,15]$. High levels of S100B, on the other hand activate early immediate genes (c-fos) [13] and long-term high levels of $\mathrm{S} 100 \mathrm{~B}$ by increasing intracellular calcium levels have been related to neurotoxicity and degeneration at different sites [16]. Besides astrocytes and other brain tissues [17], S100B is secreted by the folliculostellate cells in the anterior pituitary after stimulation of the stress axis and ACTH secretion [18]. Simultaneously, glutamate synthetase is secreted from folliculostellate celk. S100B has the highest density of intracellular binding sites (receptor for advanced glycation end products: RAGE) in neurons and glial cells of the hippocampus. Certain regions of this structure have been reported to be highly vulnerable to neurotoxic effects by S100B or glucocorticoids [13]. Such effects are thought to be glutamate driven.

Elevated levels of serum or cerebrospinal fluid S100B have been reported for psychiatric disorders such as schizophrenia [19-21] or affective disorders [22-26] which often co-oocur with alcohol addiction $[27,28]$. The role of $\mathrm{S100B}$ in psychiatric disorders is still not very clear. Taken together, it can be assumed that psychopathological alterations in different syndromes represent a fairly unspecific condition deriving from a general stress-level or increased glutamatergic drive leading to conditions of restricted declarative memory or emotional processing abilities. There seems to be a crucial role of the central nervous serotonergic system in this respect. On the one hand, Serotonin la receptor stimulation increases S100B levels on the other hand S100B has been considered to improve serotonergic neuron regeneration [29] most probably in mild concentrations.

Data on $\mathrm{S100B}$ in addictive disorders, in particular in aloohol dependence is still scarce. Animal data demonstrated that S100B reduces ethanol-induced apoptosis [30]. One clinical study measure $\mathrm{S} 100 \mathrm{~B}$ in patients undergoing inpetient withdrawal treatment assessed a significant elevation of S100B at admission compared to discharge after approximately $4-5$ weeks. However, this effect was only found in patients with severe addiction and previously high average alcohol consumption [31].

An association between homocysteine and S100B levels over the alcohol withdrawal syndrome can be hypothesized. Homocysteine levels correspond with NMDA and glutamate activity in the withdrawal period. Neurotoxic effects in certain brain areas correspond with dramatically raised $\mathrm{S} 100 \mathrm{~B}$ kvels. These are facilitated by glutamate activity. However, mild S100B increases may diminish glutamatedriven neurotoxicity. This study was performed in order to further elucidate the role of $\mathrm{S} 100 \mathrm{~B}$ in alcohol withdrawal syndromes and to correlate respective levels with withdrawal syndrome severity and the well-known alterations in serum homocysteine over the withdrawal period. Furthermore, it was of interest if values showed a connection to addiction severity, duration of addictive drinking $\alpha$ gender.

\section{Methods}

The study was approved by the local ethies committee

Thirty-one inpatients undergoing a qualified alcohol withdrawal treatment at the department of psychiatry and psychotherapy of the University of Goettingen were included into this study during October 2007 and August 2008 . Patients were males or females 18-70 years of age hospitalized for voluntary qualified detoxification treatment and suffering from alcohol addiction acoording to ICD-10 criteria [32]. Patients with any psychotic symptoms, clinically relevant major depression, polyvalent substance use (except for nicotine), incapacitating organic brain disorder, risk factors for hyperhomocysteinaemia, or regular psychotropic drug treatment in the 4 weeks before admission were excluded from participation. Subjects with relevant language problems or patients unable to give free informed consent were not included.

Patients were recruited within the first $24 \mathrm{~h}$ after admission to the clinic. After checking for in and exclusioncriteria and having given informed consent a serum sample for the assessment of S100B, homocysteine, and aloohol

\section{Q Springer}


concentration was drawn. Further serum samples were drawn after 24,48 , and $120 \mathrm{~h}$. On the latter 3 oocasions, the AWS scale [33] in order to assess withdrawal syndrome severity was applied. Blood pressure and heart rate was recorded on each of the 4 occasions, and the amount of applied withdrawal-related medication during the past $24 \mathrm{~h}$ was recorded. Blood ethanol concentration was controlled $24 \mathrm{~h}$ after the first sampling. In the end of the study ( $120 \mathrm{~h}$ after the first blood sample), participants completed a severity scale for alcohol addiction (MALT [34]). Sociodemographic data and information about duration of alcohol addiction/age of onset of aloohol addiction was collected.

S100B was measured by ELISA according to Leite [35]. Fifty-microliter serum samples were analyzed using Clone SH-B1 (Sigma Chemical Co.) as a capture antibody and a polyclonal detecting antibody (Dako). Homocysteine was measured by ELISA according the method described by Frantzen [36]. Twenty-five-microliter serum samples were analyzed using anti-SHA-antibody (Abbot Labs.) and HRP-conjugated antibody (Dako).

\section{Treatment during study}

All participants received a qualified detoxification treat ment with uniform supplementation of vitamins (B1, B6, B12) and potassium (taken orally). Qualified detoxification treatment comprised psychosocial treatment (including motivational training), physiotherapy and prescription of withdrawal related medication following cardiovascular monitoring.

\section{Stutistical analysis}

Statistical analyses were performed by using SPSS (version 17.0). Pearson correlations were computed for age and gender related to $\mathrm{S} 100 \mathrm{~B}$ and homocysteine at the respective time-points. Pearson correlations for S100B/homocysteine and syndrome severity acoording to the AWS score was calculated as well as for age of addiction onset and duration of aloohol addiction and for applied clomethiazole medication.

Repeated measures analysis (ANOVA, SPSS method Bonferroni) was performed for $\mathrm{S} 100 \mathrm{~B}$, homocysteine, and AWS scores over the study period. $P$ values below .05 were considered significant.

\section{Results}

Study population

Of the included 31 subjects ( 22 men, 9 women), 30 subjects completed the trial. Subjects were between 28 and
68 years old (mean $46.9 \pm 9.7$ ). No significant age differences between men $(45.8 \pm 7.3)$ and women $(49.4 \pm$ 12.0 ) were detected. Mean duration of alcohol addiction was $13.4 \pm 8.7$ years (range 15-33) mean age of onset of addiction was at the age of $33.5 \pm 10.5$ years (range $19-60$ years). Mean daily consumption of alcohol prior to admission was $262 \pm 124 \mathrm{~g} /$ day (range 95-631 g/day). Mean blood alcohol concentration at the first sampling time-point was $1.41 \pm 1.09$ per mille (range 0-3.5 per mille). MALT-scores had a mean of $15.5 \pm 4.7$.

\section{Serum S100B and homocysteine}

A comparable course was detected for S100B levek in serum with a linear and significant decline over the investigational period. Mean baseline values however, were still in the normal range $(74 \pm 8 \mathrm{ng} / \mathrm{l})$ and doclined to $51 \pm 6 \mathrm{ng} / \mathrm{l}$ over the following $120 \mathrm{~h}(F=5.88 ; P<.05$; see Table 1). There was no significant correlation between age and homocysteine levels, neither was there any significant correlation between age and $\mathrm{S100B}$ levels.

On average, subjects displayed mildly elevated homocysteine serum-levek at baseline $(19.3 \pm 2.2 \mu \mathrm{mol} / \mathrm{l})$ that declined significantly over the following $120 \mathrm{~h}(F=10.71$; $P<.05$; see Table 1). There was no significant correlation between age and homocysteine levels.

As an effect of gender, females displayed more rapidly declining S100B values; however, this was just a statistical trend $(r=0.35 ; P=.064$; at $120 \mathrm{~h}$; women vs. men).

A correlation between age of onset of alcohol addiction and homocysteine level could be detected. This correlation was most evident from values after $48 \mathrm{~h}(r=0.43$; $P<.05)$ and was slightly less after $24(P=.076)$ and $120 \mathrm{~h}(P=.052)$

Another remarkable finding were the lower homocysteine levels after $24 \mathrm{~h}$ in patients the more clomethiagole they received $(r=-0.64 ; P<.05)$. This effect could not be demonstrated for the subjects receiving diazepam.

Tahle 1 Mean $S 100 B$ and bomocysteine senm levels over the invesigstional period incl. $95 \%$ confidence interval

\begin{tabular}{|c|c|c|c|c|}
\hline & $\mathrm{Oh}$ & 24 h & $48 \mathrm{~h}$ & $120 \mathrm{~h}$ \\
\hline \multicolumn{5}{|c|}{ Homocysteine $\mu \mathrm{mol} / /$} \\
\hline $\operatorname{Mem} \pm$ SD & $19.3 \pm 2.2$ & $17 \pm 1.4$ & $14.8 \pm 1.1$ & $13.6 \pm 1$ \\
\hline $95 \% \propto$ & $14.9-23.8$ & $14.3-19.8$ & $12.6-17.1$ & $11.5-15.6$ \\
\hline LOS w. $0 \mathrm{~h}$ & & & & $P<.05$ \\
\hline \multicolumn{5}{|l|}{$\mathrm{S} 100 \mathrm{~B} \mathrm{ng} / 1$} \\
\hline $\operatorname{Mem} \pm$ SD & $74 \pm 8$ & $61 \pm 9$ & $54 \pm 6$ & $51 \pm 6$ \\
\hline $95 \% C I$ & $58-90$ & $43-78$ & $41-67$ & $38-63$ \\
\hline LOS v. $0 \mathrm{~h}$ & & & & $P<.05$ \\
\hline
\end{tabular}


Correlations between $\mathrm{S} 100 \mathrm{~B}$, homocysteine, and AWS-soores

Despite the linear decline of values for all three categories, no significant direct correlations could be detected between these variables.

Withdrawal syndrome severity

No withdrawal related seizures nor any withdrawal delirium was recorded in the sample over the study period.

AWS-scale

Scores on the AWS scale declined significantly $(F=4.81$; $P<.05$ ) over time with highest scores after $24 \mathrm{~h}$ $(5.97 \pm 2.97)$. Scores after $48 \mathrm{~h}$ were $4.63 \pm 1.62$ and $3.43 \pm 0.96$ after $120 \mathrm{~h}$. There were no significant differences in AWS-scores between men and women at any assessment point.

\section{Blood pressure and heart rate}

Blood pressure showed a slight but non-significant decline between 24 and $120 \mathrm{~h}(1455 \pm 5.2 \mathrm{mmHg}$ for systolic and $88.4 \pm 8.5$ for diastolic values at $24 \mathrm{~h}$ vs. $132 \pm 16.2$ for systolic and $84.3 \pm 9.4$ at $120 \mathrm{~h}$ ).

Heart rate declined non-significantly over time $(94 \pm 12.8$ at $24 \mathrm{~h}$ vs. $85 \pm 13$ at $120 \mathrm{~h})$.

Applied withdrawal medication

Clomethiazole $(n=13)$, diazepam $(n=12)$, phenoberbital $(n=3)$, and carbamazepine $n=11)$ were used in the population. Phenobarbital was used for patients with mild withdrawal syndromes who had adverse medication effects from diazepam or clomethiazole during previous withdrawal treatments.

Number of individuals treated with clomethisoole decreased from 13 at time $0 \mathrm{~h}$ to 2 at $120 \mathrm{~h}$. Applied amount of clomethiazole decreased from a mean of $7.4 \pm 4.2$ capsules ( $192 \mathrm{mg}$ each) at baseline to $1.5 \pm 0.5$ capsules at $120 \mathrm{~h}$. Mean intake of clomethiazole capsules did not differ between men $(3.9 \pm 3.0$ capsules/day) and women $(3.5 \pm 2.4$ capsules/day). Three subjects did not need any withdrawal-related medication.

\section{Discussion}

In support of our hypothesis, a significant decline of serum S100B levels over time could be detected, although average levels were in the normal range (compared to values from the literature). However, $95 \%$ confidence interval values support the likelihood of higher S100B levels at the beginning of withdrawal treatment. Although no direct correlation with withdrawal severity according to the AWS could be demonstrated, all 3 variables decline in a linear fashion. $\mathrm{S} 100 \mathrm{~B}$ appears to be of certain relevance in the biology of aloohol withdrawal syndromes, maybe giving indirect reference to stress level or glutamatergic activity. Probably these alterations are not particularly specific for alcohol withdrawal syndromes. In major depression correlations of $\mathrm{S100B}$ and symptom, severity could be demonstrated and also in schizophrenia. Yet, these entities represent syndromes connected to cognitive or emotional impairment with distinct hippocampal impairment (e.g. [37]). It could be speculated that $\mathrm{S} 100 \mathrm{~B}$ as well as homocysteine are related to effects on e.g. hippocampal areas that cause unspecific symptoms that oocur in different psychiatric disorders. Yet, actions of S100B are concentration dependent. Those higher levels at baseline compared to endpoint in this population are likely to be in the neuroprotective and trophic range of $\mathrm{S} 100 \mathrm{~B}$, and probably represent a protective, counter-regulatory mechanism against the harmful effects of hyperhomo-ysteinemia and associated glutamate-mediated neurotoxicity.

Just slighty missing the level of significance ( $P=064$; $r=0.35$ ) women tended to have lower level of serum S100B at endpoint. This is a finding that in a way contradicts the results by Yang [26] who found higher cerebrospinal fluid $\mathrm{S100B}$ in depressed women compered to men. However, women had no significantly different withdraw al severity soores according to the AWS scale. Neither were women significanty different with regard to age or in the amount of applied withdrawal medication such as clomethiazole. Therefore, despite the small n, this may reflect a gender effect. It could be hypothesized that neuroprotective effects of $\mathrm{S} 100 \mathrm{~B}$ are expressed to a lower degree in female aloohol addicted subjects. Age as well as blood ethanol levels at admission were comparable in men and women. One contributing factor, a lower average consumption of aloohol prior to withdrawal in women compared to men, cannot be excluded and would be in line with the findings of Liappes et al. [31].

As expected, homocysteine serum values declined significantly from a moderately elevated level over the $120 \mathrm{~h}$ investigational period in this population undergoing qualified alcohol detoxification treatment.

One interesting issue deriving from our data is the significant inverse relationship between serum homocysteine levels and clomethiazole intake. This effect was not immediately observable but after 1 day of intake which could represent an adaptive GABA mediated effect. In contrast to this, S100B levels were not moderated by clomethisaole. Possibly, clomethiazole treatment may need to

\section{Q Springer}


be considered as relevant in the interpretation of homocysteine levek in aloohol addiction.

Correlations between homocysteine and age have been consistently reported, and as a trend can be adapted from our data. Also amount of alcohol intake prior to admission has been found to be associated with higher serum homocysteine. This may correspond with higher stress levels and a higher risk for cardiovascular diseases. However, as suggested by some authors (e.g. [38]), we could not find gender specific effects. Animal studies have indicated circadian variations of serum homocysteine and age-related effects [39]. However, we could not detect any relationship to age of subjects. Circadian shifts in homocysteine levels were controlled by comparable time frames for all subjects. The fact that our data revealed a positive correlation between homocysteine serum levels and age of onset of alcohol addiction appears surprising. It implies an association between a shorter duration of the disorder with higher serum levek of excitatory homocysteine. Alimentary reasons for this effect due to reduced intake of methyl-groupdonators [40] can be hypothesized.

Nevertheless, the results presented here should not be over-in terpreted due to several limitations of the study. The rather small study population was probably too heterogeneous. Less than a third $(n=9)$ of the subjects were women, and the recruited subjects did not necessarily have to have positive blood alcohol concentrations at inclusion. Five patients in this population in fact were admitted to the clinic without blood alcohol, whereas several previous studies (e.g. $[7,8,41]$ did not include patients with negative blood alcohol due to a certain determination of homocys. teine levels by the degree of blood ethanol levels [7].

According to our hypothesis of a diagnosis unspecific phenomenon of elevated $S 100 B$ in parallel with elevated sress markers, we must admit that no statement at all on HPA function can be made from our study. Compared to another open-label study on S100B in aloohol withdrawal by Liappas [31] who measured S100B levels in alcoholaddicted subjects undergoing withdrawal treatment at admission and at discharge (after 4-5 woeks), this appears to be a clear limitation of that study. The investigational period in this trial was very much shorter. It was comparable with other investigations on homocysteine in alcohol withdrawal (e.g. $[7,8]$ stressing the relevance of the acute detoxification period over the first days of treatment.

Finally, although serum S100B measurements are a valid measure, we cannot entirely exclude alterations of blood-brain-berrier functioning in aloohol-addicted subjects [42] as the cause of these slightly higher initial S100B serum levels. One recent publication [43] identified the body-mass-index (BMI) as a contributing factor to serum S100B levels, which we did not take into account

\section{Conclusions}

Serum S100B levels show a decline over a 5-day period similar to homocysteine in alcohol-addicted spbjects undergoing acute inpatient aloohol withdrawal. Due to the well-known concentration-dependent trophic or neurotoxic effects of S100B, the demonstrated data may represent an adaptive, counter-regulatory function of S100B protecting sensitive neuronal brain structures against deleterious effects mediated by homocysteine or glutamate. Further investigations on larger populations taking HPA-function into acoourt appear useful. S100B serum levels and the ir relationship to homocysteine in non-abstinent alcoholics could be of interest due to the often postulated NMDA balance of excitatory homocysteine and inhibitory, GABAergic ethanol effects.

Open Access This article is distributed under the terms of the Creative Commons Atribution Noncommercial License which per. mits any nomconmercial use, dixtribution, and reprodaction in my medium, provided the criginal author(s) md scurce me cxedited

\section{References}

1. Mhatre MC, Pena G, Sieghart W, Tichu MK (1993) Antibodies specific for GABAA receptor alpha subumits reveal that chromic alcobol treatment down regulates alpha-gubunit expression in rat bain xgions. I Neurochem 61 (5) $1620-1625$

2. Tsai GI, Ragan P, Chang R, Chen S, Limnoila VM, Coyle JT (1998) Increased ghatumatergic neuroerananission and axidutive stress after aloobol withdawal. Am J Psychistry 155:726-732

3. Kril J, Halliday GM (1998) Brain shrinkage in alecholic: a decade on and what have we learned? Prog Neurobiol 58-381 387

4. Cravo ML, Gloria LM, Selnub I, Nudeau MR, Cmilo ME, Re. sende MP, Curdoso IN, Leitao CN, Min FC (1996) Hyperhom ocysteinerin in chronic alcobolism correlation with folate, ocyseinanis in chronic akcobolism. correlation with folate, vitamin B-12, and vitumin B-6 stastur. Am I Clin Nutr 63(2)
$220-224$

5. Halsted CH (2001) Lifestyle effects on bomocysteine and an alcobol paradax. Am J Clin Nute 73(3):501-502

6. Hultherg B, Berghmd M, Andessom A, Frank A (1993) Elevsed plasma homocysteine in alcobolics. Aloobol Clin Exp Res $17687-689$

7. Bleich S, Degner D, Wilfing J, Male JM, Niedmamn P, Cotrs S, Manghols A, Prorig I, Spung R, Rüher E, Kornhuber J (2000) Mlevated bomocysteine levels in alkobol withdrawal. Alrobol Elevated bomocystein

8. Bleich S, Sperling W, Wiltfang I, Maler IM, Korntuber J (2003) Excitatory neurotrananission in aloobolism. Fortschr Neurol Psychist 71(suppl 1):36-44

9. Bleich S, Hillenacher T (2009) Homocysteine, alkoholism md it: molecular networks. Pharmacoss ychiatry 42(supl 1):102-109

10. Bleich S, Degner D, Bmidelow B, von Ahren N, Futher E, Kombuher I (2000) Plasma homocysteine is a predictor of aloobol withdawal seimuxs. Neuroreqort 11(12):2749_2752

11. Bleich S, Bandelow B, Javhesiporr K, Maller A, Degner D, Wilhelm I, Havernamn-Reineche U, Sperling W, Ruther B Kombuber J (2003) Hyperhomocysteinuemin as a new risk factor 
for brain strinkage in patients with alcoholism. Neussci Let 335:179-182

12. Lipton SA, Kim WK, Choi YB, Kumr S, DEmilia DM, Rayodu PV, Arnelk DR, Stamler IS (1997) Neuro-6cricity associsted with dal actions of bomocysteine $x$ the $\mathrm{N}$-metryl-Daspatate receptor. Proc Natl Acad Sei USA 94:5923-5928

13. Hu I, Castets F, Guevra IL, Van Eldil LJ (1996) S100B stim ulates indxcible nitric aride synthase axtivity and mRNA level in rs cortical astrocytes. I Biol Chemistry 271(5): 2543-2547

14. Barger SW, Van Eldik LJ, Mattoon MP (1995) S100B protect: hippocampal neurons from damage induced by ghacose depivation. Brain Res 677:167-170

15. Whitacker-A mnitin PM, Clarke C, Armitia EC (1993) Localing tion of SHTla xceptos to astroglial celk in adul rats: Impli. cations for neuromal-glial inteactions md prychoadive drug mechmisms of action. Synapse 14:201-205

16. Barge SW, Vm Elik LJ (1992) S100B stimalates calcium influxes in glial and neuromal cell. I Biol Chemistry 267(14): $9689-9694$

17. Steine J, Berntein HG, Bieluu H, Bernit A, Brisch R, Mawin C Keilhoff G, Bogerts B (2007) Evidence for a wide extra-xtrocytix distribution of S100B in human train. BMC. Neurosci \&:?

18. Shinsawa N, Yamunouchi H (1999) Glococorticoids indxce glutamine synthetase in folliculostelate celk of rx pituitary glands in vivo md in vitro. I Anat 194:567-577

19. Ling SH, Tang YL, Jimg F, Wiste A, Goo SS, Weng YZ, Yang TS (2007) Plasma S-100B protein in Chinese putients with schizortrenircoma antipsychotics trestment. I Psychiatr Res 41(1-2)-36-42

90. Schroeter MI, Abdul-Khaliq H, Krebs M, Diefenbacher A, Bhsig IE (2009) Neuron-specific enolsse is unakered wherex $S 100 B$ is elevated in serum of patients with schirophrenia-oi. ginal reserrch and meta malysis. Paychistry Res $167.66-72$

21. Wiesmann M, Wandinge KP, Miss ler U, Eclhoff D, Rothermumt M, Arolt V, Kirchner H (1999) Flevated plasma levek of S1 00B protein in schizophrenic pstients. Biol Psychiatry 45: 1508-1511

22. Andranza AC, Cusini C, Rosa AR (2007) Serum S100B md antioxidant enzymes in bipolrs putients. I Prychint Res 41 : 523-529

23. Arolt V, Petres M, Erfusth A, Wiesmann M, Missler U, Rudolf S, Kixhner H, Rothernumdt M (2003) SIONB md xesponse to tratment in mijor depression: a pilok thady. Eur Neuropsychotrattment in major depresio

24. Rothermundt M, Arolt V, Wiesmmn M, Missle U, Peters M, Rodolf S, Kirchmer H (2001) S1 OOB is increased in melmoholic but notinnon-melmcholic major depression. JAffectDisord 66: $89-93$

25. Schroeter MI, Abdal-Khalin H, Diefenhacher A, Mlasig IF (2002) S1OOB is increased in mood discrders and may be reduced by mbidepxssive treatment. Neuroreport 13(13):1675-1678

26. Yang K, Xie GR Ha YQ, Mao FQ, Sa LY (2008) The effects of gender and number of depressive episodes on serum S100B levels inpsients with major depression. J Neural Transm 115: 1687-1694

27. Soyka M, Albex M, Immler B, Kathmann N, Hippias H (2001) Paychopathology in dual dingnosis and non-adicted schizophrenics - are there differences? Eur Axh Psychiatry Clin Neorosd 251(5):232-238

28. Mmn K, Fints T, Jung M (2004) Does ps ychintric comothidity in alkohol-dependent patients affect treatment cutcome? Eur And Psychiatry C.lin Neurosci 254(3):172-181
29. Grabe HJ, Ahrens N, Rose HJ, Kessler C, Freyberger HJ (2001) Neurotrophic factor $S 100$ beta in major depression. Neuropsychobiol $44(2)-88-90$

30. Druse MI, Gillespie RA, Tajuddin NF, Rich M (2007) S100Bmediated protection against the proapoptotic effects of ethmol on fetal thombencephalic neuroms. Prain Res 1150-46-54

31. Liappas I, Tvavellass EO, Kariyannia C, Piperi C, Schalpis C. Papassotiriou I, Sodatos CR (2006) Effect of alcobol detarification on serum S1 OOB levels of alkobol-dependent individuals. In Vivo 20(5):675-690

32. Wotd Health Organisation (WHO) (1991) Tenth xvision of the international classification of diveases, chapter $V(F)$. mental md bohavicural disorders (inchating disorders of prychological development). Oinical descriptions md dingrostic guidelines. Wotdd Healih Organisation, Geneva

33. Wetterling T, Kanitz RD, Besters B, Fischer D, Zeffass B, John U, Spranger H, Driessen M (1997) A new rating scale for the asses sment of the alkobol withdrawal syndrome. Aloobol Alechol 32)(6):753-760

34. Feuerlein W (1979) Early recognition and dingnosis of alcobol. ism. Ball Sctw Akad Wis 35(1-3).173-186

35. Leite MC, Galland F, Brolese G, Guerra MC, Bortolocto JW, Freitas R, Amneida LM, Goufried C, Goncalves CA (2008) A simple, sensitive and widdy aplicable ELISA for S10OB: Methodological featurs of the mesurenent of this glial protein. I Neunsei Methods 169(1)-93-99

36. Frantzen F, Faaren AI, Alfhein I Nordhei AK (1998) Enzyme convession immunoussay for determining total bomocysteine in plasma or serm. Oin Chem 44(2) 311-316

37. Meivenzahl EM, Seifert D, Botlender R, Teiped S, Zetrsche T Jiger M, Koutsouleria N, Schmitt G, Scheverecher I, Burgermeitter B, Hampel H, Rupprecht T, Born C, Reiser M, Moller HJ, Frodl T (2010) Differences in hippocampal volmme between major depression md schimptrenis: a comparative neuroimaging stoxdy. Eur Anch Rydintry Clin Neusosei 260(2):127-137

38. Brandno LC, Hachal H, Pitrencourt LR, Baracat EC, Tufik S, D'Almeida V (2009) Effects of isoflavone on ovidstive stres: prametes and bomocysteine in postmenopuasal women complaining of insomnin. Biol Res 42:281-287

39. Matims PJ, Galdieri LC, Souna FG, Andersen ML, BeneditoSilva AA, Tufik S, D'Ameidh V (2005) Physiological vaiabon in plasma toctal homocysteine concentration in rats. Life Sci in plama bokal h

40. Lever M, Sireland PCM, Fampion CM, Chambers ST (2004) Short and long-term variation of phasma glyaine betaine comcentations in humans. Clin Biochem 37(3) $84-90$

41. Bleich S, Degner D, Sperling W, Bonsch D, Thtranf N, Kornh uber J (2004) Homocystaine as a neurchor in in chromic alcobol. ism. Prog Neuropsychopharmacol Biol Psychiatry 28-453-464

42. Kontuher I, Kaiserane CH, Kombuher AW, Kornhuher MI (1987) Alcobol comsumpion and blood-cexbrospinal fluid bar rier dysfunction in man. Neurosei Leat 79:218-222

43. Elrrich S, Salhach-Andae H, Weiss D, Burghard R, Golkhin K, Caciun EM, Franke L, Uebelhadk R, Klapp HF, Limbuhl U (2008) $S 100 \mathrm{~B}$ in underwaigth and waigth recovered patients with anoxxia nervose. Asychomeuroendocrimology 3(6):782-788 


\section{LITERATURVERZEICHNIS}

Agartz I, Momenan R, Rawlings RR, Kerich MJ, Hommer DW (1999): Hippocampal volume in patients with alcohol dependence. Arch Gen Psychiatry $\underline{56}, 356-363$

Andreazza AC, Cassini C, Rosa AR, Leite MC, de Almeida LM, Nardin P, Cunha AB, Ceresér KM, Santin A, Gottfried C (2007): Serum S100B and antioxidant enzymes in bipolar patients, J Psychiatry Res 41(6), 523-529

APA (American Psychiatric Association): DSM-IV Diagnostic and statistical manual of mental disorders. American Psychiatric Association, Washington DC 1994

Arolt V, Peters M, Erfurth A, Wiesmann M, Missler U, Rudolf S, Kirchner H, Rothermundt M (2003): S100B and response to treatment in major depression: a pilot study. Eur Neuropsychopharmacol 13(4), 235-239

Ayaori M, Hisada T, Yoshida H, Shige H, Ito T, Nakajima K, Higashi K, Yonemura A, Ishikawa T, Ohsuzu F (2000): Effect of alcohol intake on the levels of plasma homocysteine in healthy males. J Nutr Sci Vitaminol (Tokyo) 46(4), 171-174

Barger SW, Van Eldik LJ (1992): S100 beta stimulates calcium fluxes in glial and neuronal cells. J Biol Chem 267(14), 9689-9694

Barger SW, Van Eldik LJ, Mattson MP (1995): S100 beta protects hippocampal neurons from damage induced by glucose deprivation. Brain Res $\underline{677(1)}$, 167-170

Benkert O, Hippius H: Kompendium der psychiatrischen Pharmakotherapie. 7. Auflage; Springer Medizin Verlag, Heidelberg 2009

Beulens JW, Sierksma A, Schaafsma G, Kok FJ, Struys EA, Jakobs C, Hendriks HF (2005): Kinetics of homocysteine metabolism after moderate alcohol consumption. Alcohol Clin Exp Res 29(5), 739-745

Bhattacharyya A, Oppenheim RW, Prevette D, Moore BW, Brackenbury R, Ratner N (1992): SIOO Is Present in Developing Chicken Neurons and Schwann Cells and Promotes Motor Neuron Survival in vivo. J Neurobiol 23(4), 451-466

Bleich S, Degner D, Bandelow B, Von Ahsen N, Rüther E, Kornhuber J (2000 a): Plasma homocysteine is a predictor of alcohol withdrawal seizures. Neuroreport 11(12), 2749-2752

Bleich S, Degner D, Wiltfang J, Maler JM, Niedmann P, Cohrs S, Mangholz A, Porzig J, Sprung R, Rüther E (2000 b): Elevated homocysteine levels in alcohol withdrawal. Alcohol Alcohol 35(4), 351-354

Bleich S, Bleich K, Kropp S, Bittermann HJ, Degner D, Sperling W, Rüther E, Kornhuber J (2001): Moderate alcohol consumption in social drinkers raises plasma homocysteine levels: a contradiction to the 'French paradox'? Alcohol and Alcoholism $\underline{36(3)}$, 189-192

Bleich S, Sperling W, Wiltfang J, Maler JM, Kornhuber J (2003): Excitatory neurotransmission in alcoholism. Fortschr Neurol Psychiatr 71, 36-44 
Boileau I, Assaad JM, Pihl RO, Benkelfat C, Leyton M, Diksic M,Tremblay RE, Dagher A (2003): Alcohol promotes dopamine release in the human nucleus accumbens. Synapse $\underline{49(4)}, 226-231$

Burger M, Mensink G, Brönstrup A, Thierfelder W, Pietrzik K (2004): Alcohol consumption and its relation to cardiovascular risk factors in Germany. Eur J Clin Nutr $\underline{58}, 605-614$

Chao CC, Hu S, Molitor TW, Shaskan EG, Peterson PK (1992): Activated microglia mediate oxide neuronal cell Injury via a nitric mechanism. J Immunol 149(8), 2736-2741

Cravo ML, Camilo ME (2000): Hyperhomocysteinemia in chronic alcoholism: relations to folic acid and vitamins $B(6)$ and $B(12)$ status. Nutrition 16(4), 296-302

Cravo ML, Gloria LM, Seihub J, Nadeau MR, Camilo ME, Resende MP, Cardoso JN, Leitão CN, Mira FC (1996): Hyperhomocysteinemia in chronic alcoholism: correlation with folate, vitamin B-12, and vitamin B-6 status. Am J Clin Nutr $\underline{63}$, 220-224

Deibele L (1991): Die Entwicklung der Destillationstechnik von ihren Anfängen bis zum Jahre 1800. Chem Ing Tech $\underline{63(5)}, 458-470$

Dilling $\mathrm{H}$, Mombour W, Schmidt $\mathrm{MH}$ : Internationale Klassifikation psychischer Störungen: ICD-10 Kapitel V(F), Klinisch-diagnostische Leitlinien. Weltgesundheitsorganisation, 7. überarbeitete Auflage; Verlag Hans Huber, Bern 2010

Dixon JB, Dixon ME and O'Brien PE (2002): Reduced plasma homocysteine in obese red wine consumers: a potential contributor to reduced cardiovascular risk status. Eur $\mathrm{J}$ Clin Nutr $\underline{56(7)}, 608-614$

Driessen M, Veltrup C, Weber J, John U, Wetterling T, Dilling H (1998): Psychiatric comorbidity, suicidal behaviour and suicidal ideation in alcoholics seeking treatment. Addiction 93(6), 889-894

Driessen M, Meier S, Hill A, Wetterling T, Lange W, Junghanns K (2001): The course of anxiety, depression and drinking behaviours after completed detoxification in alcoholics with and without comorbid anxiety and depressive disorders. Alcohol Alcohol $\underline{36(3)}, 249-255$

Druse MJ, Gillespie RA, Tajuddin NF, Rich M (2007): S100B-mediated protection against the pro-apoptic effects of ethanol on fetal rhombencephalic neurons. Brain Res $\underline{1150}$, 46-54

Durand P, Prost M, Loreau N, Lussier-Cacan S, Blache D (2001): Impaired Homocysteine Metabolism and Atherothrombotic Disease. Lab Invest 81(5), 645-672

Fanò G, Mariggiò MA, Angelella P, Nicoletti I, Antonica A, Fulle S, Calissano P (1993): The S-100 protein causes an increase of intracellular calcium and death of PC12 cells.

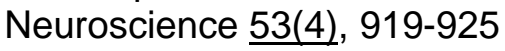

Feuerlein W: Alkoholismus: Warnsignale, Vorbeugung, Therapie. 6. Auflage; Verlag C. H. Beck, München 2008

Frantzen F, Faaren AL, Alfheim I, Nordhei AK (1998): Enzyme conversion immunoassay for determining total homocysteine in plasma or serum. Clin Chem $\underline{44(2)}$, 311-316

Franz M, Dlabal H, Kunz S, Ulferts J, Gruppe H, Gallhofer B (2001): Treatment of alcohol withdrawal: tiapride and carbamazepine versus clomethiazole. A pilot study. Eur Arch Psychiatry Clin Neurosci 251(4), 185-192 
Fulle S, Pietrangelo T, Mariggiò MA, Paola Lorenzon P, Racanicchi L, Mozrzymas J, Guarnieri S, Zucconi-Grassi G, Fanò G (2000): Calcium and fos involvement in brain-derived Ca2+-binding protein (S100)-dependent apoptosis in rat phaeochromocytoma cells. Exp Physiol $\underline{85(3)}$, 243-253

Gaertner B, Freyer-Adam J, Meyer C, John U: Alkohol - Zahlen und Fakten zum Konsum; in: Jahrbuch Sucht 2012; hrsg. v. DHS - Deutsche Hauptstelle für Suchtfragen e.V.; Pabst Science Publishers, Lengerich 2012, 41-45

Ganji V, Kafai MR (2003): Demographic, health, lifestyle, and blood vitamin determinants of serum total homocysteine concentrations in the third National Health and Nutrition Examination Survey, 1988-1994. Am J Clin Nutr 77(4), 826-833

Grant KA, Valverius P, Hudspith M, Tabakoff B (1990): Ethanol withdrawal seizures and the NMDA receptor complex. Eur J Pharmacol 176(3), 289-296

Greenfield SF, Weiss RD, Muenz LR, Vagge LM, Kelly JF, Bello LR, Michael J (1998): The effect of depression on return to drinking: a prospective study. Arch Gen Psychiatry $\underline{55(3)}$, 259-265

Griffin WST, Stanley LC, Ling C, White L, MacLeod V, Perrot LJ, White CL III, Araoz Carlos (1989): Brain interleukin 1 and S100 immunoreactivity are elevated in Down syndrome and Alzheimer disease. Proc Natl Acad Sci USA 86(19), 7611-7615

Guilliams TG (2004): Homocysteine - a risk factor for vascular diseases: guidelines for the clinical practice. J Am Nutraceut Assn 7(1), 11-24

Harris EC, Barraclough B (1997): Suicide as an outcome for mental disorders. A metaanalysis. Br J Psychiatry 170, 205-228

Hauschild A, Michaelsen J, Brenner W, Rudolph P, Gläser R, Henze E, Christophers E (1999): Prognostic significance of serum S100B detection compared with routine blood parameters in advanced metastatic melanoma patients. Melanoma Res $\underline{9(2)}$, 155-161

Herold G: Innere Medizin. Eigenverlag, Köln 2009

Holdcraft LC, Lacono WG, McGue MK (1998): Antisocial Personality Disorder and depression in relation to alcoholism: a community-based sample. J Stud Alcohol 59(2), 222-226

Hu J, Castets F, Guevara JL, Van Eldik LJ (1996): S100 beta stimulates inducible nitric oxide synthase activity and mRNA levels in rat cortical astrocytes. J Biol Chem 271(5), 2543-2547

Hultberg B, Berglund M, Andersson A, Frank A (1993): Elevated plasma homocysteine in alcoholics. Alcohol Clin Exp Res 17(3), 687-689

Huttunen HJ, Kuja-Panula J, Sorci G, Agneletti AL, Donato R, Rauvala H (2000): Coregulation of neurite outgrowth and cell survival by amphoterin and $S 100$ proteins through receptor for advanced glycation end products (RAGE) activation. J Biol Chem 275(51), 40096-40105

Jacques PF, Bostom AG, Wilson PWF, Rich S, Rosenberg IH, Selhub J (2001): Determinants of plasma total homocysteine concentration in the Framingham Offspring cohort. Am J Clin Nutr $\underline{73(3)}$, 613-621 
Janković BD, Djordjijević D (1991): Differential appearance of autoantibodies to human brain S100 protein, neuron specific enolase and myelin basic protein in psychiatric patients. Int $J$ Neurosci $\underline{60(1-2)}, 119-127$

Kanner AA, Marchi N, Fazio V, Mayberg MR, Koltz MT, Siomin V, Stevens GH, Masaryk T, Aumayr B, Vogelbaum MA (2003): Serum S100beta: a noninvasive marker of blood-brain

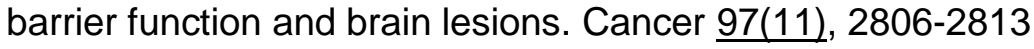

Kapural M, Krizanac-Bengez LJ, Barnett G, Perl J, Masaryk T, Apollo D, Rasmussen P, Mayberg MR, Janigro D (2002): Serum S-100beta as a possible marker of blood-brain barrier disruption. Brain Res 940(1-2), 102-104

Kenyon SH, Nicolaou A, Gibbons WA (1998): The effect of ethanol and its metabolites upon methionine synthase activity in vitro. Alcohol 15(4), 305-309

Kluge F, Seebold E: Etymologisches Wörterbuch der deutschen Sprache. 25. Auflage; Walter de Gruyter Verlag, Berlin/Boston 2011, 31, s. v. "Alkohol"

Kornhuber J, Kaiserauer CH, Kornhuber AW, Kornhuber ME (1987): Alcohol consumption and blood-cerebrospinal fluid barrier dysfunction in man. Neurosci Lett 79(1-2), 218-222

Lamers KJ, Van Engelen BG, Gabreels FJ, Hommes OR, Borm GF, Wevers RA (1995): Cerebrospinal neuon-specific enolase, S-100 and myelin basic protein in neurological disor-

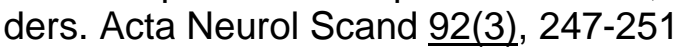

Leite MC, Galland F, Brolese G, Guerra MC, Bortolotto JW, Freitas R, Almeida LM, Gottfried C, Goncalves CA (2008): A simple, sensitive and widely applicable ELISA for S100B: Methodological features of the measurement of this glial protein. J Neurosci Methods 169(1), 9399

Li YF, Cornish KG, Patel KP (2003): Alterations of NMDA NR1 receptors within the paraventricular nucleus of hypothalamus in rats with heart failure. Circ Res 93(10), 990-997

Liappas I, Tzavellas EO, Kariyannis C, Piperi C, Schulpis C, Papassotiriou I, Soldatos CR (2006): Effect of alcohol detoxification on serum S-100B levels of alcohol-dependent individuals. In Vivo 20(5), 675-680

Lin CH, Lo WC, Hsiao M, Tung CS, Tseng CJ (2004): Interactions of carbon monoxide and metabotropic glutamate receptor groups in the nucleus tractus solitarii of rats. J Pharmacol Exp Ther 308(3), 1213-1218

Lipton SA, Kim WK, Choi YB, Kumar S, D’Emilia DM, Rayudu PV, Arnelle DR, Stamler JS (1997): Neurotoxicity associated with dual actions of homocysteine at the N-methyl-Daspartate receptor. Proc Natl Acad Sci USA 94(11), 5923-5928

Liu JP, Lauder JM (1992): S-I00 beta and insulin-like growth factor-II differentially regulate growth of developing serotonin and dopamine neurons in vitro. J Neurosci Res $\underline{33(2)}$, 248256

Lovinger DM, White G, Weight FF (1989): Ethanol inhibits NMDA-activated ion current in hippocampal neurons. Science 243(4899), 1721-1724

Mann K, Mundle G, Strayle M, Wakat P (1995): Neuroimaging in alcoholism: CT and MRI

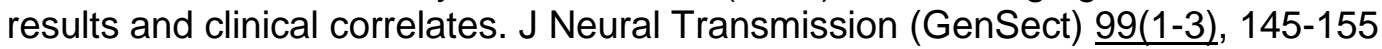


Marchi N, Fazio V, Cucullo L, Kight K, Masaryk T, Barnett G, Vogelbaum M, Kinter M, Rasmussen P, Mayberg MR (2003): Serum transthyretin monomer as a possible marker of blood-to-CSF barrier disruption. J Neurosci 23(5), 1949-1955

Massaro AR, Michetti F, Laudisio A, Bergonzi P (1985): Myelin basic protein and S-100 antigen in cerebrospinal fluid of patients with multiple sclerosis in the acute phase. Ital $\mathrm{J}$ Neurol Sci $\underline{6(1)}, 53-56$

Mayer O Jr, Simon J, Rosolová H (1999): Gender differences in serum homocysteine levels and associated factors. Cas Lek Cesk 138(17), 525-527

Mhatre MC, Pena G, Sieghart W, Ticku MK (1993): Antibodies specific for GABAA receptor alpha subunits reveal that chronic alcohol treatment down-regulates alpha-subunit expression in rat brain regions. J Neurochem $\underline{61(5)}, 1620-1625$

Mohammed MQ, Abraha HD, Sherwood RA, MacRae K, Retsas S (2001): Serum s100beta protein as a marker of disease activity in patients with malignant melanoma. Med Oncol 18(2), $109-120$

Nelson RM, Green AR, Hainsworth AH (2002): Electrophysiological actions of gammaaminobutyric acid and clomethiazole on recombinant GABA(A) receptors. Eur J Pharmacol $\underline{452(3)}, 255-262$

Nogueira MI, Abbas SY, Campos LG, Allemandi W, Lawson P, Takada SH, Azmitia EC (2009): S100beta protein expression: gender- and age-related daily changes. Neurochem Res $\underline{34(8)}, 1355-1362$

Pabst A, Kraus L (2008): Alkoholkonsum, alkoholbezogene Störungen und Trends. Ergebnisse des Epidemiologischen Suchtsurveys 2006. Sucht 54(1), 36-46

Palmer AM, Marion DW, Botscheller ML, Bowen DM, DeKosky ST (1994): Increased transmitter amino acid concentration in human ventricular CSF after brain trauma. Neuroreport $\underline{6(1)}, 153-156$

Pitsavos C, Panagiotakos DB, Kontogianni MD, Chrysohoou C, Chloptsios Y, Zampelas A, Trichopoulou A, Stefanadis C (2004): The J-shape association of ethanol intake with total homocysteine concentrations: the ATTICA study. Nutr Metab (Lond) $\underline{1(1)}, 9$

Powers RW, Majors AK, Lykins DL, Sims CJ, Lain KY, Roberts JM (2002): Plasma homocysteine and malondialdehyde are correlated in an age- and gender-specific manner. Metabolism 51(11), 1433-1438

Reeves RH, Yao J, Crowley MR, Buck S, Zhang X, Yarowsky P, Gearhart JD, Hilt DC (1994): Astrocytosis and axonal proliferation in the hippocampus of SI00b transgenic mice. Proc Natl Acad Sci USA 91(12), 5359-5363

Regier DA, Farmer ME, Rae DS, Zocke BZ, Keith SJ, Judd LL, Goodwin FK (1990): Comorbidity of mental disorders with alcohol and other drug abuse. Results from the Epidemiologic Catchment Area (ECA) Study. JAMA 264(19), 2511-2518

Renz-Polster H, Krautzig S, Braun J: Basislehrbuch Innere Medizin. 3. Auflage, Urban \& Fischer Verlag, München 2004 
Rosengren LE, Wronski A, Briving C, Haglid KG (1985): Long lasting changes in gerbil brain after chronic ethanol exposure: a quantitative study of the glial cell marker S-100 and DNA. Alcohol Clin Exp Res 9(2), 109-113

Rossetti ZL, Melis F, Carboni S, Diana M, Gessa GL (1992): Alcohol withdrawal in rats is associated with a marked fall in extraneuronal dopamine. Alcohol Clin Exp Res 16(3), 529532

Rothermundt M, Arolt V, Wiesmann M, Missler U, Peters M, Rudolf S, Kirchner H (2001): S$100 \mathrm{~B}$ is increased in melancholic but not in non-melancholic major depression. $J$ Affect Disord 66(1), 89-93

$\mathrm{Sa}$ H, Wittchen HU, Zaudig M: Diagnostisches und Statistisches Manual Psychischer Störungen DSM-IV. Hogrefe-Verlag, Göttingen 2001

Scaccianoce S, Del Bianco P, Pannitteri G, Passarelli F (2004): Relationship between stress and circulating levels of $s 100 \beta$ protein. Brain Res $\underline{1004}, 208-211$

Schneider U, Altmann A, Baumann M, Bernzen J, Bertz B, Bimber U, Broese T, Broocks A, Burtscheidt W, Cimander KF (2001): Comorbid anxiety and affective disorder in alcoholdependent patients seeking treatment: the first Multicentre Study in Germany. Alcohol Alcohol $\underline{36(3)}$, 219-223

Schott H (2001): Serie Alkoholismus - Das Alkoholproblem in der Medizingeschichte. Dtsch Arztebl 98(30), A 1958-1962

Schroeter ML, Abdul-Khaliq H, Krebs M, Diefenbacher A, Blasig IE (2009): Neuron-specific enolase is unaltered whereas $\mathrm{S100B}$ is elevated in serum of patients with schizophrenia-original research and meta-analysis. Psychiatry Res 167(1-2), 66-72

Sedaghat F, Notopoulos A (2008): S100 protein family and its application in clinical practice. Hippokratia 12(4), 198-204

Selhub J, Jacques PF, Wilson PW, Rush D, Rosenberg IH (1993): Vitamin status and intake as primary determinants of homocysteinemia in an elderly population. JAMA 270(22), 26932698

Sheng JG, Mrak RE, Griffin WS (1994): S100 beta protein expression in Alzheimer disease: potential role in the pathogenesis of neuritic plaques. J Neurosci Res 39(4), 398-404

Shield KD, Rehm M, Patra J, Sornpaisarn B, Rehm J (2011): Global and country specific adult per capita consumption of alcohol, 2008. Sucht $\underline{57(2)}$, 99-117

Shirasawa N, Yamanouchi H (1999): Glucocorticoids induce glutamine synthetase in folliculostellate cells of rat pituitary glands in vivo and in vitro. J Anat 194(4), 567-577

Shulman KI (2000): Clock-drawing: is it the ideal cognitive screening test? Int J Geriatr Psychiatry 15(6), 548-561

Singer MV, Teyssen S (2001): Serie-Alkoholismus: Alkoholassoziierte Organschäden. Dtsch Arztebl 98(33), A 2109-2120

Singer MV, Teyssen S: Alkohol und Alkoholfolgeerkrankungen. 2. Auflage; Springer Medizin Verlag, Heidelberg 2005 
Sitzmann FC: Duale Reihe Pädiatrie. 3. Auflage; Georg Thieme Verlag, Stuttgart 2007

Steiner J, Bernstein HG, Beilau H, Berndt A, Brisch R, Mawrin C, Keilhoff G, Bogerts B (2007): Evidence for a wide extra-astrocytic distribution of S100B in human brain. BMC Neurosci $\underline{8(2)}$

Stickel F, Choi SW, Kim YI, Bagley PJ, Seitz HK, Russell RM, Selhub J, Mason JB (2000): Effect of chronic alcohol consumption on plasma homocysteine level in rats. Alcohol Clin Exp Res 24(3), 259-264

Strassburg A, Krems C, Lührmann PM, Hartmann B, Neuhäuser-Berthold M (2004): Effect of age on plasma homocysteine concentrations in young and elderly subjects considering serum vitamin concentrations and different lifestyle factors. Int J Vitam Nutr Res $\underline{74(2)}, 129-136$

Suzuki F, Kato K, Kato T, Ogasawara N (1987): S-100 protein in clonal astroglioma cells is released by adrenocorticotropic hormone and corticotropin-like intermediate-lobe peptide. $\mathrm{J}$ Neurochem $\underline{49(5)}, 1557-1563$

Tsai GE, Coyle JT (1998): The role of glutamtergic neurotransmission in the pathophysiology of alcoholism. Annu Rev Med $\underline{49}, 173-184$

Tsai GE, Gastfriend DR, Coyle JT (1995): The glutamatergic basis of human alcoholism. Am J Psychiatry 152(3), 332-340

Tsai GE, Ragan P, Chang R, Chen S, Linnoila VMI, Coyle JT (1998): Increased glutamatergic neurotransmission and oxidative stress after alcohol withdrawal. Am J Psychiatry 155(6), 726-732

Ubbink JB, Fehily AM, Pickering J, Elwood PC, Hayward Vermaak WJ (1998): Homocysteine and ischaemic heart disease in the Caerphilly cohort. Atherosclerosis $\underline{140}$, 349-356

Ullrich K, Wendel U: Störung im Homocysteinstoffwechsel: Hyperhomocysteinämie, Homocystinurie; in: Handbuch der molekularen Medizin, Monogen bedingte Erbkrankheiten 1; hrsg. v. Ganten D, Ruckpaul K; Springer Verlag, Berlin 1999, 165-172

Van der Gaag MS, Ubbink JB, Sillanaukee P, Nikkari S, Hendriks HFJ (2000): Effect of consumption of red wine, spirits, and beer on serum homocysteine. Lancet $\underline{355(9214)}, 1522$

Van Eldik LG, Griffin WS (1994): s100 beta expression in Alzheimer's disease: relation to neuropathology in brain regions. Biochim Biophys Acta 1223(3), 398-403

Wang WZ, Yuan WJ, Pan YX, Tang CS, Su DF (2004): Interactions between clonidine and $\mathrm{N}$-methyl-D-aspartate receptors in the caudal ventrolateral medulla of rats. Exp Brain Res 158(2), 259-264

Wedekind D, Neumann K, Falkai P, Malchow B, Engel KR, Jamrozinski K, HavemannReinecke U (2011): S100B and homocysteine in the acute alcohol withdrawal Syndrome. Eur Arch Psychiatry Clin Neurosci 261, 133-138

Whitacker-Azmitia PM, Murphy R, Azmitia EC (1990): Stimulation of astroglial 5-HT1A receptors releases the serotonergic growth factor, protein S-100, and alters astroglial morphology. Brain Res $\underline{528(1)}$, 155-158

Wiesmann M, Missler U, Hagenström H, Gottmann D (1997): S-100 protein plasma levels after aneurysmal subarachnoid haemorrhage. Acta Neurochir (Wien) 139(12), 1155-116 
Wiesmann M, Missler U, Gottmann D, Gehring S (1998): Plasma s-100b protein concentration in healthy adults is age- and sex-independent. Clinical Chemistry 44, 1056-1058

Wiesmann M, Wandinger KP, Missler U, Eckhoff D, Rothermundt M, Arolt V, Kirchner H (1999): Elevated plasma levels of S-100b protein in schizophrenic patients. Biol Psychiatry 45(11), 1508-1511

Yang K, Xie GR, Hu YQ, Mao FQ, Su LY (2008): The effects of gender and numbers of depressive episodes on serum S100B levels in patients with major depression. J Neural Transm 115(12), 1687-1694

Zhang K, Li YF, Patel KP (2002): Reduced endogeneous GABA-mediated inhibition in the PVN on renal nerve discharge in rats with heart failure. Am J Physiol Regul Integr Comp Physiol 282(4), 1006-1015 